\title{
A REAPPRAISAL OF MESENCHYMAL-TO-EPITHELIAL TRANSITION WITHIN THE ENDOMETRIUM
}

A Thesis
presented to
the Faculty of the Graduate School
at the University of Missouri-Columbia
In Partial Fulfillment
of the Requirements for the Degree
Master of Science
by
MADELYN SPOONER
Dr. Amanda Patterson, Thesis Supervisor
JULY 2021


The undersigned, appointed by the Dean of the Graduate School, have examined the thesis entitled

A REAPPRAISAL OF MESENCHYMAL-TO-EPITHELIAL TRANSITION WITHIN THE ENDOMETRIUM

Presented by Madelyn Spooner

A candidate for the degree of Master of Science

And hereby certify that in our opinion it is worthy of acceptance

Dr. Amanda Patterson

Dr. Thomas E. Spencer

Dr. Laura Schultz

Dr. Martha Sofia Ortega Obando 


\section{ACKNOWLEDGEMENTS}

I would not have been able to complete my research without the help and support of many individuals. I would like to start off by thanking Dr. Patterson for taking the chance to bring me on as her first graduate student. It has been amazing working with you, and I appreciate all the support and guidance you have given me throughout my time in your lab. Thank you for always having your door open to me and making me a better scientist. If not for this experience and for you, I would not have found my love for uterine biology, repair and stem cells. I would also like to thank both undergraduate students who have been in the Patterson Lab during my research, Emily Youngmark and McKenzie Cranmer. Thank you both for your friendship and encouragement, keeping the lab running smoothly and all the genotype work that has allow me to continue my research.

Thank you to Dr. Spencer for sharing your laboratory equipment, in which without, a large proportion of my research would not have been possible. Additionally, thank you to Dr. Sutovsky for allowing me to use your flow cytometer, and especially to Karl for taking time out of his workdays and weekends to assist me with the analyses and training. To Dr. Ortega, I appreciate your willingness to learn more about my project in order to help me succeed. I also cannot thank you enough for your suggestions when I hit a roadblock with our fixation. Without your recommendation, I would not have useable tissue to perform analyses on. A huge thanks goes to my officemates, Kelsey, Monica, and Jess for their friendship throughout the years and adding an extra bit of fun to research. 
I cannot thank my parents enough for their unconditional love, support, and encouragement. I would not have continued through college as I have, become the individual I am today or in the position I am in without them. Lastly, I would like to thank my partner, Andrew, for his patience and shared excitement for science. Both he and my parents willingly listened to me talk about my research, the ups and downs of it, and they continued to show excitement for the mere fact that I had found something I enjoyed so much. 


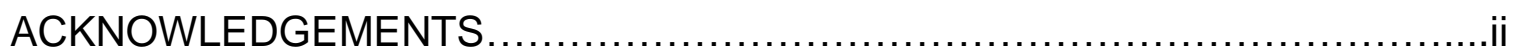

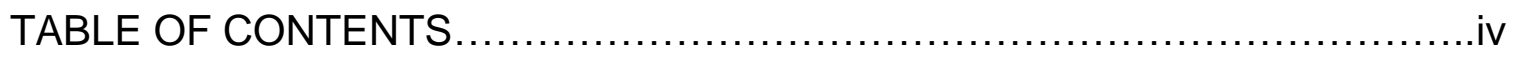

LIST OF ABBREVIATIONS .......................................................

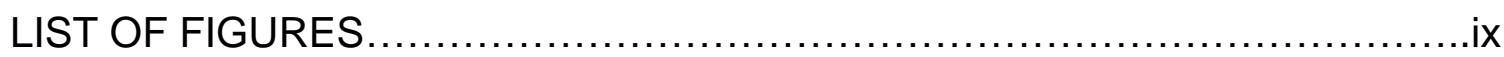

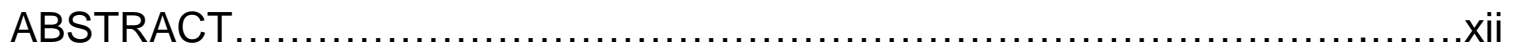

CHAPTER

1. REVIEW OF LITERATUTRE

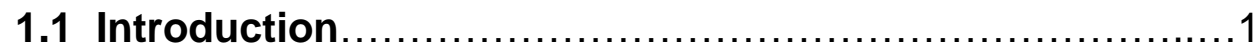

1.2 Uterine Structure and Histoarchitecture .....................

1.3 Uterine Development.......................................

1.3.1 Müllerian Duct Development..........................5

1.3.2 Overview of Postnatal Uterine Maturation.............12

1.3.3 Adenogenesis........................................

1.4 Uterine Cycles ............................................. 18

1.4.1 Menstrual Cycle...................................... 18

1.4.2 Estrous Cycle.........................................20

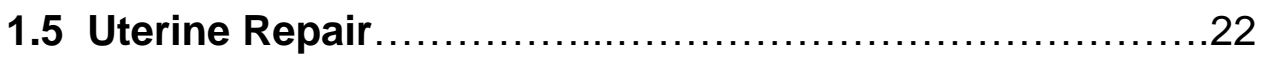

1.5.1 Epithelization During Menses........................22

1.5.2 Epithelialization Postpartum.........................24 
1.6 Mesenchymal-to-Epithelial Transition (MET) in Health and

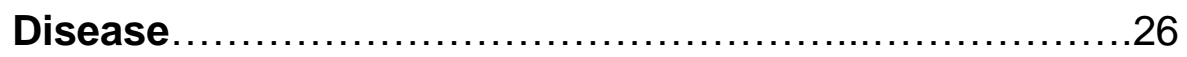

1.6.1 MET and EMT in Disease and Disorders............27

1.6.2 MET in Uterine Epithelialization......................29

2. A REAPPRAISAL OF MESENCHYMAL-TO-EPITHELIAL TRANSITION WITHIN THE ENDOMETRIUM

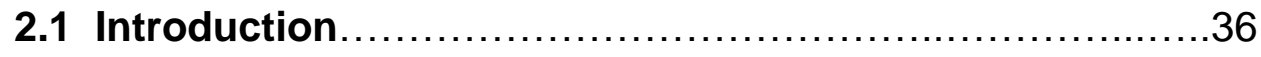

2.2 Materials and Methods.....................................

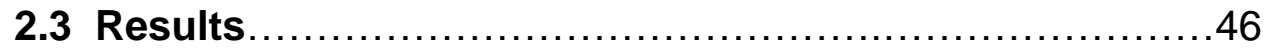

2.4 Discussion ..................................................

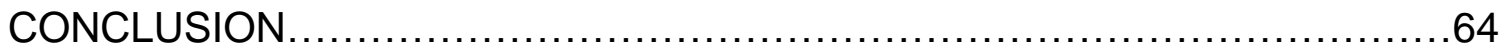

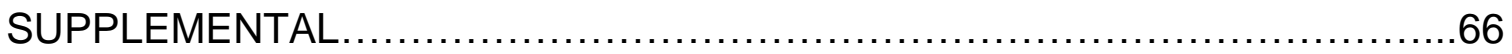

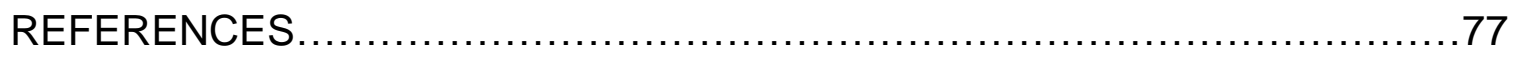




\section{LIST OF ABBREVIATIONS}

\begin{tabular}{|c|c|}
\hline Amhr2 & Anti-Müllerian Hormone Receptor 2 \\
\hline$\beta$-gal & Beta-galactosidase \\
\hline BrdU & Bromodeoxyuridine \\
\hline CE & Coelomic Epithelium \\
\hline CHD1 & Epithelial cadherin, E-cadherin \\
\hline CSPG4 & Chondroitin Sulfate Proteoglycan 4 \\
\hline DAPI & 4',6-diaminino-2-phenylindole \\
\hline DNA & Deoxyribonucleic Acid \\
\hline$E()$ & Embryonic Day ( ) \\
\hline E-cadherin & Epithelial cadherin, CHD1 \\
\hline EpCAM & Epithelial Cell Adhesion Molecule \\
\hline EMT & Epithelial-to-Mesenchymal Transition \\
\hline ESR1 & Estrogen Receptor 1 \\
\hline EYFP & Enhanced Yellow Fluorescent Protein \\
\hline E2 & Estrogen \\
\hline FOXA2 & Forkhead Box A2 \\
\hline FRT & Female Reproductive Tract \\
\hline
\end{tabular}




$\begin{array}{ll}\text { GE } & \text { Glandular Epithelium } \\ \text { GFP } & \text { Green Fluorescent Protein } \\ \text { H2B } & \text { Histone Molecule H2B } \\ \text { IGFBPs } & \text { Insulin-Like Growth Factor Binding Proteins } \\ \text { IGFBP-1 } & \text { Insulin-Like Growth Factor Binding Protein-1 } \\ \text { Ki67 } & \text { Marker of Proliferation Ki67 } \\ \text { KO } & \text { Knockout } \\ \text { LE } & \text { Luminal Epithelium } \\ \text { LHX1 } & \text { LIM Class Homeo-Domain Transcription Factor } \\ \text { PIF } & \text { Postnatal Day ( ) } \\ \text { PDEFA } & \text { Leukemia Inhibitory Factor } \\ \text { MD } & \text { Müllerian Duct } \\ \text { MDE } & \text { Müllerian Duct Epithelium } \\ \text { MDM } & \text { Müllerian Duct Mesenchyme } \\ & \end{array}$




$\begin{array}{ll}\text { PGR } & \text { Progesterone Receptor } \\ \text { PRL } & \text { Prolactin } \\ \text { P4 } & \text { Progesterone } \\ \text { RU486 } & \text { Misfepristone; Progesterone Receptor Antagonist } \\ \text { SEM } & \text { Scanning Electron Microscopy } \\ \text { SM22 } \alpha & \text { Smooth Muscle Protein 22-Alpha } \\ \text { TEM } & \text { Transmission Electron Microscopy } \\ \text { TRE } & \text { Tetracycline Response Element } \\ \text { tTA } & \text { Tetracycline Transactivator } \\ \text { TUNEL } & \text { Terminal Deoxynucleotidyl Transferase dUTP Nick } \\ \text { [125]]ldUrd } & \text { End Labeling } \\ \text { W-gal } & \text { W-Bromo-4-Chloro-3-Indolyl- } 3 \text {-D-Galactopyranoside } \\ \text { WNT } & \text { Wild-type } \\ & \end{array}$




\section{LIST OF FIGURES}

\section{CHAPTER 1}

Figure 1. Uterine Histoarchitecture and Proposed Cellular Mechanisms of

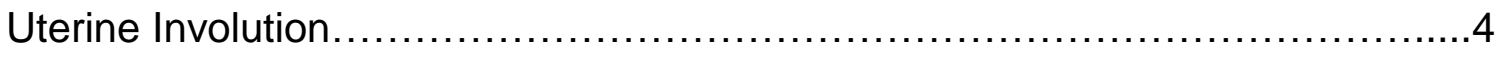

Figure 2. Stages of Müllerian Duct Development...............................

Figure 3. Uterine cross-sections during postnatal maturation...................13

\section{CHAPTER 2}

Figure 1. Schematic diagram of generating Amhr2-Cre; Rosa26-EYFP female mice and resulting constitutive EYFP expression in cells with Amhr2 promotor activity

Figure 2. Schematic diagram of generating Amhr2-Cre; Rosa26-tTA; H2B-GFP female mice and resulting H2B-GFP expression.

Figure 3. MDM-derived epithelial cells fluctuate across the estrous cycle in postpartum uteri.

Figure 4. MDM-derived epithelial populations differ across the estrous

cycle.

Figure 5. MDM-derived epithelial cells fluctuate across the estrous cycle in nulliparous and postpartum uteri....

Figure 6. MDM-derived epithelial populations demonstrate dynamic temporal patterns. 
Figure 7. MDM-derived epithelial cells co-express FOXA2 by immunofluorescence in postnatal and adult tissue. .55

Figure 8. MDM-derived epithelial cells proliferate in a dynamic temporal pattern postnatally .56

Figure 9. Proliferation of MDM-derived epithelial cells decreases during the estrous cycle. 58

Figure S1. Flow Cytometry Gating..... 66

Figure S2. EpCAM is specific to epithelial cells postnatally.

Figure S3. EpCAM is specific to epithelial cells during the estrous cycle 68

Figure S4. Verification of epithelial EYFP and GFP expression in adult and postnatal tissue

Figure S5. There is no FOXA2 expression prior to adenogenesis initation........70

Figure S6. MDM-derived epithelial cells co-express FOXA2 by immunofluorescence in postnatal and adult tissue.

Figure S7. Ki67 expression at P 8 . .72

Figure S8. Postnatal ESR1 expression by immunofluorescence. .73

Figure S9. Postnatal PGR expression by immunofluorescence. .74

Figure S10. MDM-derived epithelial cells show similar ESR1 expression as nonMDM-derived epithelial cells during the estrous cycle .75 
Figure S11. MDM-derived epithelial cells show similar PGR expression as non-

MDM-derived epithelial cells during the estrous cycle..........................76 


\section{Abstract}

A controversial topic, mesenchymal-epithelial transition (MET) is thought to be a mechanism involved in regeneration of the uterine epithelial layer following pregnancy and menstruation. Little is known about this process though, requiring further exploration. Previously, MET was thought to only occur as a damage-repair mechanism following parturition and menses-like events in mouse models. However, in the current study we hypothesized that MET would also occur in other endometrial epithelialization events as a mechanism of homeostatic epithelial turnover. To identify mesenchymal-derived cells within the adult uterine epithelium, an Amhr2-Cre; Rosa26-EYFP reporter mouse line was used. Mice were staged by vaginal cytology prior to the isolation of uterine epithelial and stromal cells, which were then stained with EpCAM to identify epithelial cells and analyzed by flow cytometry. $\mathrm{EpCAM}^{+} \mathrm{YFP}^{+}$cells were identified in all stages of the estrous cycle except diestrus, indicating a proportion of epithelial cells were derived from the stroma (i.e., mesenchyme). Up to $80 \%$ of the uterine epithelia was $\mathrm{EpCAM}^{+} \mathrm{YFP}^{+}$during estrogen-dominant stages (proestrus and estrus) of the cycle, with negligible amounts found during progesterone-dominant stages (metestrus and diestrus), suggesting this population may be responsive to estrogen. Uteri were also evaluated direct fluorescence and immunofluorescence in tissue sections. Immunofluorescence for EpCAM, forkhead box protein A2 (FOXA2), Ki67, estrogen receptor alpha (ESR1), and progesterone receptor (PGR) was performed to assess epithelial characteristics and potential functionality. To further investigate the role of MET 
in epithelialization and assess the temporal origin of mesenchymal-derived epithelial cells, we evaluated key postnatal $(P)$ developmental time points using Amhr2-Cre; Rosa26-tTA; H2B-GFP reporter mice. Flow cytometry data indicated that MET may initially occur immediately after birth at $P 0.5$, with results varying from negligible amounts $(0.21 \%)$ to approximately $82 \%$. Similar results were found at $\mathrm{P} 3$, but with decreasing variation; the highest $\mathrm{EPCAM}^{+} \mathrm{GFP}^{+}$population representing approximately $50 \%$ of the epithelium. Between P 3 and early adenogenesis at $\mathrm{P} 8$, this population decreased to average less than $2 \%$. By the completion of adenogenesis initiation at P 14, approximately $10 \%$ of epithelial cells were $\mathrm{EpCAM}^{+} \mathrm{GFP}^{+}$, suggesting MET may occur during adenogenesis initiation and is maintained through P 21. Together, these results suggest that MET may be a more ubiquitous mechanism of epithelialization than originally thought and is likely hormone regulated. This research will help elucidate the role of MET in uterine epithelialization with potential for insights into dysregulation of MET in diseases such as endometrial adenocarcinoma and endometriosis. 


\section{CHAPTER 1: REVIEW OF LITERATURE}

\subsection{Introduction}

Occurring monthly, women shed the innermost uterine layer, the endometrium, approximately 400 to 500 times during their reproductive lifespan. With the ability to not only respond to hormonal changes during the estrous/menstrual cycle, but to rapidly regenerate and repair itself following parturition, and in higher primates, menses, the uterus continually demonstrates its highly dynamic capacity. Although not every species sheds the endometrium as women do, this layer still responds to the synchronized increase and decrease of ovarian steroid hormones, estrogen and progesterone, resulting in cellular turnover through proliferation and apoptosis. This cellular turnover occurs in two different cell types present within the endometrium: mesenchymal, stromal cells capable of migration in the stromal layer, and the epithelial cells within the static epithelial layer, where damage and epithelialization occur.

Epithelialization events occur during adenogenesis, in which a single layer of luminal epithelial cells invaginates into the stroma to form endometrial glandsbeginning in gestation (humans) or soon after birth (mice)-and in adulthood during estrus, following menses and parturition. Uterine epithelial regeneration subsequent to menstruation and parturition is aided by multiple processes to ensure rapid repair of the tissue. Likely, one of these mechanisms involves the proliferation of epithelial stem cells to regenerate epithelia in damaged areas. These putative epithelial stem cells are thought to reside within the uterine epithelial glands, and historically, outgrowth of residual basal epithelial glands to 
repopulate the luminal epithelium is the most widely accepted theory of epithelialization in women (Ferenczy, 1976). Originally suggested in 1967 (Baggish), recent evidence supports an additional mechanism, mesenchymal-toepithelial transition (MET), contributes to endometrial epithelialization after tissue damage, though little is known about this mechanism (Gary et al, 2009, Huang et al, 2012, Patterson et al, 2013, Cousins et al, 2014).

MET is the process of a mesenchymal cell differentiating into an epithelial cell. Along with its reverse process, epithelial-to-mesenchymal transition (EMT), these cellular mechanisms are important during embryonic development, but contribute to disease and disorders in adults, such as cancer and endometriosis (Banyard and Bielenberg, 2016, Bartley et al, 2014, Matsuzaki and Darcha, 2011, Wilson et al, 2020). However, a reevaluation of menstrual epithelialization with histological techniques and scanning electron microscopy showed possible contribution of stromal cells to the luminal epithelium, suggesting MET may occur in this normal physiological event (Gary et al, 2009). More recently, studies have additionally suggested MET occurs within the endometrium following parturition in mice (Huang et al, 2012, Patterson et al, 2013), and support the likelihood of MET occurring in women following the shedding of the functional layer during menstruation demonstrated through the use of menses-like mouse models (Patterson et al, 2013, Cousins et al, 2014). Dual-staining with stromal and epithelial cell markers-vimentin and pancytokeratin, respectively-have also revealed cells co-expressing these markers and undergoing locational changes during the first 96 hours of menses-like endometrial regeneration, possibly 
identifying mesenchymal-epithelial transitional cells (Patterson et al, 2013, Cousins et al, 2014). Although research has begun to elucidate the contribution of MET during the first few days of epithelial regeneration/repair, studies addressing the potential of MET as a mechanism in uterine epithelialization events outside of menses-like endometrial repair and following parturition do not exist. Additional studies during postnatal epithelialization events including adenogenesis and during the estrous cycle are necessary to address this gap in knowledge and are the focus of this thesis.

\subsection{Uterine Structure and Histoarchitecture}

Human and mouse uteri are both comprised of three tissue layers. The outermost portion of the uterus is the serosa, which lines the female reproductive tract and is contiguous with the broad ligament to support the tract within the body cavity. Spanning the uterus, the region closest to the broad ligament is termed the mesometrial pole, with the opposing side being the anti-mesometrial pole. Moving inward from the serosal layer is the myometrium, which is smooth muscle. Lastly, the inner-most layer is the endometrium consisting of stroma and epithelia. The epithelia can be further classified into the luminal epithelium (LE), lining the lumen of the uterus with a single layer of cells, and glandular epithelium (GE), extending into the stromal compartment. Morphologically, endometrial epithelial cells are polygonal in shape in contrast to underlying stromal cells which are spindle-like in shape. In women and higher primates that undergo menstruation, the endometrium is partitioned into the functionalis and basalis layers (Fig. 1A). The functionalis is the upper two-thirds of the endometrium and 


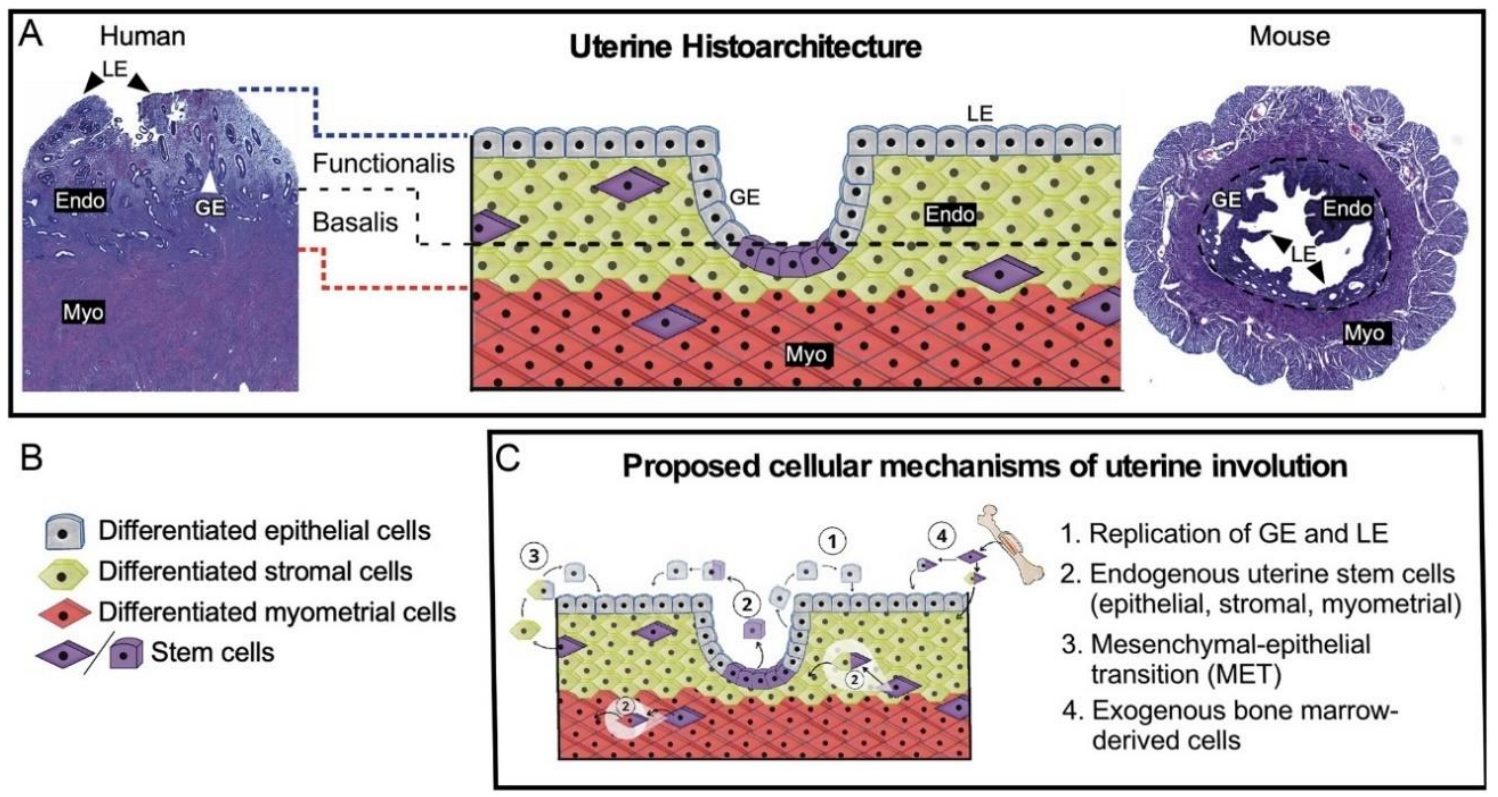

Figure 1. Uterine Histoarchitecture and Proposed Cellular Mechanisms of Uterine Involution. (A) Comparison of human and mouse uterine histoarchitecture. The human endometrium is partitioned into fuctionalis and basalis layers. Although mouse endometrium do not have specified functionalis/basalis layers, they demonstrate similar characteristics including luminal epithelium (LE) and glandular epithelium (GE) extending into the stroma. (B) Legend for illustrated uterine histoarchitecture. (C) Schematic of proposed cellular mechanisms of uterine involution including 1.) replication of GE and LE, 2.) endogenous epithelial, stromal, and myometrial stem cells, 3.) mesenchymal-to-epithelial transition (MET) and 4.) exogenous bone marrowderived cells. From Spooner et al, 2021. Reproduction 161, 3; 10.1530/REP20-0425 
is shed during menses. The lower one-third, closest to the myometrium, is the basalis, which remains during menses and serves as the seed for regenerating the functionalis (Padykula et al, 1989). Although not classified as such, mice have similar layers to the functionalis and basalis (Fig. 1A). The functionalis-like layer in mice is not shed during the estrous cycle, instead, there are cyclic changes in cellular proliferation and apoptosis resulting in waves of endometrial growth and regression (Wood et al, 2007). The functionalis-like layer is shed postpartum, however, and is then regenerated by the lower basalis-like layer. Additionally, the myometrium is comprised of two distinct muscle layers with fibers of opposing direction. These layers are the outer longitudinal and inner circular, which work together for contractile purposes during labor and parturition. The myometrium and endometrium of both species are also inundated with vasculature, lymphatics, and various leukocyte populations. Despite some differences in the histological make up of uteri between mice and humans, the two species share many qualities pertaining to the endometrium, making mice a reasonable animal model to use when addressing questions that would otherwise be unethical to perform in women.

\subsection{Uterine Development}

\subsubsection{Müllerian Duct Development}

Mesenchymal-to-epithelial transition (MET) and its counterpart, epithelialto-mesenchymal transition (EMT), are fundamental during embryonic developmental processes such as gastrulation, neural crest development and organogenesis (Handyside, 1980, Ziomek and Johnson, 1980, Fleming, 1987, 
Linask et al, 1997, Wiggan et al, 2002, Wiggan et al, 2006, Anani et al, 2014, Jackson et al, 2017.) Of importance though, is how MET affects development of the urogenital tract, specifically the formation and differentiation of the Müllerian ducts that subsequently give rise to majority of the adult female reproductive tract (FRT).

The FRT is composed of oviducts, uterus, cervix, and vagina. These tubular structures are derived from the Müllerian (paramesonephric) ducts with the exception of the lower vagina, which originates from the urogenital sinus. The male reproductive tract forms similarly via the Wolffian (mesonephric) ducts, which develop prior to the Müllerian ducts. Both Müllerian and Wolffian ducts form from the intermediate mesoderm and are both initially present in male and female embryos (Jacob et al, 1991, Kobayashi and Behringer, 2003, Spencer et al, 2005). Although Müllerian ducts develop similarly between various mammalian species as seen with Gruenwald's research using human and chick embryos (1941), a major difference in the fully formed FRT is the length of the uterine horns compared to the size of the uterine body. This variation is dependent on the degree of Müllerian duct fusion during development (Kobayashi and Behringer, 2003). Adult uteri are therefore classified based on the prominence of uterine horns and body including duplex (marsupials), simplex (higher primates), and bicornuate (bovine and equine) as a subset of examples. In both sexes, the Wolffian ducts are completely developed in mice by embryonic day 10.5 (E 10.5), approximately a day before the Müllerian ducts begin developing on E 11.5. Müllerian duct development occurs in three stages: 
initiation, invagination, and elongation (Fig. 2). Müllerian ducts were observed to derive from the coelomic epithelium (CE) which overlies the urogenital ridge (Gruenwald, 1941), but the mechanism remained poorly understood for several decades. Over 60 years later, studies have provided evidence to support this finding (Orvis and Behringer, 2007, Guioli et al, 2007) as well as develop the current model-CE cells that commit to the Müllerian duct epithelium (MDE) are located between the pronephros and mesonephros in a transitional area and are LHX1+ (LIM class homeo-domain transcription factor). The initiation stage begins with specification of LHX1+ CE cells at E 11.5, however, it is unknown what leads to expression of LHX1 (Kobayashi et al, 2004, Orvis and Behringer, 2007). LHX $1^{+}$cells then invaginate caudally towards the Wolffian duct (Kobayashi et al, 2004). Global deletion of $L h x 1$ is embryonic lethal due to failure to establish maternal-fetal placental connections, and female embryos lacked Müllerian ductderived structures (Kobayashi et al, 2004). Generation of MDE-specific Lhx1 knockout (KO) mice was possible with use of Wnt7a-Cre mice (Huang et al, 2014). A time-lapse study using the epithelial-specific KO of $L h x 1$ indicated that initiation and invagination occurred but developing Müllerian ducts did not elongate suggesting the mesoepithelial nature of invaginating cells may be affected. Epithelium was absent in adults except in shortened oviducts, and uterine mesenchyme remained undifferentiated due to the lack of interaction with epithelia and consequential mesenchymal-epithelial signaling (Huang et al, 2014).

Wingless-type MMTV integration site family members (Wnts) have been 

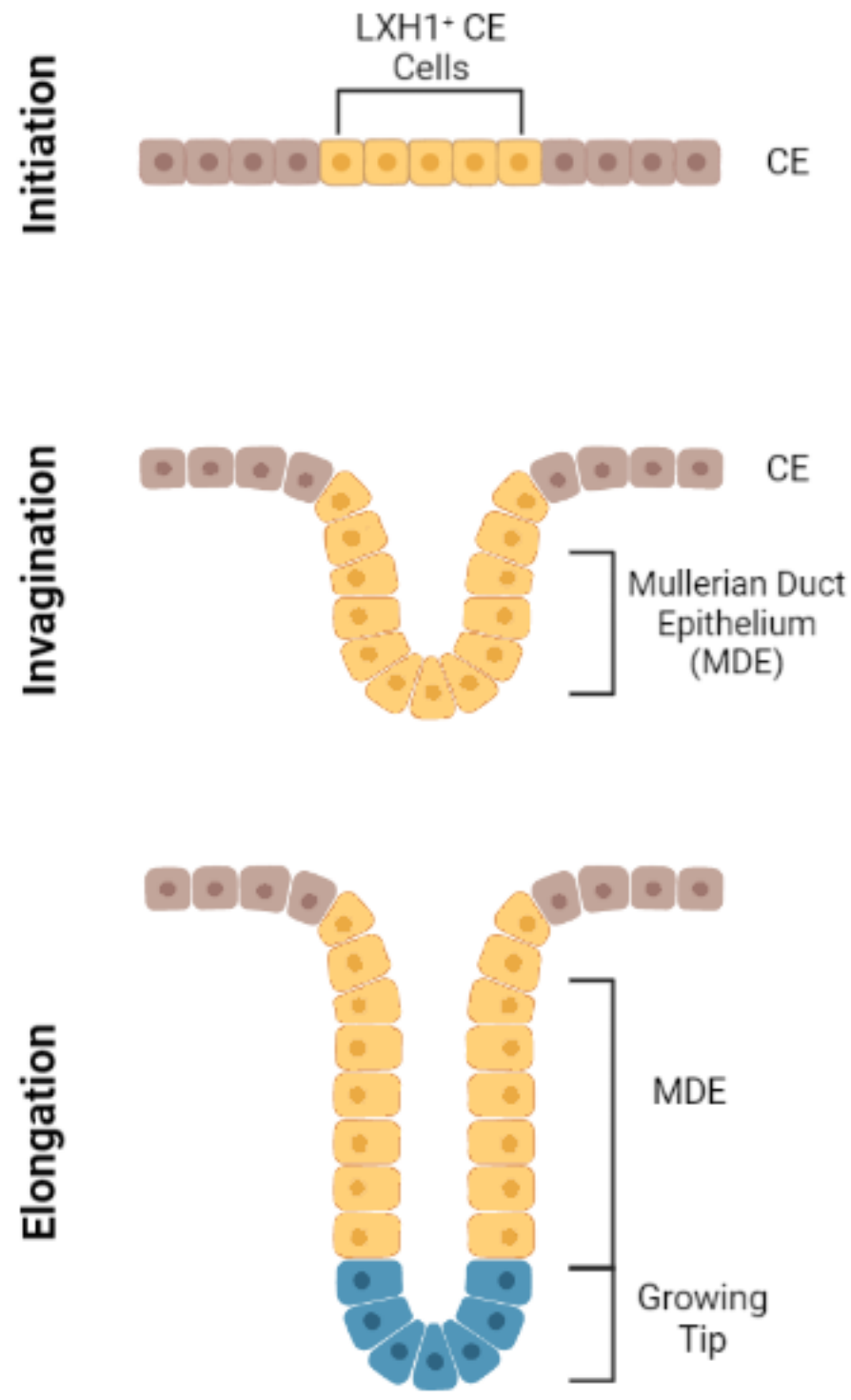

Figure 2. Stages of Müllerian Duct Development. The Müllerian duct is derived from the coelomic epithelium (CE, brown cells). The first stage of Müllerian duct development is initiation of $\mathrm{LXH} 1+\mathrm{CE}$ (yellow) cells. LXH1+ CE cells invaginate to form Müllerian duct epithelium (MDE). Elongation of the Müllerian duct occurs by proliferation of the growing tip (blue cells) until the Müllerian duct contacts and fuses with the urogenital sinus. 
shown to demonstrate a critical role in Müllerian duct development and MET. A subset of Wnts-Wnt4, Wnt5a, and Wnt7a-are required for Müllerian duct differentiation and development (Vainio et al, 1999, Mericskay et al, 2004, Parr and McMahon, 1998). Wnt4 is expressed in mesenchyme beginning at E 11 in both males and females (Vainio et al, 1999), but is expressed in both epithelia and mesenchymal cells postnatally (Hayashi et al, 2010). Specified LHX1 ${ }^{+}$cells invaginated caudally towards the Wolffian duct in response to Wnt4 signaling from the mesenchyme (Kobayashi et al, 2004). Therefore, global deletion of Wnt4 prevented Müllerian duct formation by inhibiting invagination of MDE and mesenchymal-epithelial interactions. Also expressed in mesenchyme, Wnt9b acts upstream of Wnt4 and like ablation of Wnt4, Wnt9b-null mice lack reproductive structures derived from Wolffian or Müllerian ducts in males or females due to disrupted mesenchymal-epithelial interactions (Carroll et al, 2005). MDE-specific, Wnt7a expression was seen at E 11.5 (PrunskaiteHyyryläinen et al, 2016), becoming restricted to LE in the postnatal uterus (Miller and Sassoon, 1998, Hayashi et al, 2010). Wnt7a-null mice demonstrated abnormal morphology of the female reproductive tract and in both epithelial and mesenchymal differentiation. Histologically, female reproductive tracts of these mice showed disorganized myometrial layers, shallow stroma, lacked uterine glands, and demonstrated stratified epithelium in the uterus (Miller and Sassoon, 1998, Parr and McMahon, 1998). Similar to Wnt4, Wnt5a was expressed in Müllerian duct mesenchyme (MDM) by E 15.5 (St-Jean et al, 2019), and its expression in the stroma was critical for uterine gland formation postnatally 
(Mericskay et al, 2004). Wnt5a-null mice also displayed abnormal FRT morphology but differed from Wnt7a mutant mice. Wnt5a-mutant mice developed normal oviduct and uterine horns, but posterior structures-cervix and upper vagina-were absent (Mericskay et al, 2004). Taken together, these studies indicate that proper spatio-temporal Wnt signaling is required for development, patterning, and maturation of the FRT.

The tip of the Müllerian duct continues to invaginate until it contacts the Wolffian duct at E 12.5, then begins to elongate next to the Wolffian duct with only a basement membrane separating the two structures (Orvis and Behringer, 2007, Guioli et al, 2007). This process of invagination and elongation with close association to the Wolffian ducts were also noted in both human and chick embryos by Gruenwald (1941). Because of the intimate contact between the elongating Müllerian ducts and the Wolffian ducts, the question arose whether the Wolffian duct epithelium contributed to the MDE. Using a Wolffian ductspecific Cre mouse line (Hoxb7-Cre), fate mapping was used to address this question. In Hoxb7-Cre; Rosa26-LacZ mice, MDE elongation was not aided by contribution of cells from the Wolffian duct, as no cells of the Müllerian duct expressed LacZ. Additionally, an in vitro urogenital ridge recombinant explant culture assay was developed by cutting the urogenital ridge of wild-type (WT) and $\operatorname{Lim} 1^{1 / 2+}(\mathrm{LHX} 1$; fate mapping of LHX1-derived cells reported by LacZ expression) into rostral and caudal halves and recombining Lim 1z/rostral/WT caudal sections. The elongating Müllerian duct was $L a c Z$ positive, demonstrating elongation occurred by proliferation of the growing tip instead of continual 
contribution from CE or input of Wolffian duct cells, which were LacZ negative. Elongation in mice was complete by E 13.5 as the ducts contacted and fused with the urogenital sinus (Orvis and Behringer, 2007, Arango et al, 2008).

During elongation, MDE cells are mesoepithelial as they express both mesenchymal and epithelial markers in a distinct rostral to caudal pattern. At E 12.5, epithelial marker, pancyotokeratin, was weakly expressed across the growing MDE, but E-cadherin (CDH1) was absent. Simultaneously, mesenchymal marker, vimentin, was strongly expressed in the growing tip of the MDE, but showed weak expression located at the rostral end. Upon completion of elongation at $\mathrm{E} 13.5$, pancytokeratin expression remained and $\mathrm{CDH} 1$ expression became expressed within the apical region of the rostral cells; this was coupled with diminished vimentin expression throughout the duct, as well. Despite substantially weak expression of epithelial markers at this developmental point, the acquisition of apical/basal polarity, lumen, and simple columnar morphology of the cells rostral to growing tip demonstrate those of epithelial characteristics. The mesoepithelial transitional state of MDE cells is likely necessary for the cells at the growing tip to migrate, a mesenchymal characteristic, while the cells at the rostral region become stationary and engage in cell interactions through expression of CHD1, an epithelial quality. For the remainder of gestation, there were increased expression of additional epithelial markers while mesenchymal markers were no longer seen within the epithelium (Orvis and Behringer, 2007), becoming restricted to the respective regions of stroma and myometrium of the fetal and adult uteri (Orvis and Behringer, 2007, 
$\mathrm{Ni}$ et al, 2018). This suggests that the mesoepithelial cells complete the process of MET and fully differentiate into an epithelial cell type by birth.

\subsubsection{Overview of Postnatal Uterine Maturation}

At birth (postnatal day 0.5), the mouse uterus is an aglandular, single layered epithelial tube surrounded by undifferentiated mesenchyme (Fig. 3A). From birth to postnatal day $(P) 5$, the mesenchyme begins to differentiate into stromal cells nearest the epithelium and the outer smooth muscle layers of the myometrium (Brody and Cunha, 1989). By P 10, distinct stromal, and circular and longitudinal smooth muscle layers are easily identifiable (Brody and Cunha, 1989, Cunha et al, 1989). Although the epithelium is undifferentiated at birth, scanning electron microscopy (SEM) revealed the presence of two morphologically distinct cell types: cells with small, round and convex surfaces and cells with larger, flat surfaces, both having microvilli (Plapinger, 1982). One of the earliest postnatal epithelialization events is the formation of endometrial glands, termed adenogenesis (discussed in detail below). Adenogenesis begins around P 5 and budding glands are visible at P 8 (Vue et al, 2018, Vue and Behringer, 2020) (Fig. 3B). By P 15, the histoarchitecture of the uterus resembles that of the adult with distinct, differentiated epithelial, stromal, and myometrial layers (Hu et al, 2004) (Fig. 3C). Interestingly, the two cell types identified by SEM are no longer morphologically distinct but rather only differ by size (Plapinger, 1982). Peripubertal uteri at P 21 continue with glandular morphogenesis, and the uterus is similar to the adult, although smaller in size (Vue et al, 2018) (Fig. 3D). 


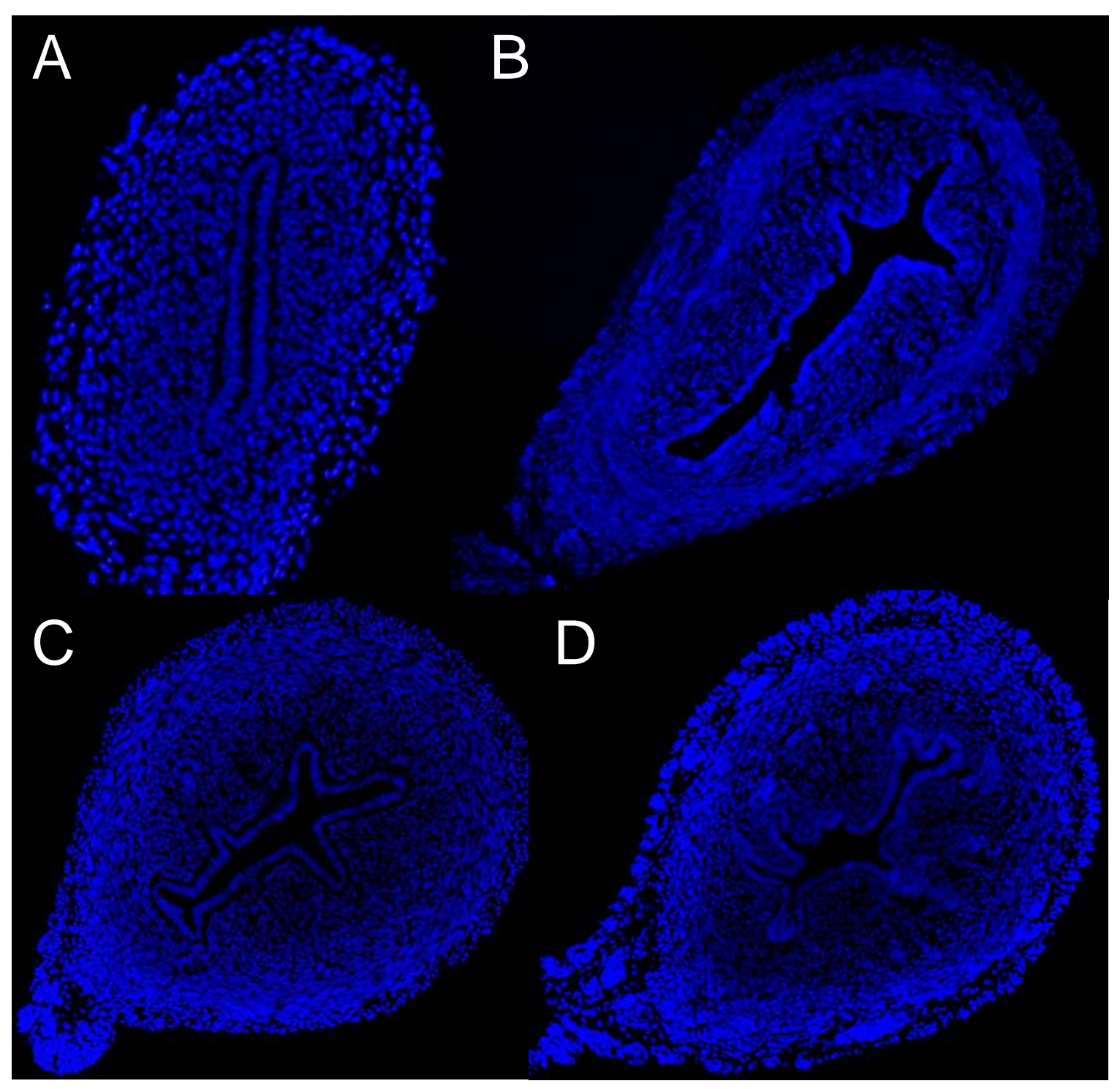

Figure 3. Uterine cross-sections during postnatal maturation. Nuclei were stained using 4',6-diaminino-2-phenylindole (DAPI). (A) Postnatal day (P) 0.5, epithelium consists of a single layer of luminal epithelium at birth; (B) $P$ 8, during glandular formation (adenogenesis). Uterine epithelia demonstrate bud- and teardrop-shaped glands; (C) P 14, uterine histoarchitecture represents that of the adult, but glandular morphogenesis continues during this time point; (D) P 21; the uterus represents that of the adult, though smaller in size. 
Proliferation of uterine cells and subsequent growth are independent of ovarian hormones neonatally (Ogasawara et al, 1983, Bigsby and Cunha, 1985, Branham et al, 1995). No difference in labeling of proliferative cells by 5 $\left[{ }^{125} \mid\right]$ iodo-2'1-deoxyuridine $\left(\left[{ }^{125} \mid\right] \mid \mathrm{d} U \mathrm{rd}\right)$ or uterine weight occurred between intact and ovariectomized neonatal mice, supporting that neither estrogen nor progesterone are required for normal uterine growth postnatally until approximately P 25 (Ogasawara et al, 1983). When both groups were given exogenous estradiol, uterine weight and [ [25]]ldUrd uptake significantly increased compared to control groups but again there was no difference between intact and ovariectomized mice. Additionally, mice that were ovariectomized on P 0 or P 25 and allowed to age to $\mathrm{P} 40$ were able to respond to exogenous estradiol. Uterine growth, measured by weight and [ $\left.\left.{ }^{125}\right]\right]$ IdUrd labeling, did not differ between the two groups, indicating the absence of ovaries and corresponding hormones beginning at $\mathrm{P} 0$ or $\mathrm{P} 25$ did not affect the ability of the adult uterus to respond to estrogen administration. Proliferative activity in response to administration of progesterone differs from estrogen in the postnatal uterus in that it was cell type specific. Mice given progesterone between $\mathrm{P} 2$ and $\mathrm{P} 10$ revealed increased stromal proliferation while inhibiting epithelial proliferation (Bigsby and Cuhna, 1985, Filant et al, 2012), and epithelial proliferation inhibition was found 18 hours following administration in mice aged P 5 (Bigsby and Cuhna, 1985). Furthermore, administration of estradiol or progesterone to neonates delayed adenogenesis and reduced the number of glands present in the adult (Stewart et al, 2011, Dhakal et al, 2015), but adults lacked uterine glands completely with 
progesterone administration during P 3 through P 9 (Cooke et al, 2012). These studies also demonstrate that although ovarian hormones are unnecessary for postnatal uterine maturation, the postnatal uterus is able to respond to exogenous estrogen and progesterone, and administration during key postnatal events, like adenogenesis initiation, negatively affect the adult uterus. It is not until increased hormone production and feedback signaling through the hypothalamic-pituitary-gonadal axis and initiation of the onset of puberty around P 30 (Swerdloff and Odell, 1975, DiVall and DiBlasi, 2018, Day et al., 1987, Safranski et al, 1993, Piekarski et al, 2017) that cyclic cellular changes in response to ovarian hormones occur.

\subsubsection{Adenogenesis}

Having a crucial role in the maintenance of pregnancy, uterine glands and their secretions are pertinent for the establishment and maintenance of pregnancy (Kelleher et al, 2019). Adenogenesis, occurs postnatally in rodents (described above) and begins during gestation in humans (Grey et al, 2001 and Cooke et al, 2013). Initial studies documenting the timeline of adenogenesis in mice indicated that at $P 3$, the uterine epithelium was still undifferentiated. But, by $P$ 6, there was budding from the luminal epithelium into the stromal compartment indicating adenogenesis had begun (Hu et al, 2004). More recently, 3D analysis was performed at select times between $\mathrm{P} 0$ and $\mathrm{P} 21$ revealing a more detailed timeline of key events in adenogenesis. According to these studies, adenogenesis began as early as P4 with initiation of budding from the luminal epithelium, and by P 8 there was a mixture of bud-shaped and 
teardrop-shaped glands (Vue et al, 2018, Vue and Behringer, 2020). With these analyses, identification of the uterine rail was possible-a region of epithelium that runs along the mesometrial pole that does not form glands. By P 15, initial gland formation was complete and was followed by morphogenesis of these glands ( $\mathrm{Vu}$ et al, 2018). During morphogenesis, glands first elongate, then become sinuous in morphology around $\mathrm{P} 21$, and finally branch as they continue to mature into adulthood (Vue et al, 2018).

Adenogenesis has also been evaluated by expression of forkhead box protein A2 (Foxa2). Foxa2 was shown to be expressed in uterine glands of various species, including mice and humans, although the extent of knowledge regarding Foxa2 in humans is lacking due to ethical considerations (Villacorte et al, 2013). In mice, detection of Foxa2 mRNA by in situ hybridization began as early as P 3 (just prior to bud initiation) and was localized to the cytoplasm of the undifferentiated LE, and interestingly, was also present in the cytoplasm of differentiating mesenchymal cells. This pattern of expression continued to be observed through $P 15$ in both cell types. However, at P 9, when both bud- and teardrop-shaped glands were present, Foxa2 was nuclear, and shortly thereafter at $P 12$ and $P$ 15, Ki67 expression increased in the epithelia as an indicator of proliferation. By P 28, Foxa2 expression was solely restricted to the nuclei of GE and continued as such throughout adulthood (Dunlap et al, 2011).

As with Müllerian duct development and differentiation, Wnts are necessary for gland formation in the postnatal mouse. Global deletion of Wnt7a embryonically resulted in an abnormal anteroposterior phenotype of the FRT 
such that morphologically and histologically, proximal structures represented distal structures (e.g., oviducts represented uterine characteristics), and a glandless uterus in the adult (Miller and Sassoon, 1998, Parr and McMahon, 1998). However, the effect of deleting Wnt7a postnatally on the developing uterus was unclear. To investigate the roles of Wnt7a and Foxa2 in the postnatal uterus, specifically their effects on adenogenesis, these genes were conditionally ablated using Pgr-Cre mice (Dunlap et al, 2011, Jeong et al, 2010). At P 3 , preceding adenogenesis initiation, PGR was expressed in the uterine epithelia and stroma by P 7 (Franco et al, 2008, Kurita et al, 2001) thus genes of interest were deleted beginning at these times points. Both conditional deletions of Wnt7a and FOXA2 in the neonate resulted in glandless uteri, suggesting that they are important to the process of adenogenesis (Dunlap et al, 2011, Jeong et al, 2010, Kelleher et al, 2017). As adults, mice lacking uterine glands were infertile due to implantation failure, reduced decidual response and decreased or lack of expression of genes required for uterine receptivity and implantation (Dunlap et al, 2011, Jeong et al, 2010, Kelleher et al, 2017).

As mentioned previously, Wnt5a-null mice also demonstrated abnormal anteroposterior phenotype. Like Wnt7a-null mice, mice lacking Wnt5a were unable to form glands (Mericskay et al, 2004). Interestingly, Mericskay and others (2004) utilized tissue recombination with Wnt5a-null and WT mice where Wnt5a-null epithelia were recombined with WT mesenchyme, and vice versa. Glands did not form in recombined WT epithelia/Wnt5a-null stroma, but adenogenesis was rescued in Wnt5a-null epithelia/WT stroma tissue. This would 
suggest that WNT5a is required in the stroma and acts to signal to the epithelia to initiate adenogenesis. The study also showed Wnt7a was restricted to the luminal epithelium postnatally and was not found in GE. With this, they hypothesized that Wnt5a was required within the stroma to downregulate Wnt7a in regions of the LE that form glands (Mericskay et al, 2004). This study further supports that epithelial-mesenchymal interactions are necessary for correct postnatal development in addition to embryonic development.

Information relating to the development of the FRT in humans is limited, though in 1973, some light was shed on the development of the uterus from late fetal life through late adolescence (Valdes-Dapena). Gross anatomy demonstrated little growth of the uterine body during late gestation and early life, but within this time, morphological changes occurred. Although majority of adenogenesis occurred postnatally in humans (Valdes-Dapena, 1973, Grey et al, 2001), initiation occurred during gestation: no glands were seen at 23 weeks of gestation via histological sections, but budding was seen by 26 weeks of gestation (Valdes-Dapena, 1973). Adenogenesis continued, resulting in elongated glands that were torturous in nature, and representative of adult glands, by puberty (Valdes-Dapena, 1973).

\subsection{Uterine Cycles}

\subsubsection{Menstrual Cycle}

The menstrual cycle has been standardized to 28 days and is divided into three phases: menses, proliferative and secretory. The first day of menses is designated day 1 of the menstrual cycle and ensues with the shedding of the 
functionalis lasting 2-7 days (Padykula et al, 1989). The proliferative phase follows menstruation up to day 14 and is characterized by epithelial and stromal proliferation in response to increased circulating estradiol levels. This proliferative response causes the endometrium to thicken substantially from 1-4 $\mathrm{mm}$ to $11 \mathrm{~mm}$ (Nalaboff et al, 2001), and simple uterine glands become torturous extending the length of the endometrium (Rock and Bartlett, 1937, Garry et al, 2010). Serum estrogen levels are dominant during the proliferative phase leading up to ovulation on day 14 , at which time they decline rapidly. Progesterone levels are low but rising during the proliferative phase and dominate in the post-ovulatory, secretory phase of the menstrual cycle from days 14-28 (Sherman and Korenman, 1975, Apter et al, 1978). Ciliated and secretory epithelial cell populations are not static throughout the menstrual cycle, with ciliated cells primarily located around glandular openings following menses and increasing in number throughout the LE at the end of the proliferative phase. In the secretory phase, secretory cells within the epithelia developed mature microvilli, giant mitochondria, glycogen particles and ribosomes. They then acquired the ability to produce secretions seen by cytoplasmic budding and secretory droplets with scanning electron microscopy (Ferenczy and Richart, 1973). Under progesterone stimulation, the endometrium also continues to thicken until reaching its peak measurement of $16 \mathrm{~mm}$ during the mid-secretory phase (Nalaboff et al, 2001). This thickening is due to distention of glands caused by increased secretory activity of GE (Hempstock et al, 2004), stromal edema and stromal decidualization (Teacher, 1930). 
Spontaneous decidualization of stromal cells in humans is induced by progesterone, which as previously stated, is the dominant ovarian steroidal hormone at this time (Daly et al, 1983, Brosens et al, 1999). This has been shown in vitro utilizing isolated stromal cells from patient endometrial samples collected during the proliferative phase, cultured and treated with estradiol, progesterone, or a combination of estradiol and progesterone. In treatments of progesterone alone or with the addition to estradiol, decidualization occurred, but decidualization was delayed with addition of estradiol (Daly et al, 1983). Decidual cells become enlarged and rounded in shape, and gain gap junctions, and are described as being epithelial-like (Kerns and Lala, 1983). These specialized cells must produce factors including leukemia inhibitory factor (LIF), prolactin (PRL), and insulin-like growth factor binding protein-1 (IGFBP-1), among others to be competent decidua and support an implanting embryo (reviewed by Vinketova et al, 2016). Without implantation of an embryo during the window of receptivity in the secretory phase, the decidua is shed during menses and the endometrium undergoes regeneration thus continuing the cycle.

\subsubsection{Estrous Cycle}

In mice, the estrous cycle lasts approximately 4 to 5 days and is composed of 4 stages-proestrus, estrus, metestrus, and diestrus. As seen in the menstrual cycle, ovarian steroids, estrogen and progesterone, are dominant hormones during different stages of the estrous cycle. Proestrus and estrus stages correspond to the estrogen-dominant follicular phase of the ovary, while 
metestrus and diestrus are progesterone-dominant stages corresponding to the ovarian luteal phase (Walmer et al, 1992, Wood et al, 2007).

Prior to ovulation, there is increased proliferation during proestrus in response to elevated serum estrogen concentrations: Wood and colleagues used immunohistochemistry to determine prolific cells with PCNA and apoptotic nuclei with in situ DNA end labeling. The authors noted a trend of high luminal epithelial proliferation and stromal proliferation correlated with high serum estrogen concentrations during proestrus or estrus. In contrast, the greatest amount of apoptosis was noted in metestrus with the LE demonstrating a percentage of apoptotic nuclei approximately ten times greater than the GE or stroma (2007). Unlike women, mice do not demonstrate decidualization in the absence of pregnancy but do express similar decidual markers like prolactin (Monice et al, 2001). Because there is no decidualization, the endometrium is not shed as seen during the menstrual cycle, however, there is coordinated apoptosis and proliferation resulting in growth and reabsorption of endometrial tissue throughout the cycle (Wood et al, 2007).

Cycle stages can be determined by circulating serum concentrations, visual assessment of the vaginal opening, or vaginal cytology. Most commonly used, vaginal cytology shows varying proportions of nucleated epithelial cells, cornified epithelial cells, and leukocytes are indicative of different cycle stages. Proestrus largely consists of nucleated epithelial cells, estrus distinctively shows cornified epithelial cells, metestrus has all three types of cells and diestrus predominantly consists of leukocytes (Byers et al, 2012, Caligioni, 2009, 
Ekambaram et al, 2016, Ajayi and Akhigbe, 2020). It is important to note that although these four stages are referenced throughout the scientific community, they are not absolute-transitional stages occur between each stage, easily seen with the short estrous cycle length in rodents.

\subsection{Uterine Repair}

\subsubsection{Epithelialization During Menses}

As mentioned previously, the luteal phase of the menstrual cycle is influenced by dominant levels of progesterone followed by a substantial decrease in the steroid hormone nearing the end of the luteal phase due to regression of the corpus luteum. It is widely accepted this sharp decline in progesterone induces multiple pathways leading to menstruation in women (Slayden and Brenner, 2004, Patel et al, 2014). Progesterone loss results in vascular changes, promotion of inflammatory response through chemokines, and increased expression of matrix metalloproteinases (MMP) thus contributing to tissue destruction and subsequent shedding of the functionalis (Rock and Bartlett 1937, Critchley et al, 1994, Jones et al, 1997, Milne et al, 1999, Salamonsen et al, 1997). In response to the upregulation of inflammatory factors, an initial increase in leukocyte number, and their migration from the stroma to clear debris from the sloughing tissue is noted immediately prior to menses and during the first few days (Rock and Bartlett, 1937, Ludwig and Spornitz, 1991, Garry et al, 2010). Concomitantly with tissue degradation due to necrosis, is an increase in the number of apoptotic cells within the functionalis in menstruating primates and humans (Xu et al, 2007). With sloughing of the functionalis layer, tissue repair 
and regeneration ensue. Of significance is epithelialization of the endometrium: in the degenerated state, the endometrium is essentially an extensive wound and rapid epithelialization is needed to prevent infection and continued hemorrhage. Epithelial repair occurs through the rise of novel epithelial cells in the form of islands over the denuded area and from the mouths of the uterine gland stumps in the thin basalis layer. Using SEM, mature ciliated cells were visualized in residual gland stumps during early epithelialization, but ciliogenesis in de novo epithelial cells did not occur until days 7 and 9 (Ludwig and Metzger, 1976, Ludwig and Spronitz, 1991). Repair and epithelialization occur concurrently with the shedding of the endometrium beginning on day 2 , and novel surface epithelium covers over $2 / 3$ of the denuded area by day 4 of the menstrual cycle (Garry et al, 2009, Ferenczy, 1976, Ludwig and Metzger, 1976, Ludwig and Spornitz, 1991).

Menses-like mouse models have been critical in studying endometrial tissue regeneration that mimics menses in women. Timed mating with vasectomized males induces pseudopregnancy in female mice and maintains increased progesterone levels. Day 0.5 begins at observation of a vaginal plug indicating the female was mated. On Day 4, mice are anesthetized for sesame oil injection into the lumen of the uterine horns to induce decidualization. Misfepristone (RU486), a progesterone receptor antagonist, is administered subcutaneously on days 7.5 and 8.5 ( 4 and 5 days after sesame oil injection) to induce shedding of the endometrium. This can also be induced by ovariectomy to remove progesterone stimulus on the decidua. Endometrial shedding in the 
menses-like model simulates menses in women in that the shedding occurs progressively, initiates an immune response, and results in rapid repair (Finn and Pope, 1984, Brasted et al, 2003, Xu et al, 2007, Cousins et al, 2014). An alternative method to the use of timed mating with vasectomized males is ovariectomizing and giving coordinated injections of estrogen and progesterone to prime the uterus. In place of progesterone injections, a progesterone implant can be placed subcutaneously and removed following decidualization to induce endometrial shedding (Cousins et al, 2014).

\subsubsection{Epithelialization Postpartum}

To maintain a successful pregnancy, the stroma must differentiate into decidual cells, and without proper decidualization, the uterus is unable to sustain and support a pregnancy in both women and mice (Kara et al, 2007). Decidua provide protection to the embryo from being recognized as foreign by the maternal immune system, and to the mother by limiting the amount of invasion that occurs (Verma et al, 2005, Hiby et al, 1997). Production of prolactin (PRL), leukemia inhibitory factor (LIF), and insulin-like growth factor-binding proteins (IGFBPs) to support an implanting embryo and developing fetus also occur (Rosenberg et al, 1980, Bryant-Greenwood et al ,1987, Golander et al, 1988, Sawai et al, 1997, Rutanen et al, 1986, Clemmons et al, 1990). Both mice and humans have intrusive implantations in which embryonic trophoblasts displace the LE and invade into the decidualized stromal cells of the endometrium by destroying the basement membrane (Schlafke and Enders, 1975, Bischof and Campana, 1996, Li et al, 2015). Although they differ slightly in the extent of 
invasion, structure, and number of trophoblast layers, both species exhibit a hemochorial placenta-the most intimate relationship between mother and fetus. Women demonstrate greater amounts of remodeling due to invasion occurring through the stroma to the myometrium and including remodeling of spiral arteries (as reviewed by Schmidt et al, 2015, Rossant and Cross, 2001).

As with menses, the process following parturition in which the uterus returns to its pre-gravid state, termed uterine involution, requires an extensive amount of remodeling and epithelialization. Endometrial regeneration and myometrial remodeling are required to return the uterus to its original state and size before pregnancy. In 1953, Sharman observed the appearance of glands lined with cuboidal epithelial cells in the non-placental regions in women 4 days postpartum. By day 7 postpartum, the non-placental site had distinct LE and was almost devoid of decidual cells within the stroma. At the placental site, blood clots and leukocytes predominated early on, but similar repair as the nonplacental site began with few glands comprised of squamous shaped epithelium and a fibrous covering over the denuded stroma. By Day 14, epithelialization of the entire endometrium was complete, and this was followed by stromal repair and expansion (Sharman, 1953).

In postpartum mouse models, proliferative and apoptotic cells have been identified within the endometrium following damage using bromodeoxyuridine (BrdU) (Huang et al, 2012 and Cousins et al, 2014) and terminal deoxynucleotidyl transferase dUTP nick end labeling (TUNEL) assays, respectfully (Huang et al, 2012). Few stromal and LE cells were positive for 
BrdU at the time of progesterone withdrawal but increased in both layers by 4 hours after withdrawal. At 24 hours following progesterone withdrawal, BrdU labeling was detected in cells lining the basal glands with immunohistochemistry (Cousins et al, 2014). Not surprisingly, a shift from increased apoptosis to proliferation occurred following parturition as endometrial repair continued (Huang et al, 2012). Specifically, more cells located within the mesometrial pole were shown to express BrdU, indicating the mesometrial pole undergoes greater proliferation than the anti-mesometrial pole (Huang et al, 2012). Since implantation occurs within the mesometrial pole, this likely is indicative of the required rapid repair that must take place within this region of the uterus postpartum.

Hypothesized uterine repair mechanisms contributing to epithelialization following menses and parturition include: 1.) replication of residual GE and LE, 2.) uterine stem cells (epithelial, stromal and myometrial, 3.) exogenous bone marrow-derived cells, and 4.) mesenchymal-to-epithelial transition (MET) (Fig. 1B and C). The focus of this thesis is MET during uterine epithelization and differentiation events in postnatal and adult uteri.

\subsection{Mesenchymal-to-Epithelial Transition (MET) in Health and Disease}

Mesenchymal-to-epithelial transition (MET) is the change of a mesenchymal cell type to an epithelial cell type-regarding the uterus, MET is the transition of a stromal cell into either a luminal or glandular epithelial cell. Mesenchymal cell types are known for their migratory and invasive properties. These cells are spindle-like in shape, demonstrate little-to-no apical-basal 
polarity, and do not have strong cell-to-cell adhesions thus aiding their migratory capability. Conversely, epithelial cell types are stationary, with strong cell-to-cell adhesions through cell adhesion molecules on the cell surface, tight junctions, and integrins which interact with components of the basement membrane allowing for greater stability. Epithelial cells also demonstrate apical-basal polarity and are polygonal in shape. During MET, mesenchymal cells differentiate into epithelial cells through the acquisition of epithelial characteristics and loss of mesenchymal characteristics; vice versa is seen in the reverse process, EMT (as reviewed in Thiery and Sleeman, 2006). MET and EMT are critical processes that take place embryonically during gastrulation, neural crest development and organogenesis (Thiery, 2002, Thiery et al, 2009) and are also implicated in uterine diseases. Evidence is growing to support a role for MET in non-pathological endometrial events, specifically epithelial repair postpartum and/or during menstruation.

\subsubsection{MET and EMT in Disease and Disorders}

Despite MET and EMT being critical to physiologically normal processes during embryonic development, when these mechanisms are exploited and dysregulated, diseases and disorders occur. MET has been hypothesized to be a contributing mechanism to uterine cancer and endometriosis, but it is still unclear how it is dysregulated.

Uterine cancer has the $4^{\text {th }}$ highest rate of new cases and $6^{\text {th }}$ highest rate of deaths in the United States (CDC, 2017), and like other cancers, it can metastasize if not caught in early stages. To produce a secondary tumor away 
from the primary site, cancer cells must travel to the new site and microenvironmental conditions must be favorable. Cancer cells may use EMT in which they lose epithelial characteristics, including the downregulation of epithelial cadherin (E-cadherin), to invade and travel through the lymphatic and vascular systems before the reverse process, MET, is required to set up a secondary tumor at a novel site (Banyard and Bielenberg, 2016).

Occurring in approximately $10 \%$ of women (Buck Louis et al, 2011), it has long been hypothesized that endometriotic lesions are a result of retrograde menstruation (Sampson, 1927a, Sampson, 1927b). A recent study developed a mouse model to address this theory. This menses-like mouse model was utilized to induce shedding of the endometrium: an incision was made at the utero-tubule junction in conjunction with a salpingectomy to allow endometrial fluid and tissue access to the peritoneal cavity. Over $50 \%$ of mice showed visible lesions, adding credibility to retrograde menstruation contributing to endometriosis in an in vivo model (Wilson et al, 2020). Interestingly, 90\% of women experience retrograde menstruation, but only a subset of those women develop and suffer from endometriosis (Halme et al, 1984). This begs the question: what causes endometriotic lesions in some women and not others with retrograde menstruation? The answer has been elusive, but some scientists speculate that MET and EMT may be occurring concurrent with retrograde menstruation. Like with metastatic cancer, is it suggested that EMT occurs, allowing shed endometrial epithelial cells to become mesenchymal-like, thus allowing them to migrate to a secondary site outside of the uterine cavity due to retrograde 
menstruation and re-differentiate through MET (Bartley et al, 2014, Matsuzaki and Darcha, 2011, Wilson et al, 2020). Endometrial tissue samples from women diagnosed with endometriosis show a decrease in E-cadherin with an increase in mesenchymal-cadherin, $\mathrm{N}$-cadherin, by immunohistochemistry on lesion sections (Bartley et al, 2014, Matsuzaki and Darcha, 2011). Bartley and colleagues (2014) showed in addition to the altered expressions of E-cadherin and Ncadherin, transcription factors associated with EMT, Twist, Snail and Slug, were increased in tumors via immunohistochemical and mRNA level analyses. These findings support EMT, and likely its counterpart MET, as mechanisms exploited in endometriosis.

\subsubsection{MET in Uterine Epithelialization}

MET was hypothesized as a mechanism of uterine epithelialization in the 1960s. Baggish and colleagues used various staining techniques including hematoxylin and eosin (H\&E) and acridine orange fluorescence to investigate endometrial mitotic cells during menses (1967). A subset of surface epithelial cells demonstrated similar characteristics with "indifferent" cells within the stromal-epithelial junction with H\&E staining, such as ill-defined morphology, intense nuclear stain, and little cytoplasm similar to adjacent stromal cells. Intense nuclear staining with acridine orange fluorescence were seen in stromal cells and some "indifferent" epithelial cells within the stromal-epithelial junction, indicating they were actively proliferating. In contrast, mature surface epithelial cells showed minimal nuclear staining, suggesting these cells were inactive. Baggish and others speculated that these mature, inactive epithelial cells were 
unlikely to contribute to the expansion of new surface epithelial progeny. With stromal cells and the subset of epithelial cells both proliferating at the stromaepithelial border, this begged the question whether the stroma and epithelia could be derived from the same stem cell-a reasonable theory considering the process of growth and differentiation during embryonic development (1967).

Following this research, studies using scanning/transmission electron microscopy (SEM/TEM) concluded that residual glandular stumps protruding from the denuded surface, as well as persistent LE in the cornua and isthmus regions of the uterus, were the source of proliferating and migrating epithelial cells that reformed the LE. Many years later using SEM, hysteroscopy, and histology, a reappraisal of endometrial repair in the uterus was performed during menses (Garry et al, 2009). In the early stages of repair, single cells and small patches of de novo LE cells were frequently found to be isolated and without direct contact with protruding gland stumps. The new epithelial cells were cuboidal in shape and lacked microvilli unlike the mature, microvilli columnar cells around the glands. Following fusion of the new islands with each other, they grew toward the remaining cells surrounding the basal glands to form a continuous epithelial lining that covered the underlying remodeled stroma (Garry et al, 2009). These results suggested that it was unlikely that the mature, differentiated cells surrounding the glands would be able to give rise to the new, morphologically different epithelial cells seen, but rather the isolated singlets or small clusters originated from the stroma presumably by MET (Garry et al, 2009). 
A number of scientists used lineage tracing mouse models, direct fluorescence, immunofluorescence and immunohistochemistry to investigate MET as a uterine repair mechanism and to identify putative transitional cells. In nulliparous mice, pancytokeratin was specific to epithelia. Following decidualization and progesterone removal in menses-like mouse models, cells co-expressing pancytokeratin (epithelial marker) and vimentin (stromal marker) were observed in the stromal compartment at 12 hours (Cousins et al, 2014) and up to 48 hours (Patterson et al, 2013) suggesting identification of mesenchymalepithelial transitional cells. The co-expressing cells were initially located at the border of the endometrial stroma and myometrium, a proposed mesenchymal stem cell niche for the stroma (Cervelló et al, 2007, DePace et al, 1981), and advanced towards the luminal epithelialization zone over time (Patterson et al, 2013). In two studies, lineage tracing was performed using Anti-Müllerian Hormone Receptor Type 2 (Amhr2)-Cre mice to drive expression of either EYFP (Amhr2-Cre;Rosa26-Eyfp) or LacZ (Amhr2-Cre;Rosa26-LacZ) reporters (Huang et al, 2012, Patterson et al, 2013). The Amhr2 promoter is active only in the mesenchymal cells of the uterus (i.e., stroma and myometrium), therefore reporter expression was restricted to stromal and myometrial cells of the developing and adult uteri. Following completed endometrial regeneration postpartum or using a menses-like model, EYFP+ or $\mathrm{LacZ}^{+}$mesenchyme-derived cells were identified in the GE and LE. These studies concluded that stromal cells underwent MET as a mechanism to repair the epithelium, and that this mechanism is reserved for damage/repair processes such as that seen following 
menstruation or pregnancy, but not during the minimal turnover that occurs during the estrous cycle. These mesenchyme-derived epithelial cells were shown to persist up to 2 months postpartum (Huang et al, 2012).

Underpinning these studies is the assumption that the Amhr2 promoter is only active in the mesenchyme and not in the epithelia to be able to conclude that reporter-positive epithelial cells are derived from the stroma. Amhr2 promoter activity has been investigated using Amhr2-LacZ mice; LacZ expression is only seen when Amhr2 promotor is active and is detected by $\beta$ galactosidase staining. At E 13.5, E 14.5, E 15.5, and E 18.5, $\beta$-galactosidase expression was seen only in the Müllerian duct mesenchyme and was more robust in the anti-mesometrial mesenchyme (Arango et al, 2008). In mice aged P 14, P 25, 6 weeks and 6 months, LacZ expression in postnatal tissue was not identified in LE or GE and was restricted to the myometrium in adults. Additionally, Amhr2-LacZ mice collected at 3 days postpartum or 2 days following progesterone removal (ovariectomy) in a menses-like model demonstrated no LacZ expression in the epithelia during endometrial regeneration (Patterson et al, 2013). These data indicate that no Amhr2 promotor activity occurs within epithelia embryonically, postnatally or in adulthood, thus supporting the use and validity of Amhr2-lineage tracing models when studying MET within the uterus.

A recent study evaluated the contribution of putative stromal stem/progenitor cells to epithelial repair using a menses-like mouse model (Yin et al, 2019). SM22a $\alpha^{+}$cells were identified as a subpopulation of $A M H R 2^{+}$cells and co-expressed CD34 in the repairing zone of the endometrium. SM22a marks 
perivascular pericytes, a putative mesenchymal stem cell population, while AMHR2 is a well-known marker of endometrial mesenchyme and CD34 is expressed by various types of stem/progenitor cells (Arango et al, 2008, Cervelló et al, 2011). SM22a $\alpha^{+}$stromal-derived cells appeared to populate the epithelium and were $\mathrm{CDH} 1^{+}$(epithelial marker) as epithelial repair progressed. To further validate this finding, $S M 22 \alpha ; m T / m G$ reporter mice were used to track the fate of SM22a-expressing stromal cells and their progeny during endometrial repair. During the first 36 hours, SM22 $\alpha^{+}$GFP $^{+}$stromal cells increased drastically, followed by an increase in GFP+ cells found in the epithelium after 72 hours of repair. Within the epithelium, stromal-derived GFP+ cells remained even after repair was completed by 96 hours supporting their contribution to epithelialization following damage. Interestingly, this study also demonstrated a subset of stromal cells transition to epithelial cells when treated with estrogen for 10 days in vitro (Yin et al, 2019). Results from this research not only supports MET as a mechanism of epithelial repair but begins to address Baggish's theory that one progenitor population potentially contributes to both stromal and epithelial lineages. Additionally, it suggests that estrogen may play a role in the transition of mesenchyme to epithelia, however further validation is required.

Using multiple lineage tracing models with mesenchyme-specific Cre reporters (Amhr2, Cspg4, Pdgfr $\beta$ ) that are initially expressed during Müllerian duct development, it was suggested that resulting labeled epithelia in the postnatal and adult uteri are maintained from embryonic epithelial labeling and are not derived from the stroma by MET (Ghosh et al, 2020). All models 
discussed use $L a c Z$ reporters, and of importance, one of the models was Amhr2Cre driven. The investigators identified $\mathrm{LacZ}^{+}$epithelial cells in adult nulliparous mice that had not undergone endometrial damage and repair in contrast to prior reports (Huang et al, 2012, Patterson et al, 2013). To determine the origin of these cells, Amhr2 expression (e.g., promoter activity) was examined embryonically by in situ hybridization. As previously described, the MDE is derived from invaginating CE and so, Amhr2 promotor activity was evaluated in the CE, MDE and MDM, in E 15.5 embryos. The MDM was positive for Amhr2, the MDE was negative, and the overlying CE was positive. It was concluded that because $\mathrm{CE}$ gives rise to the first MDE cells at E 11.5, that $A m h r 2+\mathrm{CE}$ cells contributing to the MDE must be the source of $\mathrm{LacZ}^{+}$epithelial cells in adult reporter mice. However, the Amhr2 promoter is not active until E 12.5 after the contribution of CE cells to the MDE (Arango et al, 2008). As detailed previously, after initial invagination of the CE, the MDE elongates of its own accord and does not receive additional input from the CE (Orvis and Behringer, 2007, Arango et al, 2008). This would explain why the investigators did not observe LacZ expression in the MDE. Therefore, it is very unlikely that $\mathrm{LacZ}^{+}$epithelial cells in the adult are derived from $\mathrm{LacZ}^{+} \mathrm{MDE}$ in the embryo. Using another mesenchyme-specific marker, Cspg4 promotor activity was found grossly in the Müllerian duct, although MDE or MDM were not specified. At P 1, promotor activity within the stroma was restricted to stromal perivascular cells and maintained through adulthood (Ghosh et al, 2020). Immunostaining demonstrated X-gal expression in uterine epithelia at P 35 and P 56 in Cspg4 ${ }^{C r e}$ - 
LacZ $Z^{f /+}$ mice with increased expression in LE and GE following tamoxifen administration (Ghosh et al, 2020), but with promotor activity specific to mesenchyme, this may indicate MET postnatally and responsiveness to estrogen despite alternate interpretation. Using a third mesenchyme-specific marker, Pdgfr $\beta^{\text {rtTa; }}$ tetOCre; R26-LacZ ${ }^{f l /+}$ mice were generated and labeling of $P d g f r \beta^{+}$cells was controlled with doxycycline administration to encompass Müllerian duct E 8.5-P 1 development (Ghosh et al, 2020). Adult mesenchyme and epithelia, specifically uterine GE, expressed LacZ, indicating progeny of embryonically labeled cells. Again, it is unknown if cells labeled during this period were within MDE or restricted to MDM. A second period of labeling was induced in adults for 3 days, then these mice were chased for a year before collection, and X-gal positive cells were identified within the uterine epithelia (Ghosh et al, 2020). Since these models are lineage tracing or fate mapping, and promotor activity has been shown to be restricted to mesenchymal cells in two mouse models, it is still unclear whether labeled epithelial cells are maintained from embryonic origin as suggested or arise at later times from labeled mesenchyme via MET outside of the context of postpartum or menses-like epithelial repair. 


\section{CHAPTER 2: A REAPPRAISAL OF MESENCHYMAL-TO-EPITHELIAL}

TRANSITION WITHIN THE ENDOMETRIUM

\subsection{Introduction}

The uterus is a dynamic organ that not only responds to hormonal changes throughout the estrous/menstrual cycle but is also able to regenerate and repair itself rapidly following parturition, and in higher primates, during menses. A woman will undergo approximately 400 to 500 damage/repair cycles (i.e. the menstrual cycle) throughout her reproductive lifetime. Although not every species sheds the innermost layer of the uterus, the endometrium, as women do, this layer still responds to the synchronized increase and decrease of ovarian steroid hormones, estrogen and progesterone, resulting in cellular turnover through proliferation and apoptosis. Within the endometrium, two phenotypically different cell types are present: the underlying stromal layer contains mesenchymal, stromal cells capable of migration, and the static epithelial layer, luminal (LE) and glandular (GE), where epithelialization occur.

Uterine epithelial regeneration is aided by multiple processes to ensure swift repair of the tissue. One of these processes likely involves stem cells of the epithelium that proliferate to regenerate the epithelium over damaged areas. These putative epithelial stem cells are thought to reside in the epithelial glands of the uterus (Ferenczy, 1976) with subsequent research both supporting this as well as putting it into question (Padykula et al, 1989, Gary et al, 2009, Jin et al, 2019). It is possible that another stem cell population within the epithelium contributes to the regeneration of the epithelium, but this has yet to be definitively shown. More recently, evidence suggests the mechanism, mesenchymal-to- 
epithelial transition (MET), contributes to endometrial epithelialization following tissue damage, though little is known about this mechanism (Huang et al, 2012; Patterson et al, 2013; Cousins et al 2014; Yin et al, 2019).

MET and its counterpart, epithelial-to-mesenchymal transition (EMT) are cellular mechanisms important in embryonic development but may become dysregulated and contribute to diseases like cancer and endometriosis (Banyard and Bielenberg, 2016, Bartley et al, 2014, Matsuzaki and Darcha, 2011, Wilson et al, 2020). Recent studies have demonstrated that MET occurs within the endometrium following parturition and induced endometrial shedding in mice (Huang et al, 2012, Patterson et al, 2013, Cousins et al, 2014). It is probable that MET occurs monthly in women following the shedding of the functional layer of the endometrium, although human studies are limited in this area. Historically, the most widely accepted theory of endometrial epithelialization in women is regrowth of residual basal epithelial glands to repopulate the LE layer (Ferenczy, 1976). However, in 2009, histological techniques and scanning electron microscopy (SEM) were utilized to reevaluate menstrual epithelialization, revealing possible contribution of stromal cells to the LE, presumably through MET (Garry et al). Utilizing mouse models, several studies were conducted in the next few years that supported previous findings. Dual-staining identified cells co-expressing stromal and epithelial cell markers-vimentin and pancytokeratin, respectively-and undergoing locational changes over the first 96 hours of menses-like endometrial regeneration, possibly identifying mesenchymalepithelial transitional cells (Patterson et al, 2013, Cousins et al, 2014). While 
previous research has focused on the first few days of repair/regeneration, information and characterization of mesenchymal-derived cells following these foundational hours when epithelial regeneration is complete and throughout the estrous cycle do not currently exist.

In addition to epithelialization events in the adult-during estrus, following menses and parturition-epithelialization occurs during adenogenesis, in which a single layer of LE cells invaginates into the stroma to form endometrial glands. This process begins during late gestation in humans and after birth in mice at approximately postnatal day $(\mathrm{P}) 5$. By $\mathrm{P} 15$, the adult uterine histoarchitecture is established and the uterus continues to increase in size until reaching sexual maturity at approximately 5-6 weeks of age (Hu et al, 2014, Vue et al, 2018). Because epithelialization events are not confined to the adult, it is possible that MET also occurs prior to adulthood. Recently, it was suggested that the putative mesenchymal-derived cells seen within the uterus are maintained from embryonic origin and that MET does not occur in the adult uterus (Ghosh et al, 2020). Due to these gaps in knowledge, the current study aims to: 1.) identify the temporal origin of these cells 2.) investigate the contribution of MET to epithelialization events postnatally (adenogenesis) and in the nulliparous adult (during the estrous cycle) and 3.) assess the longevity of mesenchymal-derived epithelial cells following postpartum endometrial epithelial repair. We hypothesize that MET contributes to additional epithelialization events outside of menses-like and postpartum regeneration, including adenogenesis and during the estrous cycle as homeostatic epithelial turnover. 


\subsection{Materials and Methods}

\section{Animals}

All protocols involving animal experiments were approved by Animal Care and Use Committee at University of Missouri. Amhr2-Cre mice (Arango et al, 2008) were obtained from the Mutant Mouse Resource and Research Center (MMRCC), Rosa26-Stop f/ft-EYFP, Rosa26-Stop ${ }^{\text {fl/f-tTA }}$, and TRE-H2B-GFP (Fuchs and Horsley, 2012) mice were obtained from Jackson Laboratories.

\section{Fate-mapping Studies}

Amhr2-Cre mice were crossed to Rosa26-Stop ${ }^{\text {flft-EYFP }}$ mice to generate double transgenic reporter females (Amhr2-Cre; Rosa26-EYFP) and littermate controls (Amhr2-WT; Rosa26-Stop $\left.{ }^{f / f t-E Y F P}\right)$. In cells with Amhr2 promotor activity, Cremediated excision of the loxP floxed stop codon in the Rosa26 promotor allow constitutive expression of EYFP (Fig. 1). Uteri from Amhr2-Cre; Rosa26-EYFP and control females were collected at 8 weeks or greater in nulliparous mice $(n=25)$ and after one pregnancy $(n=20)$ at each stage of the estrous cycle (nulliparous: proestrus $n=7$, estrus $n=4$, metestrus $n=10$, diestrus $n=4$, postpartum: proestrus $n=4$, estrus $n=4$, metestrus $n=5$, diestrus $n=8$ ). Uteri were also collected from Amhr2-Cre; Rosa26-EYFP females at postnatal day $21(\mathrm{n}=4)$. To generate triple transgenic females (Amhr2-Cre; Rosa26-tTA; H2B-GFP), Rosa26-Stop ${ }^{\text {fl/f-ITA }}$ mice were crossed with TRE-H2B-GFP reporter mice to produce homozygous, double transgenic mice (Rosa26-Stop ${ }^{f / f t-t T A}$; H2B-GFP) before a final cross with Amhr2-Cre mice (Fig. 2). Rosa26-Stop $p^{f / f f-t T A} ;$ H2B-GFP mice served as controls. This tet-off system allows for constitutive expression of 

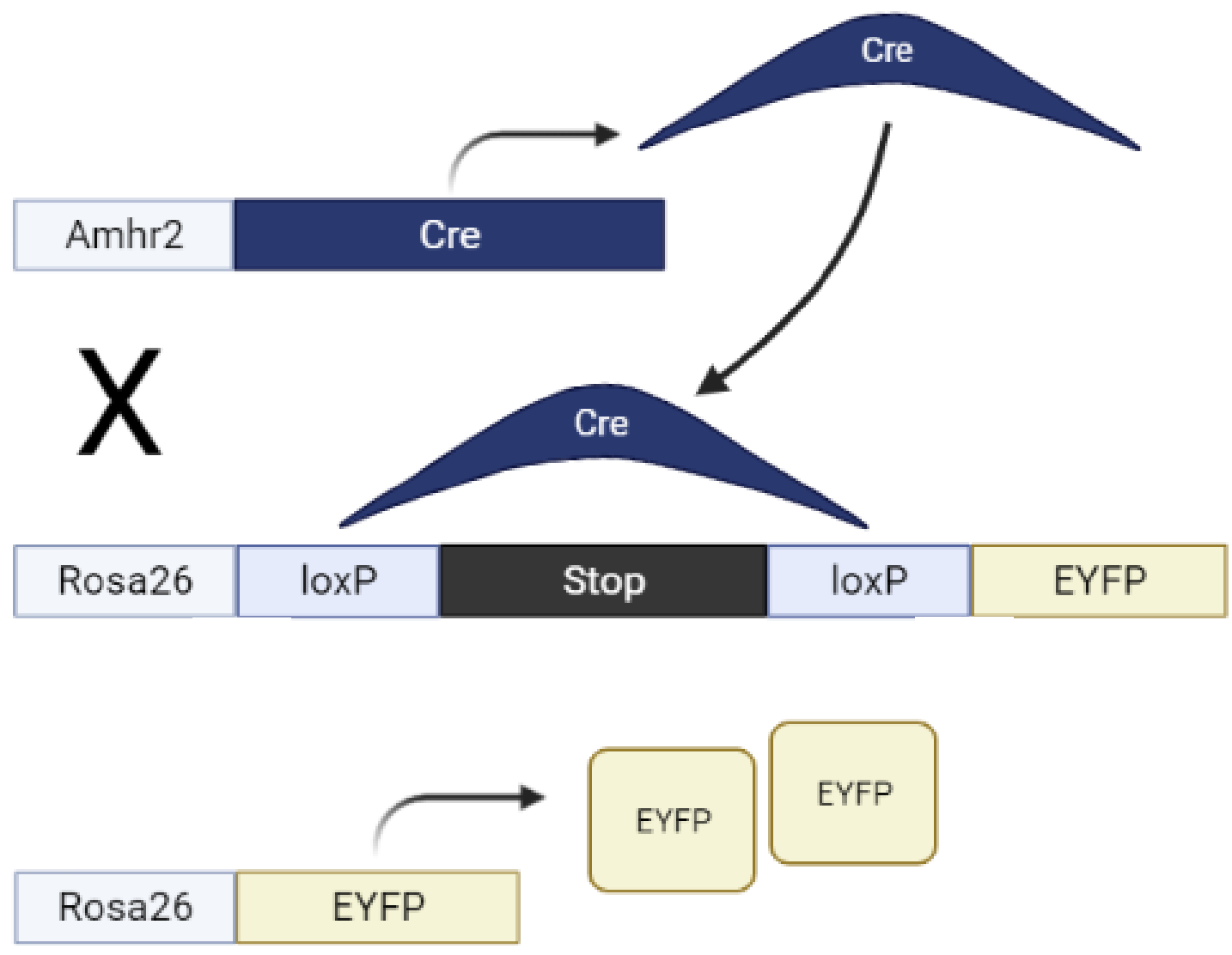

Figure 1. Schematic diagram of generating Amhr2-Cre; Rosa26-EYFP female mice and resulting constitutive EYFP expression. Amhr2-Cre mice were crossed with Rosa26-Stop pl/fil-EYFP mice. In cells with Amhr2 promotor activity, there is Cre-mediated excision of the loxP floxed stop codon in the Rosa26 promotor. With this stop codon cleaved out, EYFP is constitutively expressed in cells with Amhr2 promotor activity. 


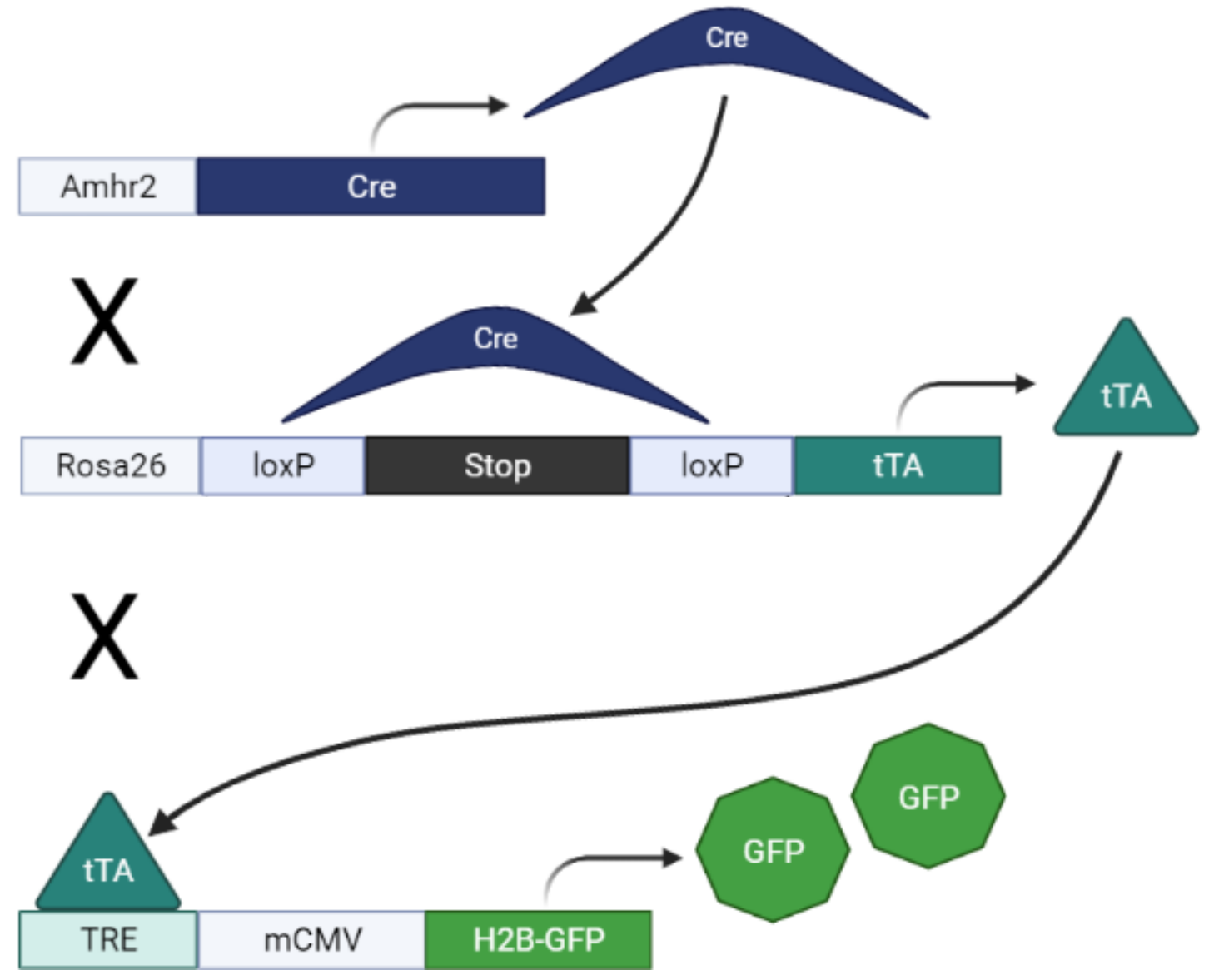

Figure 2. Schematic diagram of generating Amhr2-Cre; Rosa26-tTA; H2BGFP female mice and resulting H2B-GFP expression. Triple transgenic females were produced crossing Amhr2-Cre, Rosa26-Stop ${ }^{f / f-f-T T A}$ and TRE-H2BGFP reporter mice. Under Amhr2 promotor activity, Cre-mediated excision of the loxP floxed stop codon in the Rosa26 promotor allows expression of tetracycline transactivator (tTA), which binds to its response element (TRE). In the absence of doxycycline, this tet-off system allows for constitutive expression of H2B-GFP in cells with Amhr2 promotor activity. 
H2B-GFP in the absence of doxycycline administration specific to cells with Amhr2 promotor activity due to Cre-mediated excision of the loxP floxed stop codon in the Rosa26 promotor and subsequent binding of tTA to TRE. Uteri were collected at P $0.5(n=5)$, P $3(n=4), P 8(n=6), P 14(n=6)$, and P21 $(n=5)$.

\section{Estrous Cycle Staging}

Cycle staging was ascertained using vaginal lavage method with $40 \mu \mathrm{L}$ of $10 \%$ trypan blue/PBS solution. Stage was determined microscopically according to proportions of cornified epithelial cells, nucleated epithelial cells, and leukocytes as seen by (Caligioni, 2009, Ajayi and Akhigbe, 2020), and verified by gross visualization of the uterus (Croy et al, 2014).

\section{Uterine Epithelial Cell Isolation and Flow Cytometry}

Uterine epithelial cell isolation was performed using a modified protocol (De Clercq et al, 2017). Uterine horns were collected from Amhr2-Cre; Rosa26EYFP females aged 8 weeks or older that were either nulliparous or had 1 pregnancy, and from Amhr2-Cre; Rosa26-tTA; H2B-GFP at PND 0.5, 3, 8, 14 and 21. At time of collection, uterine horns were cut longitudinally to expose the lumen, cut cross-sectionally at $2-4 \mathrm{~mm}$ apart to expose uterine glands and placed in $15 \mathrm{~mL}$ conical tubes with $10 \mathrm{~mL}$ of HBSS+ (Hank's Balanced Salt Solution with antibiotic/antimycotics; Gibco) with $1 \mathrm{~mL}$ of $2.5 \%$ Trypsin (reconstituted; Sigma; Cat: T7409-1G). Adult uteri underwent a series of digestions: $4^{\circ} \mathrm{C}$ oscillating at 50-70 rpm for $1 \mathrm{hr}$, RT without oscillation for $40 \mathrm{~min}, 37^{\circ} \mathrm{C}$ without oscillation for 25 min. Postnatal uteri underwent a similar series of digestions: RT without oscillation for 12 min (P 0.5), 17 min (P 3), 20 min (P 8), 25 min (P 14), or 30 min 
(P 21), $37^{\circ} \mathrm{C}$ without oscillation for $5 \mathrm{~min}(\mathrm{P} 0.5), 10 \mathrm{~min}(\mathrm{P} \mathrm{3}, \mathrm{P} 8), 15 \mathrm{~min}(\mathrm{P} 14)$, or 20 min (P 21). All contents were poured through $100 \mu \mathrm{m}$ nylon mesh filters into $50 \mathrm{~mL}$ conical tubes and uteri were then transferred into Mouse Endometrial Epithelial Cell (MEEC) media for 5 min. Uteri were transferred into $2.5 \mathrm{~mL}$ of HBSS+ in $15 \mathrm{~mL}$ conical tubes and vortexed vigorously for $10 \mathrm{sec}$ because contents were poured through filters. Transfer of tissue into MEEC media, vortex and filtration were repeated 3 times before tubes and petri dishes were rinsed and poured through filter. Uteri were rinsed on filter with $1 \mathrm{~mL} H B S S+$ before discarded. $50 \mathrm{~mL}$ conical tubes were centrifuged at $500 \mathrm{xg}$ for $5 \mathrm{~min}$ before supernatant were aspirated. Cell pellets from adult uteri underwent red blood cell lysis with 2 mL AKC lysis buffer (Gibco, Grand Island, NY; cat \# A10492-01) for 5 min, then $20 \mathrm{~mL} 1 \times$ phosphate-buffered saline (PBS) was added before centrifugation at $300 \mathrm{xg}$ for $5 \mathrm{~min}$ and aspiration of supernatants. Cells were resuspended before transferring into Eppendorf tubes. Tubes were rinsed with 1 $\mathrm{mL} \mathrm{HBSS}+$ before added to Eppendorf tubes and centrifuged at $300 \mathrm{xg}$ for $5 \mathrm{~min}$. Supernatants were aspirated and pellets were resuspended in $1 \mathrm{~mL}$ PBS working buffer (De Clercq et al, 2017) and incubated for $10 \mathrm{~min}$. Tubes were centrifuged at $300 \mathrm{xg}$ for $5 \mathrm{~min}$, aspirated and stained with $10 \mu \mathrm{L}$ of EpCAM (APC rat antimouse CD326; BD Biosciences; PLACE; cat \# 563478) in $90 \mu \mathrm{L}$ of PBS working buffer for $15 \mathrm{~min}$. $1 \mathrm{~mL}$ of PBS working buffer was added and tubes were centrifuged at $300 \mathrm{xg}$ for 5 min before aspiration and cells were washed with 1 $\mathrm{mL}$ of PBS working solution. Following centrifugation at $300 \mathrm{xg}$ for $5 \mathrm{~min}$ and aspiration of supernatants, cells were resuspended in $30 \mu \mathrm{L}$ of PBS working 
solution before being analyzed by FlowSight (Amnis; IDEAS Version 6.2; Fig S1).

\section{Gelatin Embedding and Frozen Tissue Preparation}

EYFP-expressing, GFP-expressing and control uteri were fixed using 8\% PFA for 30 min at $4^{\circ} \mathrm{C}$ before washed 3 times with $1 \times$ PBS and incubated in $15 \%$ sucrose buffered in PBS overnight. Samples were incubated in gelatin $(7.5 \%$ gelatin in PBS; Gelatin from porcine skin; Sigma Life Science; cat \# G2500) for $1 \mathrm{hr}$ at $37^{\circ} \mathrm{C}$, embedded in gelatin, and frozen at $-50^{\circ} \mathrm{C}$ to $-65^{\circ} \mathrm{C}$ in $2-$ Methylbutane cooled by liquid nitrogen, and stored at $-80^{\circ} \mathrm{C}$ until cryo-sectioning. Tissues were cryo-sectioned at 5-8 $\mu \mathrm{m}$ and thaw mounted. Gelatin was removed in $37^{\circ} \mathrm{C}$ PBS before mounting with a proportion of slides undergoing immunohistochemistry, but all samples were stained with 4',6-diaminino-2-phenylindole (DAPI) prior to mounting with aqueous mounting media (Fluoro-gel with TES; Electron Microscopy Sciences, Hartfield, PA; cat \# 17985-30) and viewed using fluorescent microscopy (Leica 5500 microscope; LAS X version: 3.7.4.23463).

\section{Immunohistochemistry and Indirect Immunofluorescence}

Uteri from EYFP-expressing and GFP-expressing uteri were obtained to perform IHC by fluorescence. Postnatal tissue (P 0.5, P 3, P 8, P 14, and P 21; $n=4-6$ per time point) and adult tissue (nulliparous or postpartum in proestrus, estrus, metestrus, or diestrus; $n=3-4$ per cycle stage) were collected, fixed in $8 \%$ PFA for 30 min at $4^{\circ} \mathrm{C}$, processed for gelatin imbedding and freezing and sectioned at 5-8 $\mu \mathrm{m}$. Following thaw mounting and removal of gelatin in $37^{\circ} \mathrm{C}$ PBS, immunofluorescence for EpCAM (Purified rat anti-mouse CD326; BD 
Biosciences, 1:100; PLACE; cat \# 552370), Ki67 (rabbit monoclonal; 1:100; Invitrogen, Rockford, IL; cat \# MA5-14520), estrogen receptor a (ESR1; 1:100; Santa Cruz Biotechnology; cat \# A0716, discontinued), progesterone receptor (PGR; rabbit monoclonal 1:100; Invitrogen; cat \# MA5-14505), and FOXA2 (rabbit monoclonal 1:100; Abcam, Cambridge, MA; cat \# ab108422) were performed. To verify EYFP and GFP expression, tissues were stained using an anti-GFP antibody (Rabbit polyclonal 1:1000; Invitrogen, Eugene, OR; cat \# A11122). Briefly, PBS working buffer (PBS, 10\% BSA, 10\% NGS, and Triton) was applied to block tissue for $1 \mathrm{hr}$ at RT before incubation in primary antibodies; EpCAM, Ki67 and GFP antibodies were applied for $1 \mathrm{hr}$ at RT, and ESR1, PGR, and FOXA2 were applied and tissue incubated overnight at $4^{\circ} \mathrm{C}$ following blocking. Tissues were washed thrice for 10 min each before incubation in secondary antibodies for 40 min in dark (Anti-rat lgG $(\mathrm{H}+\mathrm{L})$ Alexa Fluor 555 Conjugate, 1:1000, Cell Signaling Technology, cat \# 4417; Alexa Fluor 568 goat anit-rabbit $(\mathrm{H}+\mathrm{L}), 1: 1000$, Invitrogen, Eugene OR, cat \# A11036). After two, 10 min washes, tissues were incubated in DAPI $(300 \mathrm{nM})$ for 5 min and washed twice, as before. After incubation in DI water for 5 minutes, tissues were mounted with aqueous mounting solution (Fluoro-gel with TES; Electron Microscopy Sciences, Hartfield, PA; cat \# 17985-30) and stored at $4^{\circ} \mathrm{C}$ in dark. Fluorescent imaging was performed using a Leica 5500 microscope (LAS X version: 3.7.4.23463).

\section{Blood Serum Collection and ELISAs}

Amhr2-Cre; Rosa-EYFP females aged P 21 were anesthetized prior to 
submandibular bleed and collected in Eppendorf tubes. Samples were allowed to coagulate for $30 \mathrm{~min}$ to $1 \mathrm{hr}$ before centrifugation at $4^{\circ} \mathrm{C}$ for $10 \mathrm{~min}$. Blood serum was removed and transferred into a clean Eppendorf tube and stored at $20^{\circ} \mathrm{C}$ until use. Mouse/rat estradiol and progesterone ELIZA kits (Calibiotech; cat \#s ES180S-100 and PG362S, respectively) were used to assess blood serum estradiol and progesterone concentrations and read using a a Synergy HT multidetection microplate reader (BioTek).

\section{Statistical Analyses}

All statistical analyses were performed using GraphPad Prism version 9.1.2 (226) for Windows, GraphPad Software, San Diego, California USA, www.graphpad.com.

\subsection{Results}

Epithelialization is the process by which epithelial cells migrate, proliferate and repair a denuded surface. This term can be broadened to include growth of epithelial tissues under various physiological conditions such as the growth that occurs following prior resorption in the estrous cycle, or growth to form endometrial glands, termed adenogenesis. In this study we investigated the contribution of MDM-derived cells (i.e., endometrial stromal cells) to epithelialization in mouse uteri during different physiological and hormonal circumstances.

MDM-derived epithelial cells fluctuate across the estrous cycle in postpartum and nulliparous uteri.

Previous studies using lineage tracing mouse models identified MDMderived epithelial cells following postpartum and menses-like endometrial 
regeneration but did not observe them in nulliparous mice. It was therefore hypothesized that MDM cells (i.e., endometrial stromal cells) underwent MET as a mechanism to regenerate the epithelium following endometrial damage. MDMderived cells were shown to be present in the epithelium for at least two months postpartum, but additional evaluation of these cells was not conducted. Here, to further characterize MDM-derived epithelial cells, uteri were collected from Amhr2-Cre; Rosa-EYFP females at $96 \mathrm{hr}, 2$ wks, 3 wks, 2 mo and 3 mo postpartum. By flow cytometry, no significant differences in the percentage of $\mathrm{EpCAM}^{+} \mathrm{EYFP}^{+}$cells (i.e. MDM-derived epithelial cells) were found by time postpartum or by number of implantation sites (Fig. 3A and C). This was due to the high variability of samples. For example, with five implantation sites, the range in $\mathrm{EpCAM}^{+} \mathrm{EYFP}^{+}$cells was $0.03 \%$ to $61.4 \%$. There was no difference in locational expression of $\mathrm{YFP}^{+}$epithelial cells in implantation and interimplantation sites (Fig. 3B). Subsequently samples were categorized by stage of the estrous cycle based on vaginal cytologies, and there was a significant decline in the percentage of EpCAM+EYFP+ cells from proestrus $(47.35 \pm 7.48)$ to diestrus $(0.81 \pm 0.09)$, with no difference between diestrus and control uteri (Fig. 3D). Because of the high variability in MDM-derived epithelial cells observed across the estrous cycle in postpartum uteri, a re-evaluation of nulliparous uteri (i.e. no endometrial damage and repair) was performed based on stage of the cycle. Similar to postpartum uteri, there was a high percentage of $\mathrm{EpCAM}^{+} \mathrm{EYFP}^{+}$cells identified in nulliparous uteri during proestrus that significantly declined to indistinguishable from control uteri in diestrus Amhr2- 

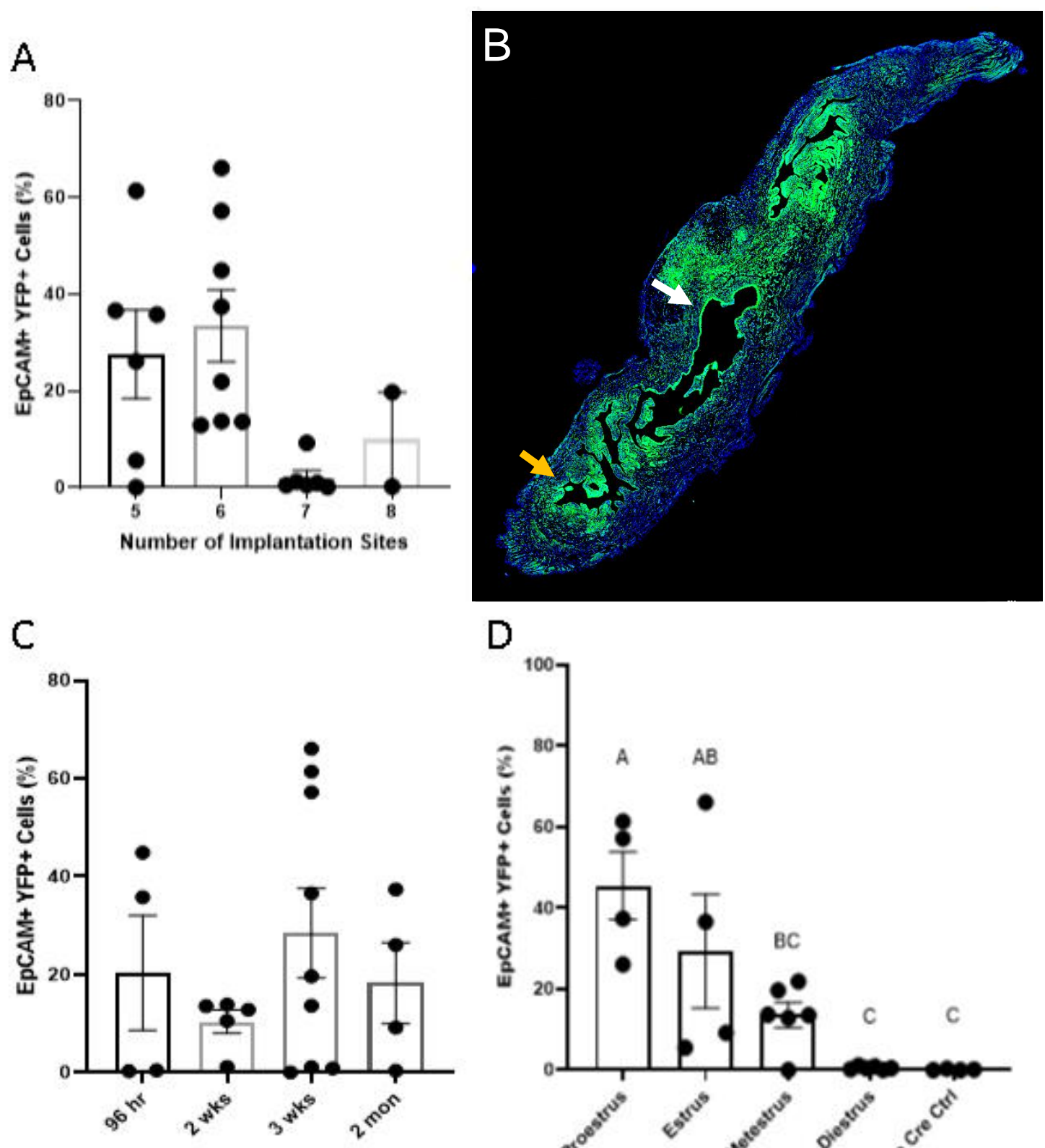

D

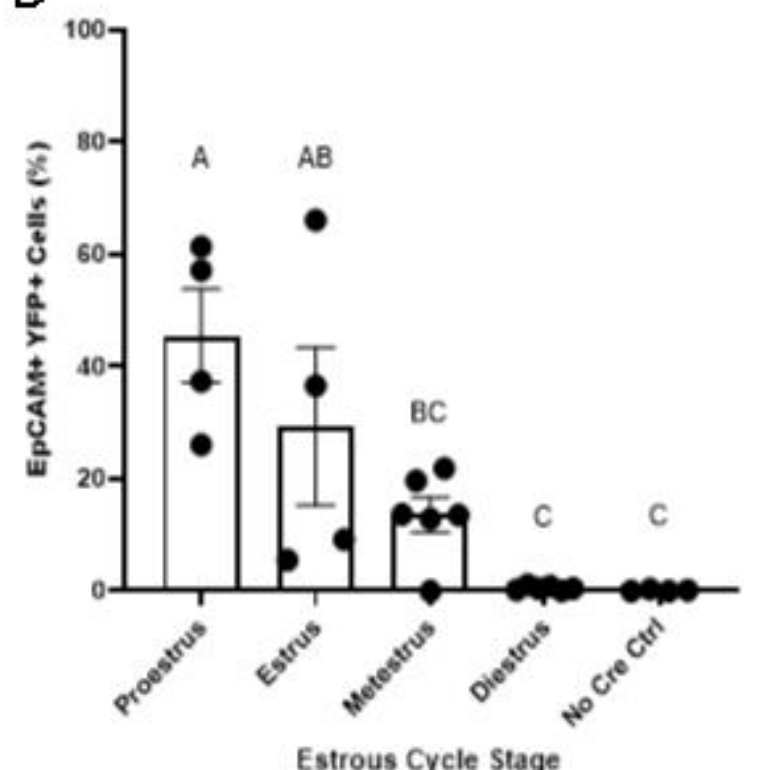

Time After Parturition

Estrous Cycle Stage

Figure 3. MDM-derived epithelial cells fluctuate across the estrous cycle in postpartum uteri. (A) Percent of MDM-derived epithelial $\left(\mathrm{EpCAM}^{+} \mathrm{YFP}^{+}\right)$cells is variable across number of implantation sites with no difference by direct fluorescence of YFP expression in epithelial cells (B) within the implantation site (white arrow) and inter-implantation sites (yellow arrow). (C) Variability in percent of EpCAM ${ }^{+} \mathrm{YFP}^{+}$cells was also found at collection times following parturition. (D) When mice were characterized by estrous cycle stage, statistical significant $(p<0.05)$ was found in proestrus and estrus when compared to control mice (No Cre Ctrl). Diestrus uteri were not statistically different from control uteri $(p>0.9999)$. 
Cre; Rosa-EYFP mice (Fig. 4A-H and Fig. 5.A). When compared by cycle stage, EpCAM+EYFP ${ }^{+}$cells in postpartum and nulliparous uteri were statistically similar (Fig. 5B). These data suggest that MDM-derived epithelial cell populations fluctuate across the estrous cycle regardless of prior endometrial damage and repair events.

\section{MDM-derived epithelial cells exhibit dynamic temporal expression patterns during postnatal uterine maturation and epithelialization.}

Involvement of MDM-derived epithelial cells in postnatal uterine maturation has not been previously explored. To investigate the temporal origin and possible contribution of MET during epithelialization events postnatally, uteri were collected from Amhr2-Cre; Rosa26-tTa; H2B-GFP females at postnatal day (P) 0.5, P 3, P 8, P 14, and P 21 to encompass epithelial differentiation and adenogenesis. Flow cytometry data showed that MDM-derived epithelial cells, $\mathrm{EpCAM}^{+} \mathrm{GFP}^{+}$cells, arose rapidly after birth $(\mathrm{P} 0.5)$ as seen by a high variability in samples ranging from $0.21 \%$ to $81.84 \%$, before a significant decline at $\mathrm{P} 8$, during initiation of adenogenesis (Fig. 6A). $\mathrm{EpCAM}^{+} \mathrm{GFP}^{+}$and $\mathrm{EpCAM}^{+} \mathrm{GFP}^{-}$ cells also segregated into two distinct populations by side scatter (Fig. 6C), an indicator of cellular complexity in all samples at P 0.5 and in one sample at P 21 . P 3 similarly showed high variability between samples as seen at P 0.5 (Fig. 6A, D and E). The variability in the data may indicate dynamic turnover of the two epithelial cell populations leading up to adenogenesis, which is predominated by EpCAM+GFP- (non-MDM-derived) cells. At P 14, during the shift from adenogenesis to glandular morphogenesis, the percentage of $\mathrm{ECAM}^{+} \mathrm{GFP}+$ 

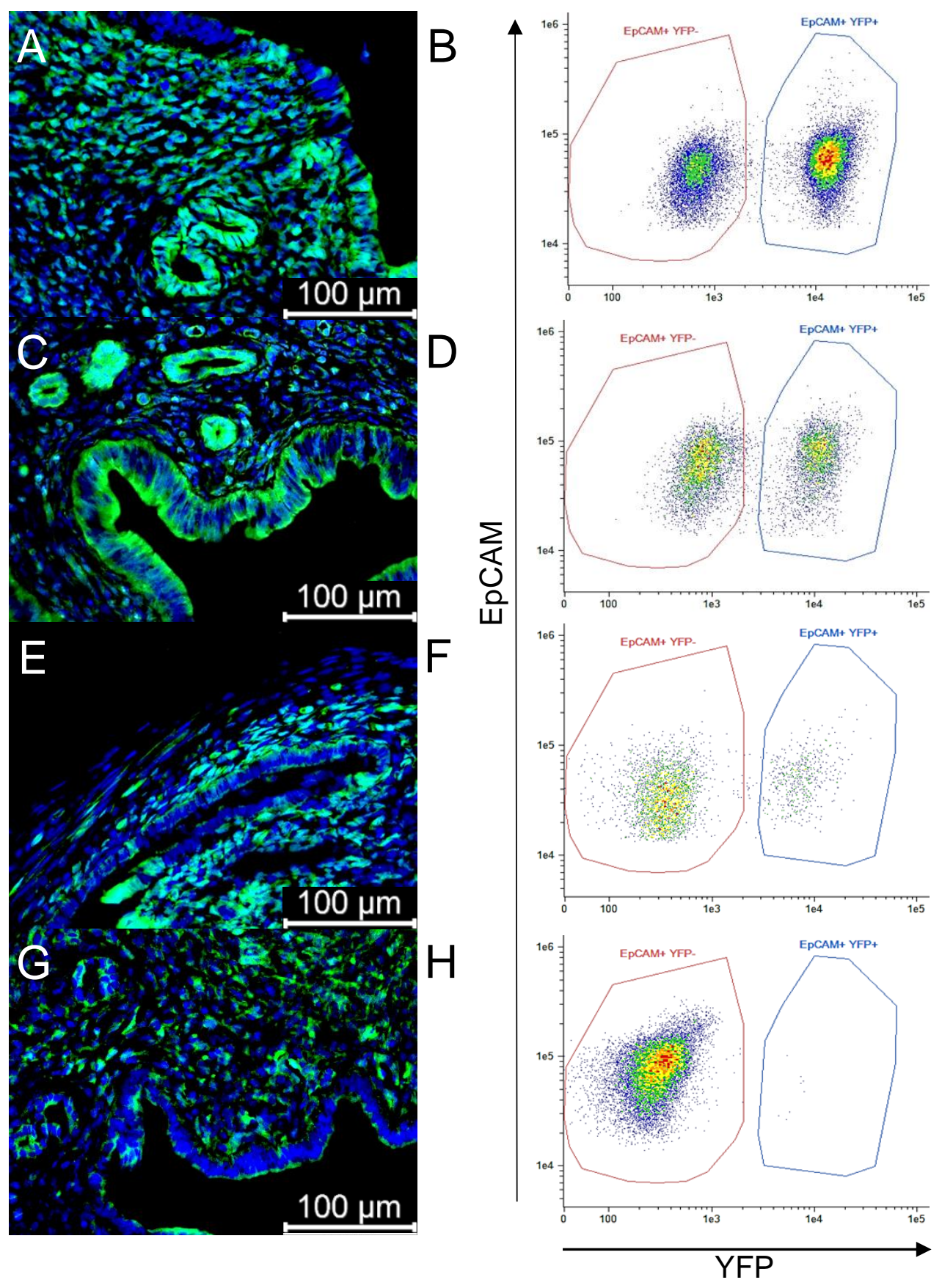

Figure 4. MDM-derived epithelial populations differ across the estrous cycle. Direct fluorescence of $\mathrm{YFP}^{+}$epithelial cells during (A) proestrus, (C) estrus, (E) metestrus, and (G) diestrus, with corresponding EpCAM+YFP- and $\mathrm{EpCAM}^{+} \mathrm{FFP}^{+}$epithelial populations by flow cytometry (B-proestrus, D-estrus, Fmetestrus, $\mathbf{H}$-diestrus). 

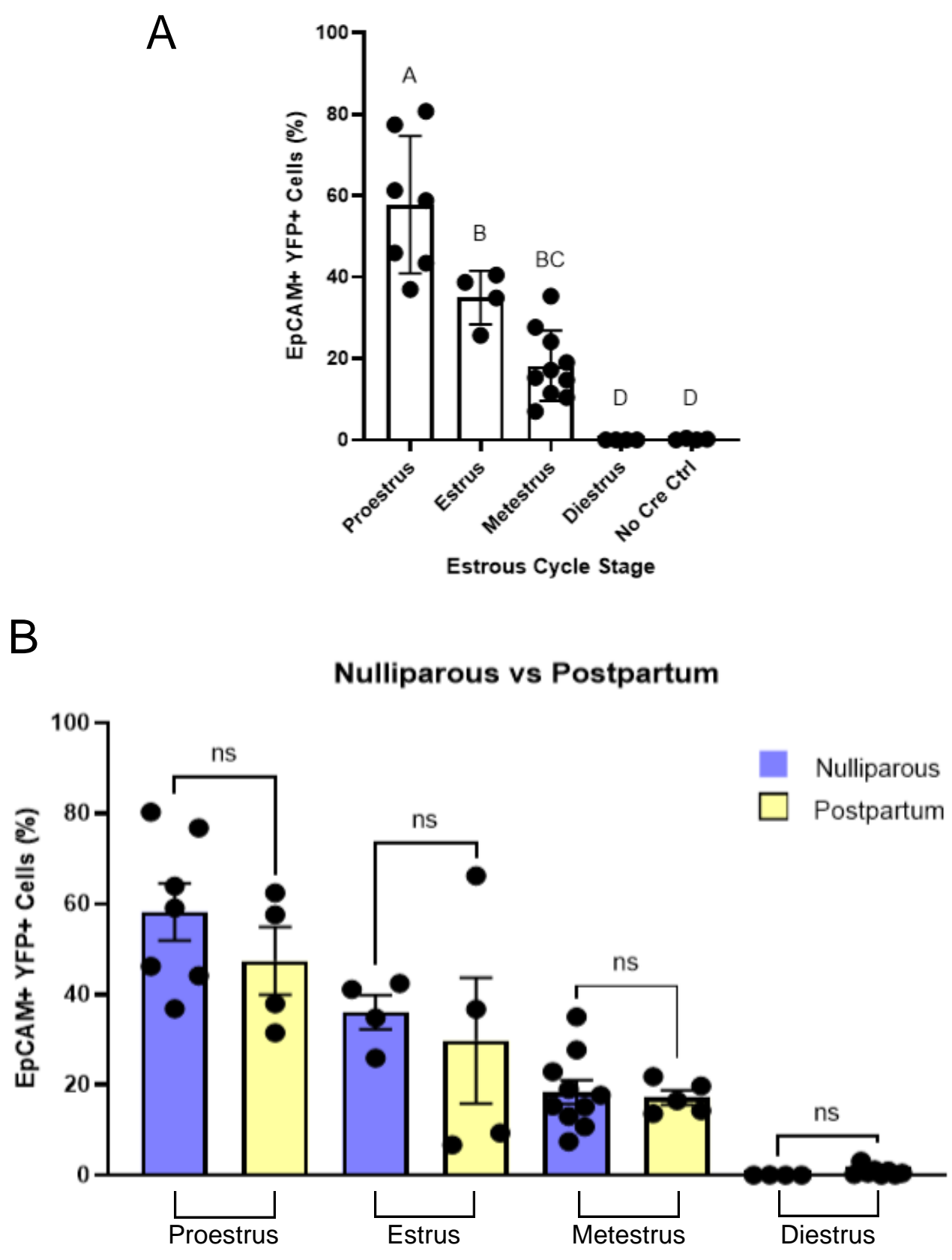

Estrous Cycle Stage

Figure 5. MDM-derived epithelial cells fluctuate across the estrous cycle in nulliparous and postpartum uteri. (A) $\mathrm{EpCAM}^{+} \mathrm{YFP}^{+}$populations during proestrus, estrus, and metestrus were statistically different $(p<0.0001,0.001$, and 0.05 , respectively) from diestrus and control uteri. Diestrus and control uteri were not statistically different $(p>0.9999)$. (B) Based on estrous cycle stage, nulliparous and postpartum uteri did not differ during the same stage. 

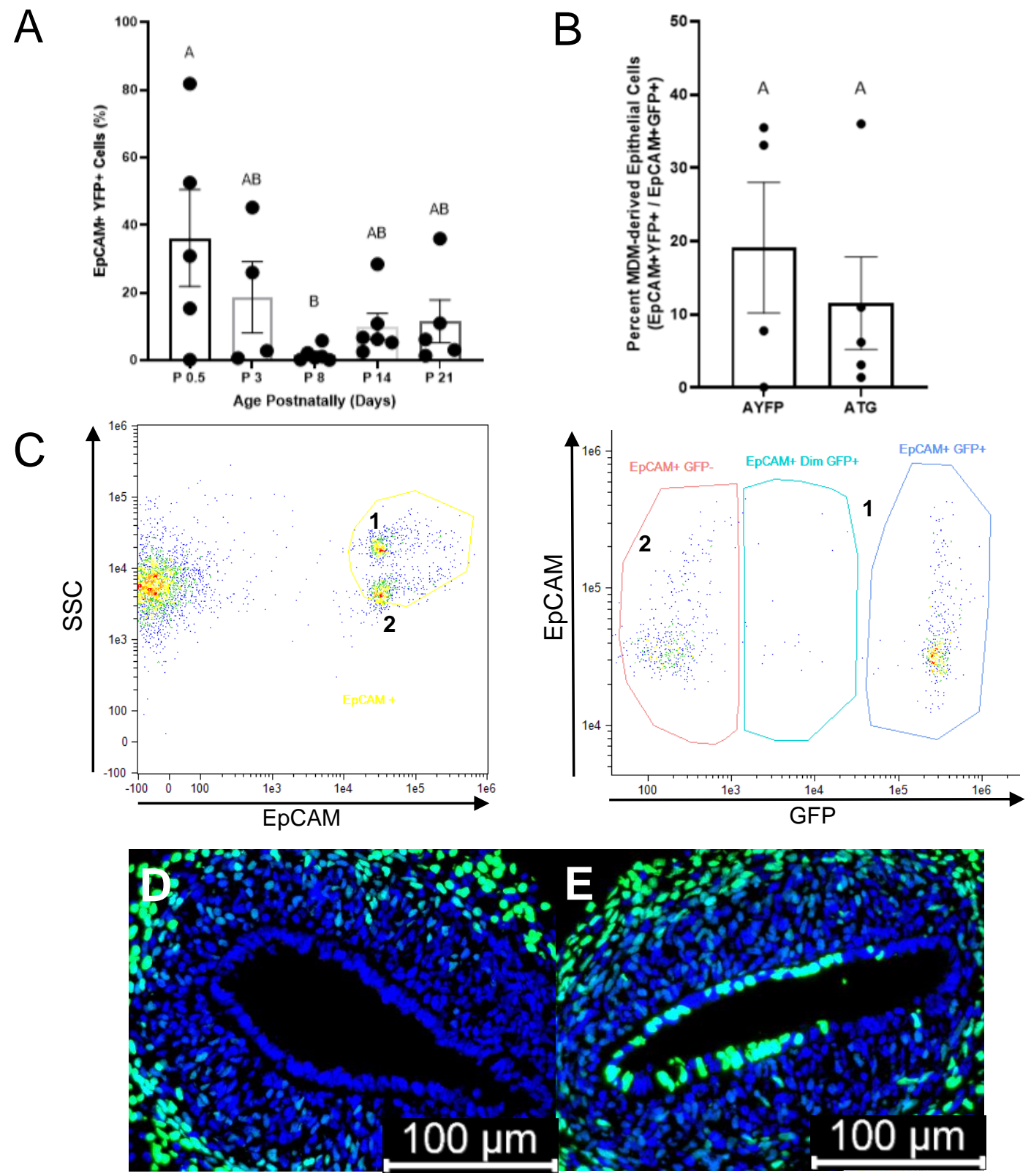

Figure 6. MDM-derived epithelial populations demonstrate dynamic temporal patterns. (A) MDM-derived epithelial $\left(\mathrm{EpCAM}^{+} \mathrm{GFP}^{+}\right)$populations fluxuate dynamically during postnatal uterine maturation. High variability is seen in $\mathrm{P} 0.5$ and $\mathrm{P} 3$ before the population averages less than $2 \%$ during adenogenesis initiation at $P$ 8. During glandular morphogenesis (P 14) through the peripubertal stage (P 21), MDM-derived epithelial cells increase and are maintained. (B) No difference is seen between Amhr2-Cre; Rosa-EYFP (AYFP) and Amhr2-Cre; Rosa26-tTa; H2B-GFP (ATG) females at P 21. (C) $\mathrm{EpCAM}^{+} \mathrm{GFP}^{+}$and $\mathrm{EpCAM}{ }^{+} \mathrm{GFP}-$ populations segregate based on sidescatter (SSC; cellular complexity), with EpCAM+GFP+ ${ }^{+}$cells showing greater complexity (population 2). (D and E) Representative images by direct fluorescence of variability in Amhr2-Cre; Rosa26-tTa; H2B-GFP uteri at P 3. 
cells increased slightly and was maintained through P 21 (Fig. 6A). Variation at P 21 Some variability was noted at P 21 with results from Amhr2-Cre; RosaEYFP females supporting the same findings at P 21 (Fig. 6B). Together, these data indicate that epithelial cells originate from the MDM very early after birth, presumably through MET, and are quickly replaced by non-MDM-derived epithelial cells during adenogenesis. However, they return during gland morphogenesis and differentiation. Analyses of blood serum estradiol (E2) and progesterone (P4) concentrations at P 21 did not show any correlation with MDM-derived epithelial cell populations in Amhr2-Cre; Rosa-EYFP and Amhr2Cre; Rosa26-tTa; H2B-GFP females. These results suggest that the mechanism, MET, is independent of ovarian steroids postnatally through P 21.

\section{MDM-derived epithelial cells persist in the adult and are characteristic of functional epithelial cells.}

We have shown in addition to endometrial regeneration, MDM-derived epithelial cells contribute to epithelialization postnatally and in nulliparous mice. Due to the high turnover or replacement of MDM-derived epithelial cells by nonMDM-derived epithelial cells during postnatal uterine maturation and the estrous cycle, we investigated their epithelial characteristics to determine if they are capable of functioning as bone fide endometrial epithelial cells. MDM-derived epithelial cells expressed the epithelial marker, EpCAM, at all postnatal and adult time points. Importantly, EpCAM was specific to LE and GE, indicating mesenchymal cells were not inadvertently analyzed by flow cytometry (Figs. S2 and S3). FOXA2, a marker of GE, was first observed at P 8 (adenogenesis 
initiation), in which few cells showed nuclear expression, and was also found cytoplasmically in some stromal cells (Fig. 7A-C). Because very few MDMderived epithelial cells (GFP+) were found at this time, subsequently no coexpression of GFP and FOXA2 was observed. From P 14 through adulthood, expression of FOXA2 was restricted to nuclei of GE cells and was expressed by both MDM-derived and non-MDM-derived epithelial cells (Fig. 7D-L and Fig. S6A-I).

During postnatal maturation, initially there was high proliferation in both epithelial and stromal compartments (P 0.5) in which both GFP+ (MDM-derived) and GFP- (non-MDM-derived) epithelial cells expressed Ki67 (Fig. 8A-C). After a decline in proliferation at P 3 (Fig. 8D-F), there was another increase in proliferation in the stroma at P 8 (Fig. S7A-C) and in the epithelia at P 14. Few $\mathrm{GFP}^{+}$epithelial cells expressed Ki67 at P 14, with majority of expression found in GFP- epithelial cells, specifically GE cells, indicating that few MDM-derived epithelial cells contribute to proliferating epithelium, thus maintaining GFP+ populations from P 14 to P 21 (Fig. 8G-L). Additionally, both ESR1 and PGR were present in both non-MDM-derived and MDM-derived epithelia, and stroma, at P 0.5 but were absent by P 3 (Figs. S8A-F and S9A-F). The abundance of ESR1 returned by $P$ 8, specifically within the stroma, and began to be highly expressed within glands at P 14 and was maintained at P 21 (Fig. S8G-O). Conversely, PGR was highly expressed within the epithelia at P 8 and increased through P 21 (Fig. S9G-0). At all postnatal stages in this study, there were no qualitative differences in marker expression between MDM-derived and non- 


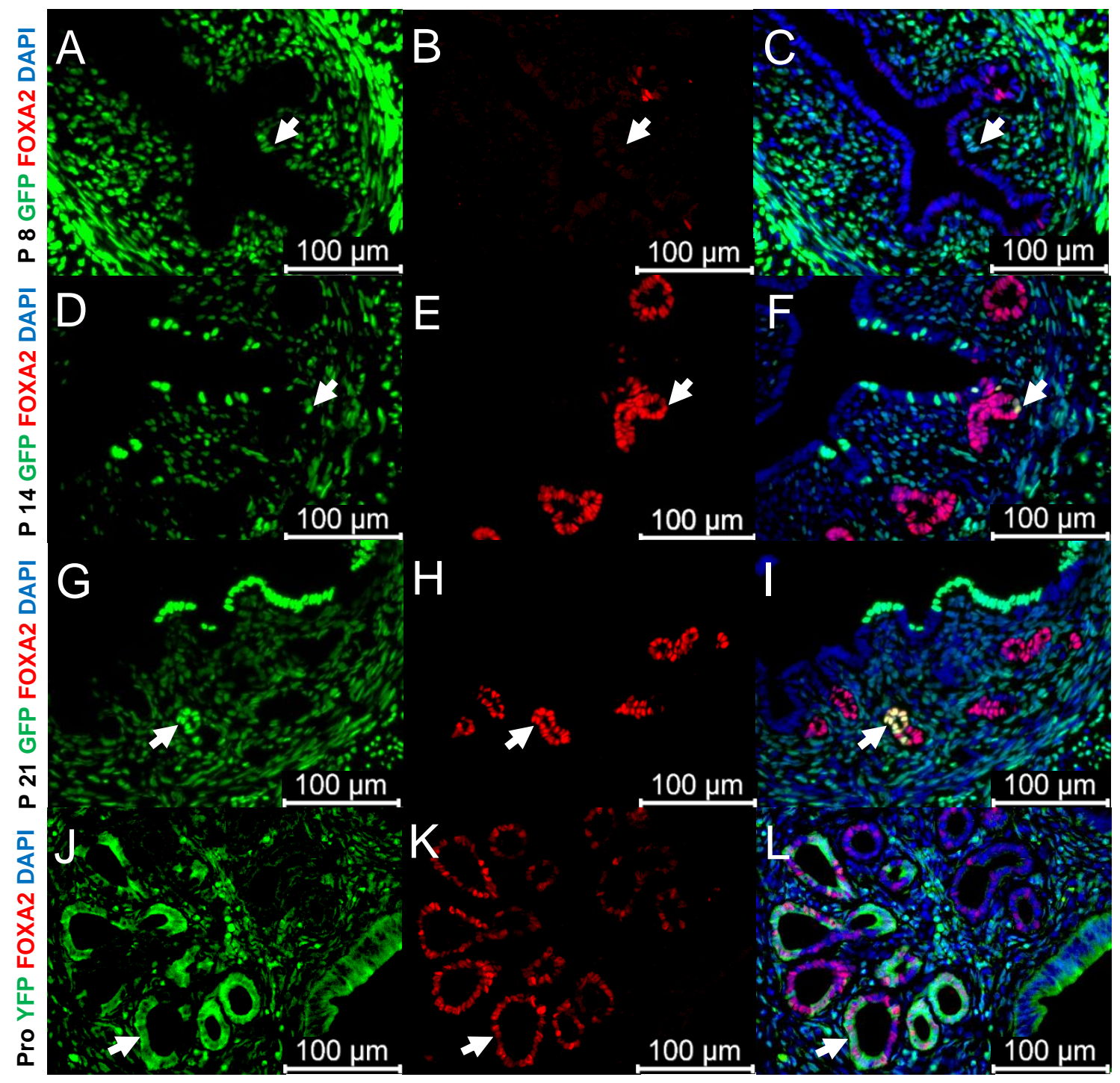

Figure 7. MDM-derived epithelial cells co-express FOXA2 by immunofluorescence in postnatal and adult tissue. MDM-derived and nonMDM-derived epithelia showed mosaicism in the LE and GE. Few MDM-derived epithelial cells were found by direct fluorescence at $P 8$ during adenogenesis initiation, supporting flow cytometry data. (A-C) FOXA2 expression was found either cytoplasmically in subsets of epithelial and stromal cells (white arrowstromal cell expressing FOXA2 cytoplasmically), with few epithelial cells showing nuclear expression. (D-F) Robust nuclear expression of FOXA2 was found specific to the GE at $P$ 14, with a proportion of these cells being GFP+ (white arrow). (G-I) Like P 14, FOXA2 expression at P 21 was found in GE cells with a proportion of these cells being GFP+ (white arrow). (J-K) Maintained from the peripubertal uterus, FOXA2 expression was nuclear in GE cells, and a subset of these cells were $\mathrm{YFP}^{+}$(white arrow). 


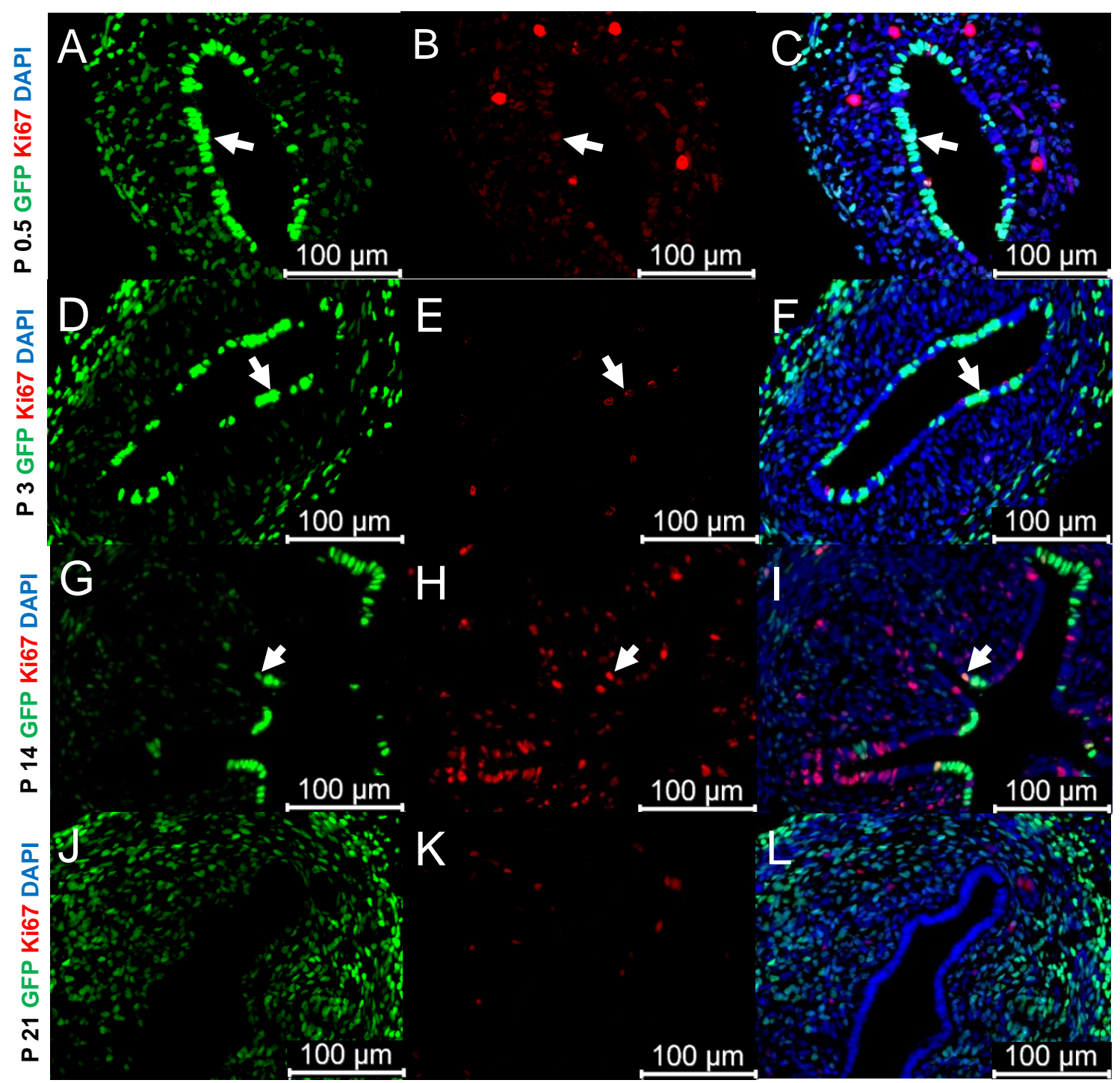

Figure 8. MDM-derived epithelial cells proliferate in a dynamic temporal pattern postnatally. (A-C) Both stromal and epithelial layers showed Ki67 expression, indicating stromal and epithelial cells proliferate at $P$ 0.5. No difference in Ki67 expression was found between GFP+ and GFP- epithelial cells, suggesting MDM-derived epithelial cells proliferate and contribute to the epithelial layer at this time (white arrow). (D-F) Proliferation decreased at P 3, with greater proliferation found in the epithelium compared to the stroma. Few GFP+ epithelial cells were found to express Ki67 during this time (white arrow) in comparison to GFP- epithelial cells. (G-I) At P 14, both stroma and epithelia were found proliferating, with more epithelial cells expressing Ki67 than stromal cells. Some GFP ${ }^{+}$epithelial cells also expressed Ki67 (white arrow), but majority of epithelial cells expressing Ki67 were GFP- (J-L) Proliferation decreased from P 14 in epithelial and stromal compartments. With little-to-no Ki67 expression in epithelia at P21, GFP+ ${ }^{+}$and GFP- epithelial cells expression was similar. 
MDM-derived epithelial cells, suggesting MDM-derived epithelial cells acquired non-MDM-derived epithelial cell characteristics throughout postnatal maturation.

During the estrous cycle, Ki67, ESR1 and PGR expression vary dynamically from stage to stage (Wood et al, 2007, Lessey et al, 1988). Regarding each stage, ESR1 and PGR expression did not differ between MDMderived and non-MDM-derived epithelial cells (Figs. S10A-L and S11A-L). Interestingly, Ki67 expression did not differ between YFP+ (MDM-derived) and YFP- (non-MDM-derived) epithelial cells in proestrus (Fig. 9A-C) but began to become restricted to YFP- epithelial cells through subsequent stages of the estrous cycle (Fig. 9D-L). These data support MDM-derived epithelial cells retain epithelial characteristics through the estrous cycle, but do not continue to proliferate. Total epithelial proliferation decreased during progesterone-dominant stages, metestrus and diestrus, with few proliferating cells being non-MDMderived epithelial cells.

\section{Discussion}

Prior research using the same lineage tracing models showed that MDMderived epithelial cells populated the epithelium following postpartum or menseslike repair (Huang et al, 2012, Patterson et al, 2013, Cousins et al, 2014). These cells were not observed in pre-pubertal or nulliparous mice. It was thus hypothesized that stromal cells (e.g. MDM cells) underwent MET as a mechanism of endometrial epithelialization following physiological damage. Contrary, in a recent report, MDM-derived epithelial cells were identified in nulliparous mice using the same lineage tracing model and it was concluded that 


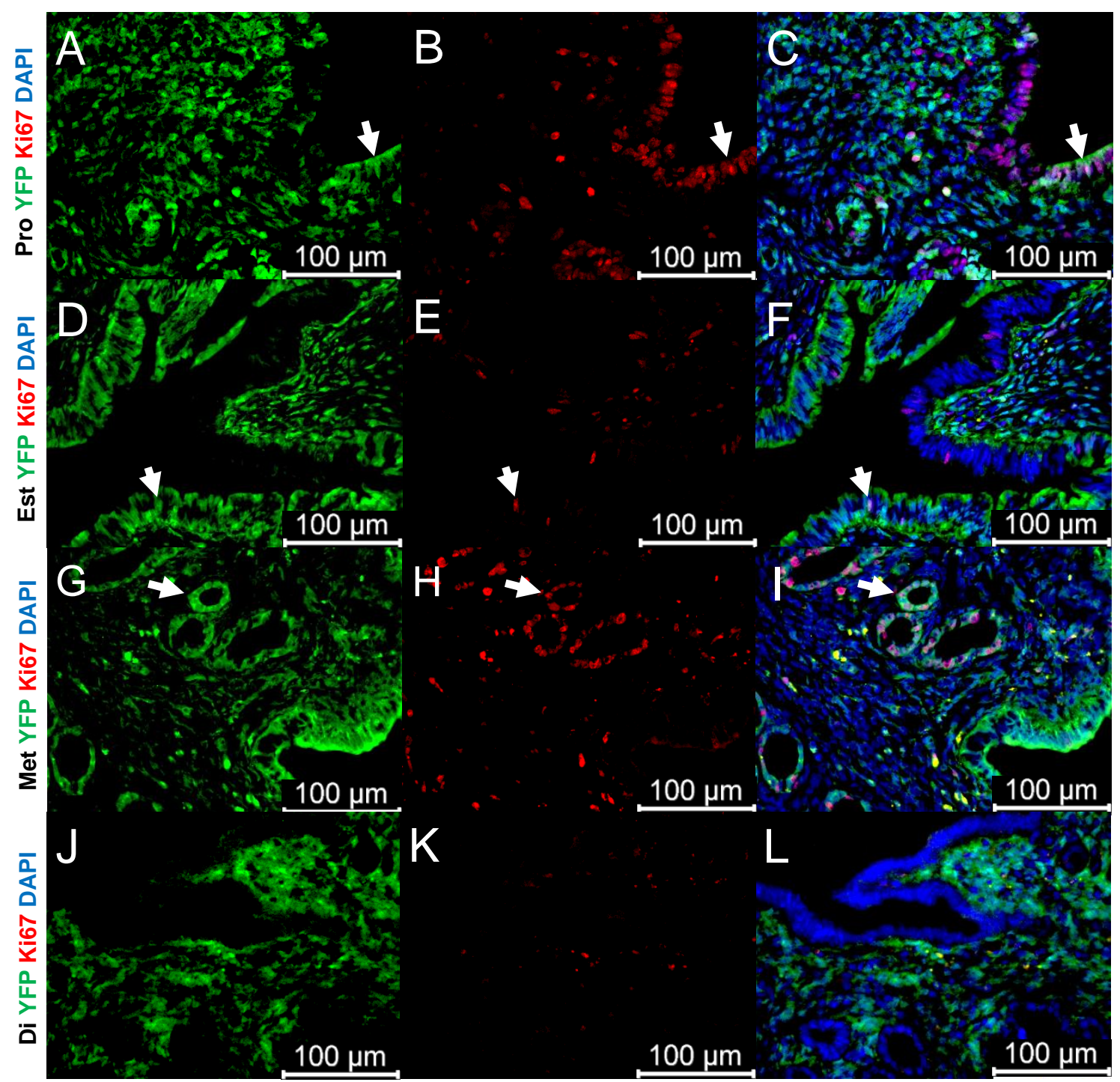

Figure 9. Proliferation of MDM-derived epithelial cells decreases during the estrous cycle. (A-C) Epithelial proliferation was greatest during proestrus. No difference was seen in Ki67 expression of MDM-derived and non-MDM-derived epithelia (white arrow). (D-F) Epithelial proliferation decreased from proestrus to estrus, and few MDM-derived epithelial cells expressed Ki67 during estrus, suggesting they do not continue to contribute greatly to the epithelia at this time. (G-I) Glandular proliferation increased during metestrus, while few luminal epithelial cells showed Ki67 expression. Proliferating glandular epithelial cells

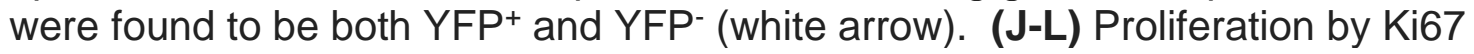
expression was minimal in diestrus, though some stromal cells and few YFPepithelial cells expressed this marker. YFP ${ }^{+}$epithelial cells were rare and did not contribute to epithelial proliferation during diestrus. 
these cells were embryonically derived rather than by MET in endometrial repair. Evidence suggesting embryonic origin is lacking though. Amhr2 promotor activity has been investigated previously embryonically, postnatally, and in adults: at no point during Müllerian duct development, postnatal uterine maturation or in cyclic adult uteri have epithelia demonstrated Amhr2 promotor activity, supporting epithelial cells found in lineage tracing models are MDM-derived epithelial cells (Arango et al, 2008, Patterson et al, 2013). In the current study, using more sensitive techniques, MDM-derived epithelial cells were also identified in nulliparous mice and during postnatal uterine maturation.

At birth, fetuses experience a sudden change in their environment hormonally. The gestational environment is dominated by progesterone produced by the mother, with progesterone (P4) withdrawal occurring when the fetuses are removed from the uterine environment at birth. In humans, some newborn females experience uterine bleeding similar to that seen during menstruation in the adult and has been suggested to be due to P4 withdrawal (Ober and Bernstein, 1955, Puttemans et al, 2018). Due to the extreme variation of MDM-derived epithelial cells from negligible amounts to over $80 \%$ at P 0.5 , we speculate that these cells arise rapidly after birth, instead of embryonically, influenced by P4 withdrawal. In humans and rats, circulating estrogen (E2) is high at birth and may further aid MDM-derived epithelial cell contribution in neonates (Bell, 2018). However, since mice do not show detectable levels of E2 at birth, the future use of rats may better recapitulate neonatal events in humans. Although E2 is known to not be required for postnatal epithelialization 
(adenogenesis and differentiation) (Ogasawara et al, 1983, Bigsby and Cunha, 1985, Branham et al, 1995), it is crucial for adult epithelial turnover (Galand et al, 1971, Cooke et al, 1986). We show that MDM-derived epithelial cells may arise by MET in the adult due to increasing E2 as the highest percentages were observed in proestrus and estrus. This is somewhat substantiated by a report of MET in vitro. Cultured adult uterine mesenchymal cells were shown to transition to epithelial cells after 10 days of E2 treatment (Yin et al, 2019), but the mechanistic process of this has not been further explored. Because postnatal uterine maturation is ovarian steroid independent until approximately P 25 (Ogasawara et al, 1983), we hypothesize that MET following birth is correlated to sudden withdrawal of P4 whereas in the adult, it may be both P4 withdrawal and E2 stimulation. At P 21, our results showed no correlation between MDMderived epithelial populations and serum E2 or P4 concentrations, supporting the uterus is still E2/P4 independent at this time. Because of this, MET in the postnatal uterus is likely mechanistically different from MET occurring in adult uteri until at least $P$ 21. Further exploration during peripubertal time points is necessary to determine the temporal change of the MET initiation mechanism in the uterus.

In addition to this in vivo model, in vitro analyses can continue to elucidate how E2 and P4 affect MET in postnatal cells. Cultured adult uterine mesenchymal cells have previously been shown to transition to epithelial cells after 10 days of estradiol treatment (Yin et al, 2019), but the mechanistic process of this transition postnatally has not been explored. Because postnatal uterine 
maturation is ovarian steroid independent, we hypothesize that increased MET following birth is correlated to sudden withdrawal of P4 instead of increased E2 and will be addressed in future research.

Previous research suggested MET occurred following natural and artificial decidualization, indicating epithelial damage was necessary. Uteri were also found with MDM-derived epithelial cells persisting for 2 months postpartum ( $\mathrm{Hu}$ et al, 2012). This study identified MDM-derived epithelial cells during homeostatic conditions of the estrous cycle without prior damage/repair. Peak percentages were observed during the E2-dominant stages, proestrus and estrus. The MDM-derived epithelial populations during diestrus did not differ from control uteri, but interestingly increased significantly to comprising approximately $50 \%$ of the epithelia in proestrus. Since the estrous cycle in mice is 4-5 days long, these data indicates that there is a rapid contribution from the stroma to epithelial expansion in no more than one day's time. Yet these MDMderived epithelial cells are cleared or replaced in an exceptionally short amount of time, as well. With the current findings, it is likely that the uteri with cells identified to persist for 2 months postpartum were collected during E2-dominant stages of the estrous cycle. Furthermore, MDM-derived epithelial cells did not continue to proliferate beginning in estrus and are rarely found during diestrus, suggesting that they do not continue to populate and contribute to the epithelium during these stages. Previous studies have identified putative endometrial epithelial stem/progenitor cells in mice using label-retaining cell (LRC) and single-cell lineage tracing (Chan and Gargett, 2006, Kaitu'u-Lino et al, 2010, 
Patterson and Pru, 2013, Jin, 2019). Together with current results, it is speculated that both putative epithelial and stromal stem cell populations contribute to epithelialization in the uterus postnatally and in the adult. Since MDM-derived cells arose rapidly, appear to be cleared or replaced quickly, and do not continue to proliferate through the estrous cycle, it is likely that they are replaced via this putative epithelial stem cell population. Because MDM-derived epithelial cells demonstrate rapid turnover during homeostasis, further analyses are needed during initial hours following natural or artificial decidualization to determine the direct contribution of these cells to epithelial regeneration. Additionally, endometrial organoids may be used to better recapitulate the uterine environment in an in vitro model since epithelial-stromal interactions are crucial to respond correctly to hormones. Future 3D culture systems with human endometrial cells can then provide further understanding of the role of MET within women.

This research has demonstrated MET occurs during homeostatic conditions using lineage tracing models, contrary to previous belief. MDMderived epithelial cells were found during E2-dominant stages of the estrous cycle, as well as during postnatal maturation, suggesting MET has greater contribution to epithelialization events than solely being a mechanism for endometrial repair. In both postnatal maturation and during the estrous cycle, MDM-derived epithelial cells exhibited rapid turnover, likely contributing to the lack of evidence that MET occurs during homeostasis in the uterus. Despite rapid turnover, MDM-derived epithelial cells expressed similar markers to non- 
MDM-derived epithelial cells, supporting that these cells have gained epithelial characteristics during MET. Our data suggests E2 may have a role in MET in the adult, but P4 withdrawal may contribute during ovarian steroid independent stages: the mechanism inducing MET is still unknown and requires further study. Future research will continue to characterize MDM-epithelial cells with lineage tracing models, organoids, and begin to address the mechanism behind MET. 


\section{CONCLUSION}

Previous research has indicated MET occurs as an endometrial repair mechanism following damage, but the current research has indicated MET occurs during endometrial epithelialization events as a mechanism of homeostatic epithelial turnover in the adult and during epithelialization events postnatally. Adult Amhr2-Cre; Rosa26-EYFP females were used to assess MDM-derived epithelial populations by flow cytometry during estrous cycle stages in nulliparous and postpartum mice. Estrogen-dominant stages, proestrus and estrus, showed the greatest MDM-derived epithelial populations, with up to $80 \%$ of the uterine epithelia being $\mathrm{EpCAM}^{+} \mathrm{YFP}^{+}$in proestrus. Additionally, progesterone-dominant stages, metestrus and diestrus, had little to no MDMderived epithelial cells. Together, these results suggest this population may be responsive to $\mathrm{E} 2$ in the adult.

Since Amhr2 promotor activity is restricted to mesenchyme embryonically, postnatally, and in the adult, our postnatal data using Amhr2-Cre; Rosa-flox-stoptTA; TRE-H2B-GFP female mice indicate a rapid contribution of MDM-derived epithelial cells at birth (P 0.5), contrary to recent report. Through postnatal uterine maturation, MDM-derived epithelial populations demonstrated dynamic temporal expression patterns: by P 8 during adenogenesis initiation, MDMderived epithelial populations were less than $2 \%$ before increasing to a mean of approximately $11 \%$ at P 14 during glandular morphogenesis. This population

was maintained from $P 14$ to $P 21$. Because there was some variation at $P 14$ and P 21, E2 and P4 serum concentrations were evaluated, but showed no 
correlation to MDM-derived epithelial populations in Amhr2-Cre; Rosa26-EYFP or Amhr2-Cre; Rosa-flox-stop-tTA; TRE-H2B-GFP females, indicating this population is not dependent on ovarian steroids through P 21. The mechanism inducing MET is still unknown and requires further study in both postnatal uteri and adults.

To address embryonic contribution in mice, future studies aim to collect embryonic uterine horns during late gestation. Furthermore, Amhr2-Cre; Rosaflox-stop-tTA; TRE-H2B-GFP female mice can be used to identify the time of contribution: this inducible model can block labeling during embryogenesis with maternal administration of doxycycline, and upon removal of doxycycline treatment, labeling will begin. This model can better identify the temporal origin of MDM-derived epithelial cells during adenogenesis, as well. Additionally, despite rapid turnover, MDM-derived epithelial cells expressed similar markers to non-MDM-derived epithelial cells, supporting that these cells have gained epithelial characteristics during MET. Future research will continue to characterize MDM-epithelial cells with lineage tracing models, organoids, and begin to address the mechanism behind MET. 


\section{SUPPLEMENTAL}
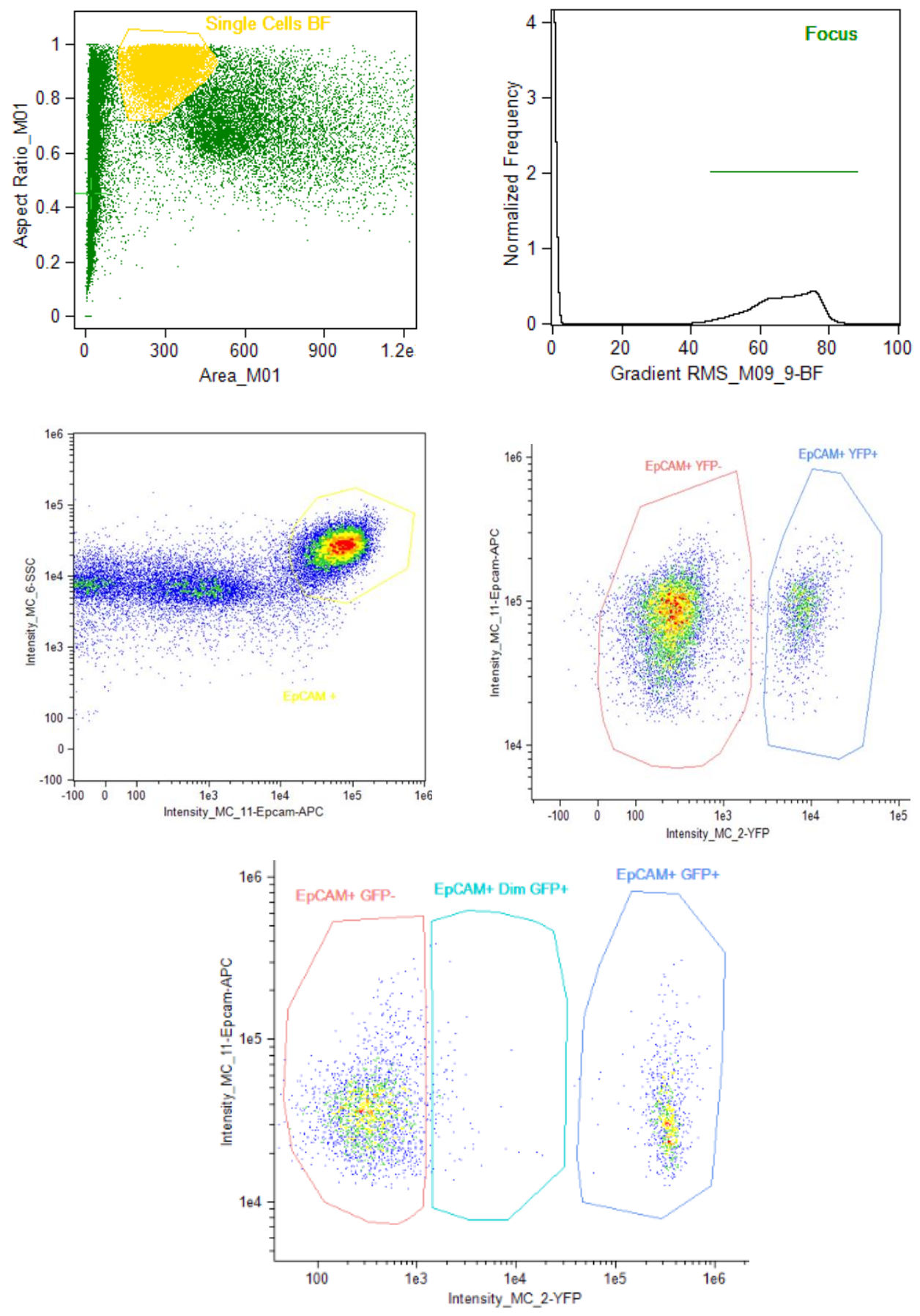

Figure S1. Flow Cytometry Gating. Flow cytometry gating for $\mathrm{EpCAM}^{+} \mathrm{YFP}^{+} / \mathrm{EpCAM}^{+} \mathrm{YFP}^{-}$and $\mathrm{EpCAM}^{+} \mathrm{GFP}^{+} / \mathrm{EpCAM}^{+} \mathrm{GFP}^{-}(\mathrm{MDM}-$ derived/non-MDM-derived) epithelial cells on FlowSight machine. 


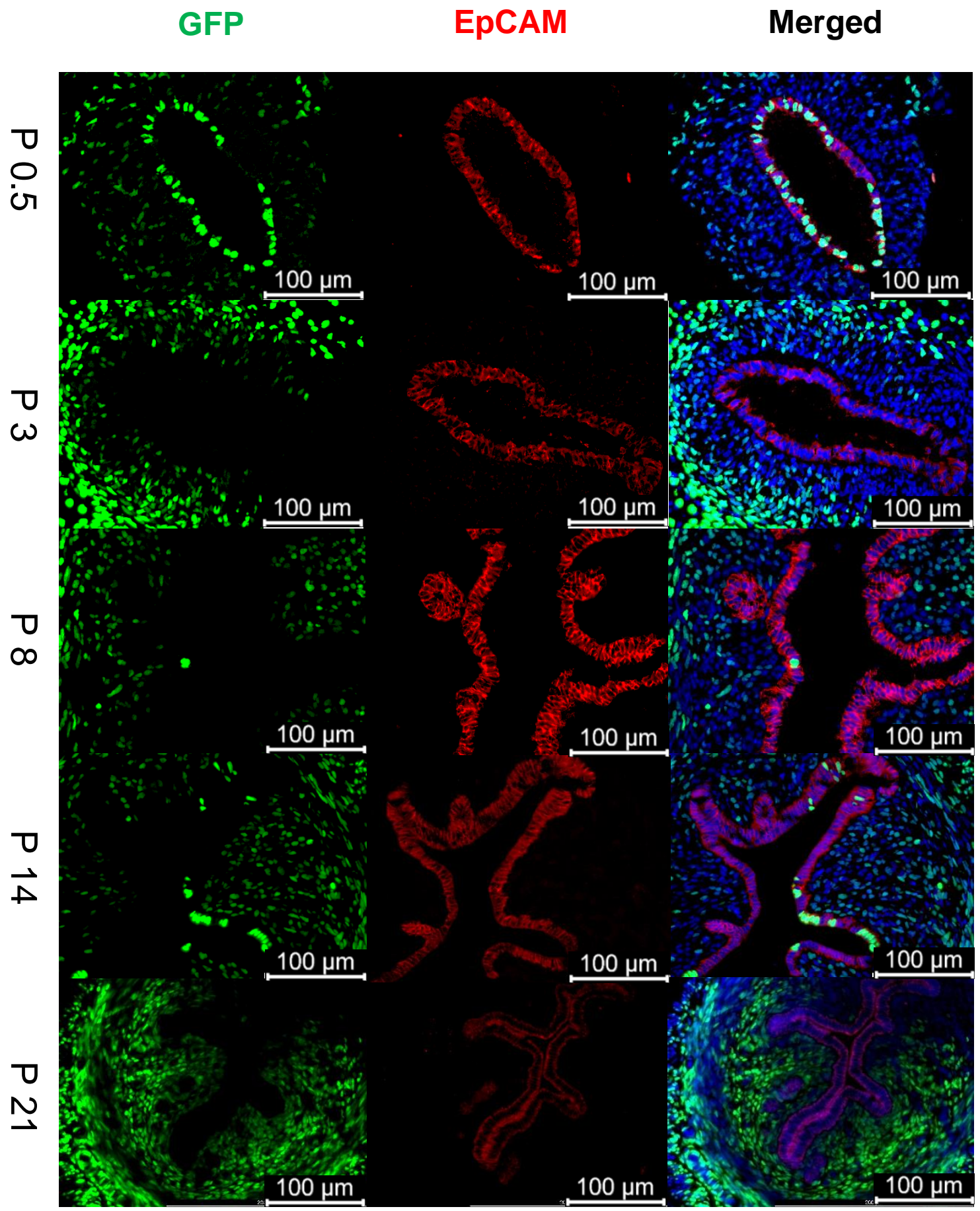

Figure S2. EpCAM is specific to epithelial cells postnatally. Immunofluorescence showed EpcAM was specific to epithelial cells, further supporting mesenchymal cells were not inadvertently analyzed during flow cytometry. 


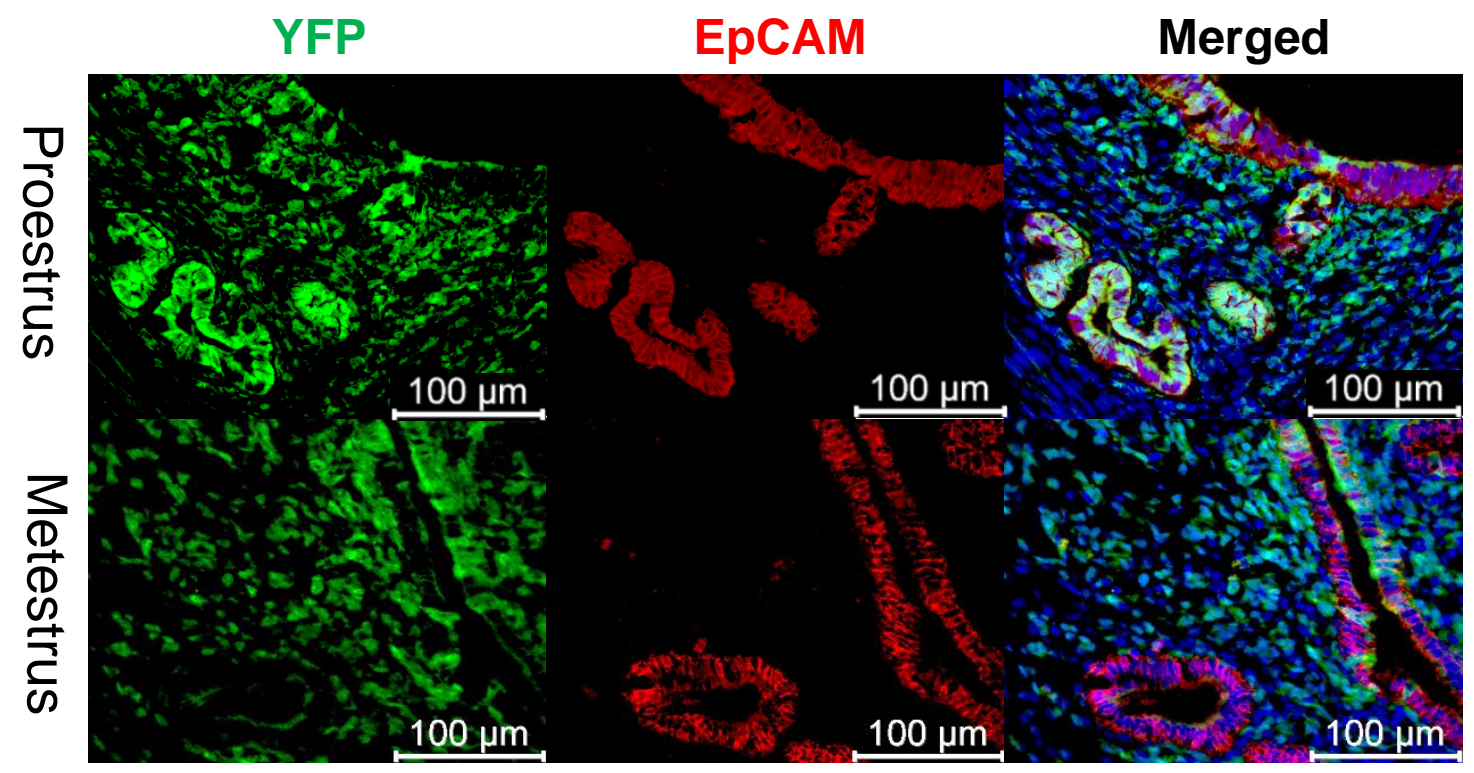

Figure S3. EpCAM is specific to epithelial cells during the estrous cycle. Immunofluorescence showed EpCAM was specific to epithelial cells during cyclic adult mice. These data support mesenchymal cells were not inadvertently analyzed during flow cytometry. 

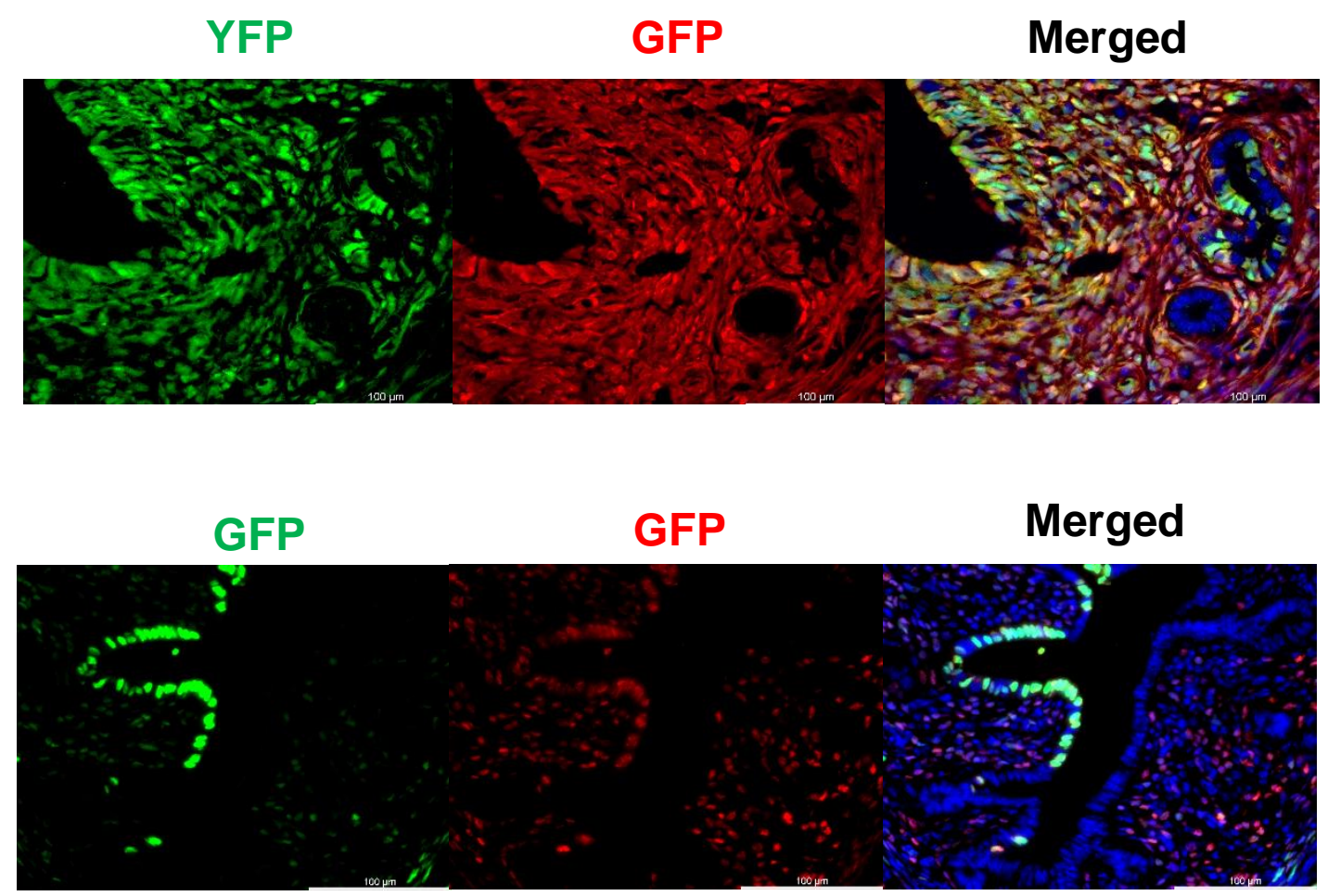

Figure S4. Verification of Epithelial EYFP and GFP Expression in Adult and Postnatal Tissue. Using a GFP antibody, $\mathrm{YFP}^{+}$and GFP+ epithelial cells showed the same patterning as GFP antibody, validating their expression in postnatal and adult tissue. 


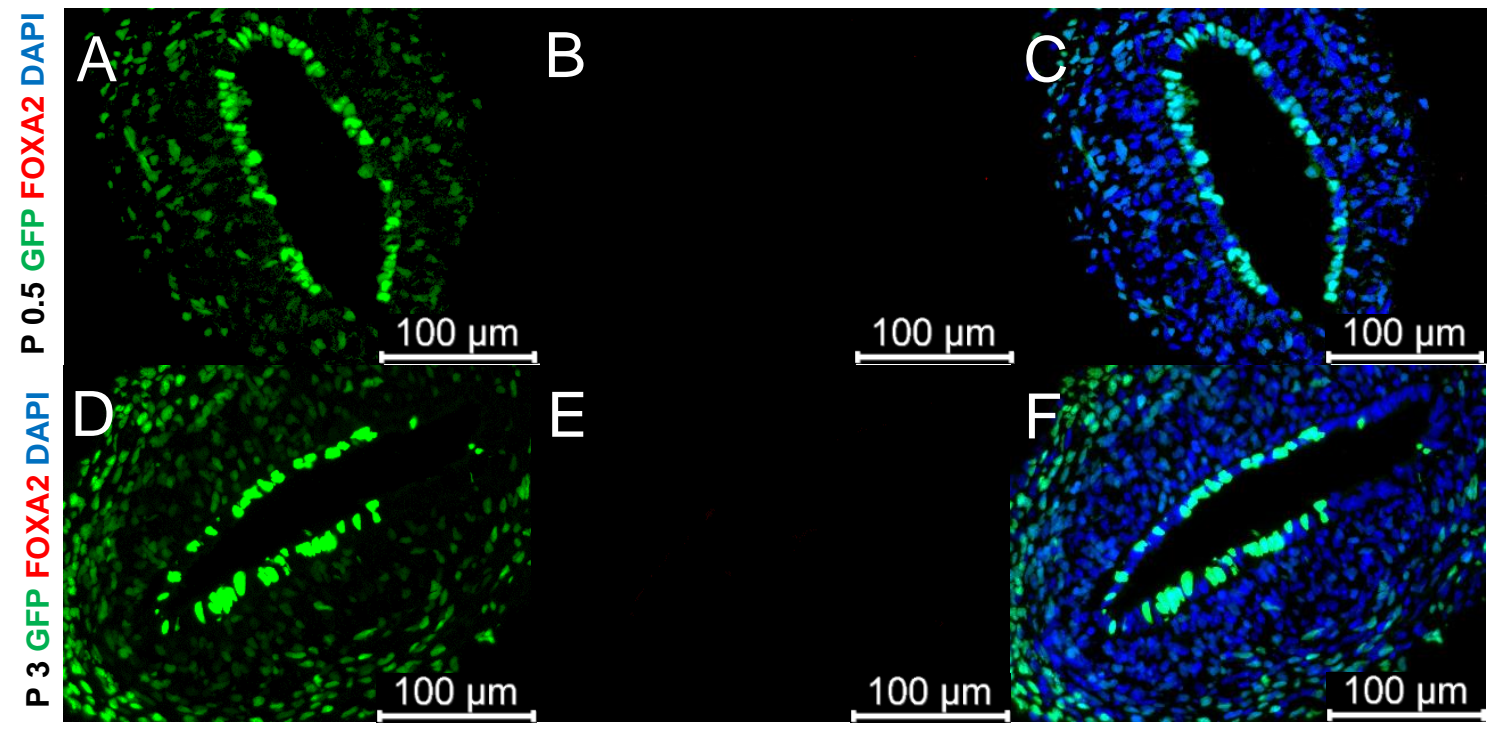

Figure S5. There is no FOXA2 expression prior to adenogenesis initation. No FOXA2 expression was found at (A-C) P 0.5 or (D-F) P 3. 


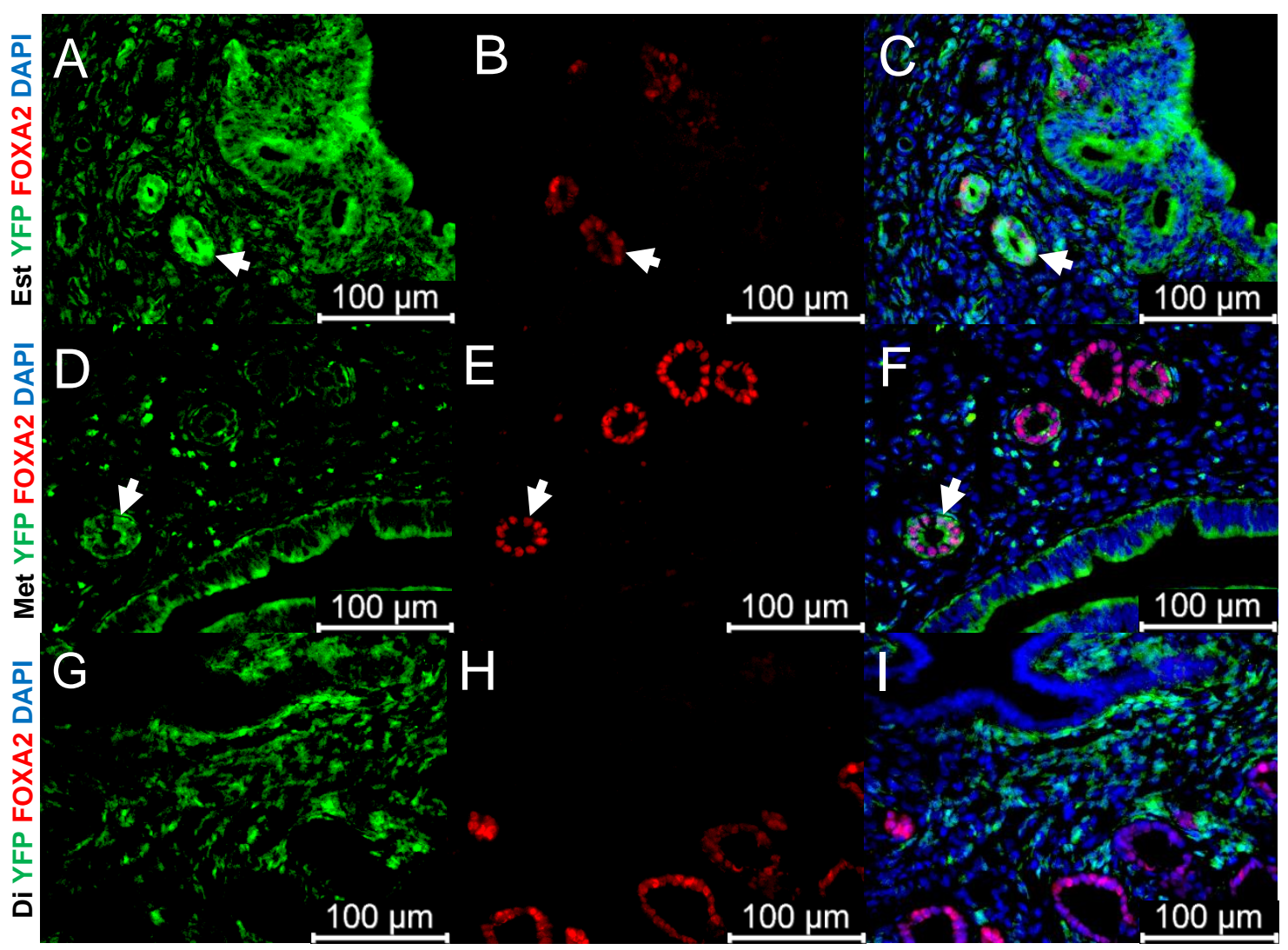

Figure S6. MDM-derived epithelial cells co-express FOXA2 during the estrous cycle. Nuclear FOXA2 expression was maintained during all stages of the estrous cycle and was found in $\mathrm{YFP}^{+}$and $\mathrm{YFP}^{-}$epithelial cells during (A-C) estrus and (D-F) metestrus. (G-I) Nuclear FOXA2 expression was found in diestrus, but $\mathrm{YFP}^{+}$epithelial cells were rarely found during this stage. 


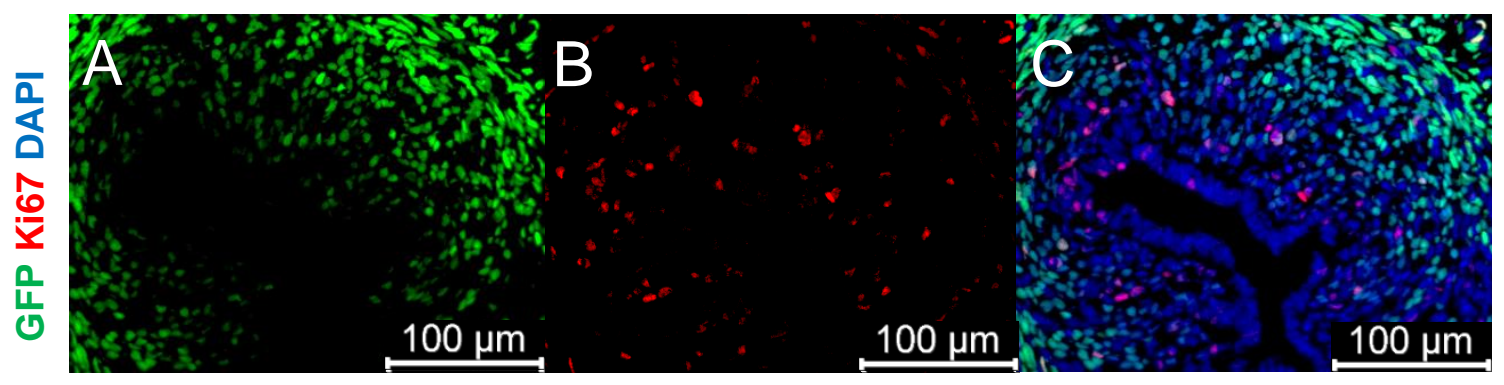

Figure S7. Ki67 expression at P 8. (A-C) Both stromal and epithelial cells were found expressing Ki67 during this time, but stromal proliferation was greater in comparison. 


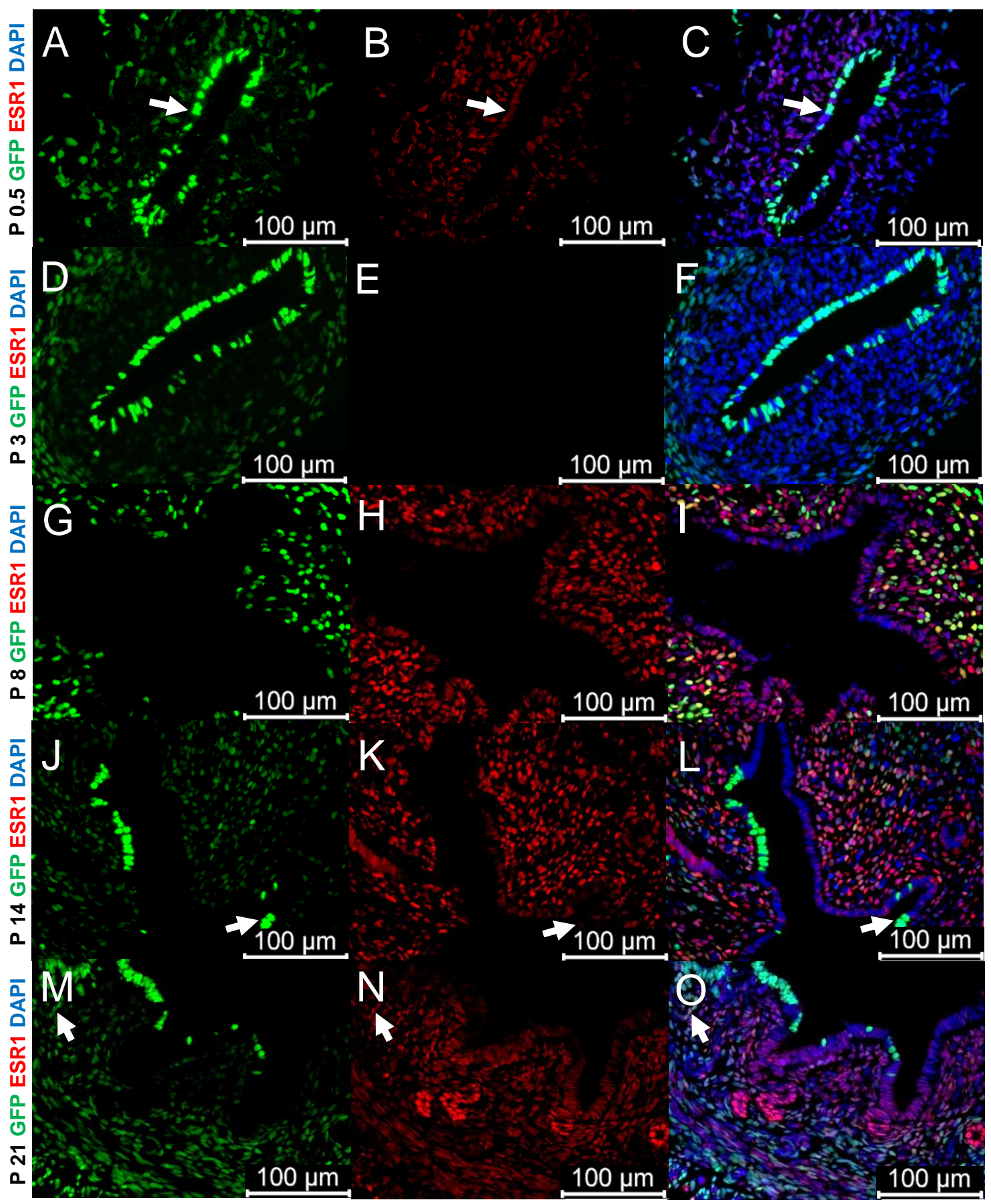

Figure S8. Postnatal ESR1 expression by immunofluorescence. (A-C) Moderate ESR1 expression was found throughout the stroma, with varying expression in the epithelium at P 0.5. GFP ${ }^{+}$epithelial cells show similar ESR1 expression to GFPepithelial cells (white arrow). (D-F) ESR1 expression was not found at P 3 in GFP+ or GFP- epithelial cells. (G-I) At P 8, stroma showed robust ESR1 expression with moderate expression in the epithelia. (J-L) ESR1 was found variably in epithelia at P 14 with maintained robust expression in the stroma. (M-O) ESR1 expression was found to be robust in GE but showed decreased expression in LE at P 21. GFP+ epithelial cells expressed ESR1 similar to GFP' epithelial cells (white arrows). 


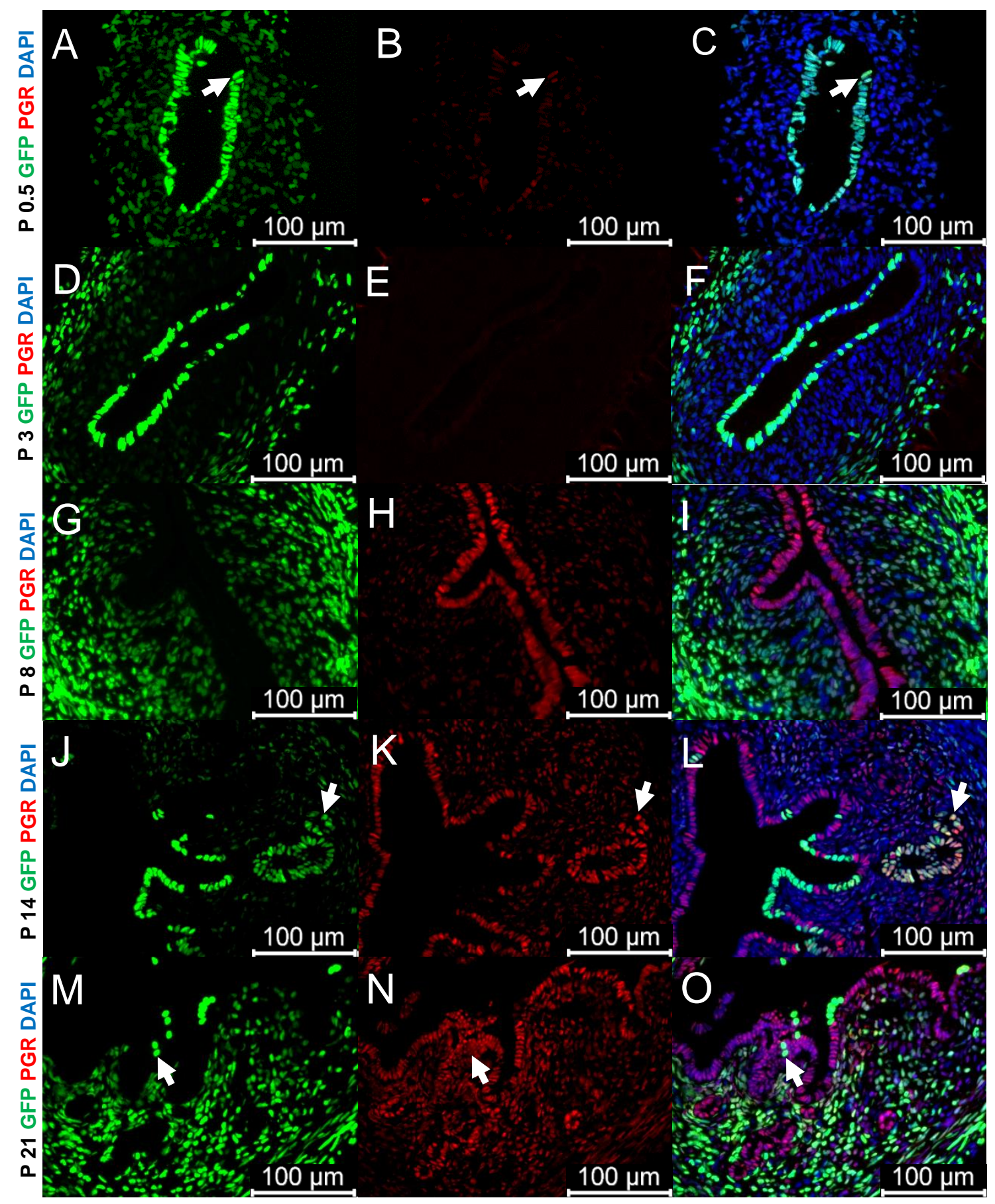

Figure S9. Postnatal PGR expression by immunofluorescence. (A-C) Stromal cells showed little to no PGR at P 0.5, with epithelium showing greater expression. Both GFP+ and GFP- epithelial cells were found to express PGR. (D-F) Little to no PGR expression was found in stromal or epithelial cells at P 3, indicating no difference between GFP ${ }^{+}$and GFPepithelial cells. (G-I) At P 8, epithelia exhibited robust expression of PGR, while stroma showed mild to moderate expression. (J-L) Robust epithelial expression was maintained at P 14, while stromal cells showed moderate expression. (M-O) At P 21, PGR expression is high in both epithelia and stroma. GFP ${ }^{+}$epithelial cells expressed ESR1 and PGR similar to GFP- epithelial cells at P 14 and P 21 (white arrows). 


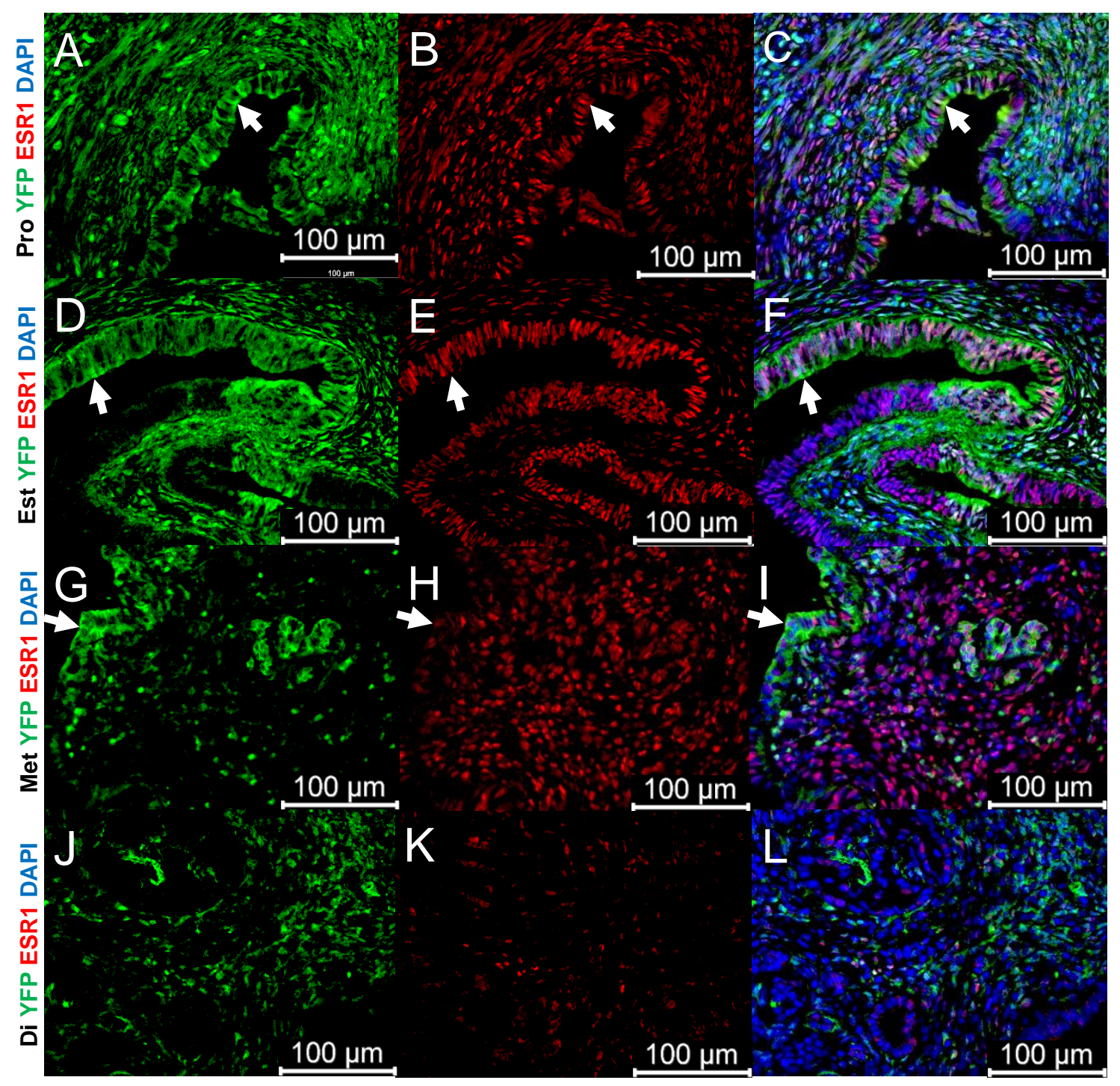

Figure S10. MDM-derived epithelial cells show similar ESR1 expression as non-MDM-derived epithelial cells during the estrous cycle. (A-C) Stromal and epithelial cells showed robust ESR1 expression, with YFP+ epithelial cells maintaining robust expression during proestrus (white arrow). (D-F) ESR1 expression decreased in stromal cells during estrus but maintained robust expression in both $\mathrm{YFP}^{+}$and YFP- epithelial cells (white arrow). (G-I) Epithelial expression of ESR1 began to decease during metestrus, though no difference was seen between MDM-derived and non-MDM-derived epithelial cells (white arrow), and expression in stroma was moderate to robust, similar to ESR1 stromal expression during estrus. (J-L) ESR1 expression was mild in both epithelium and stroma during diestrus. 


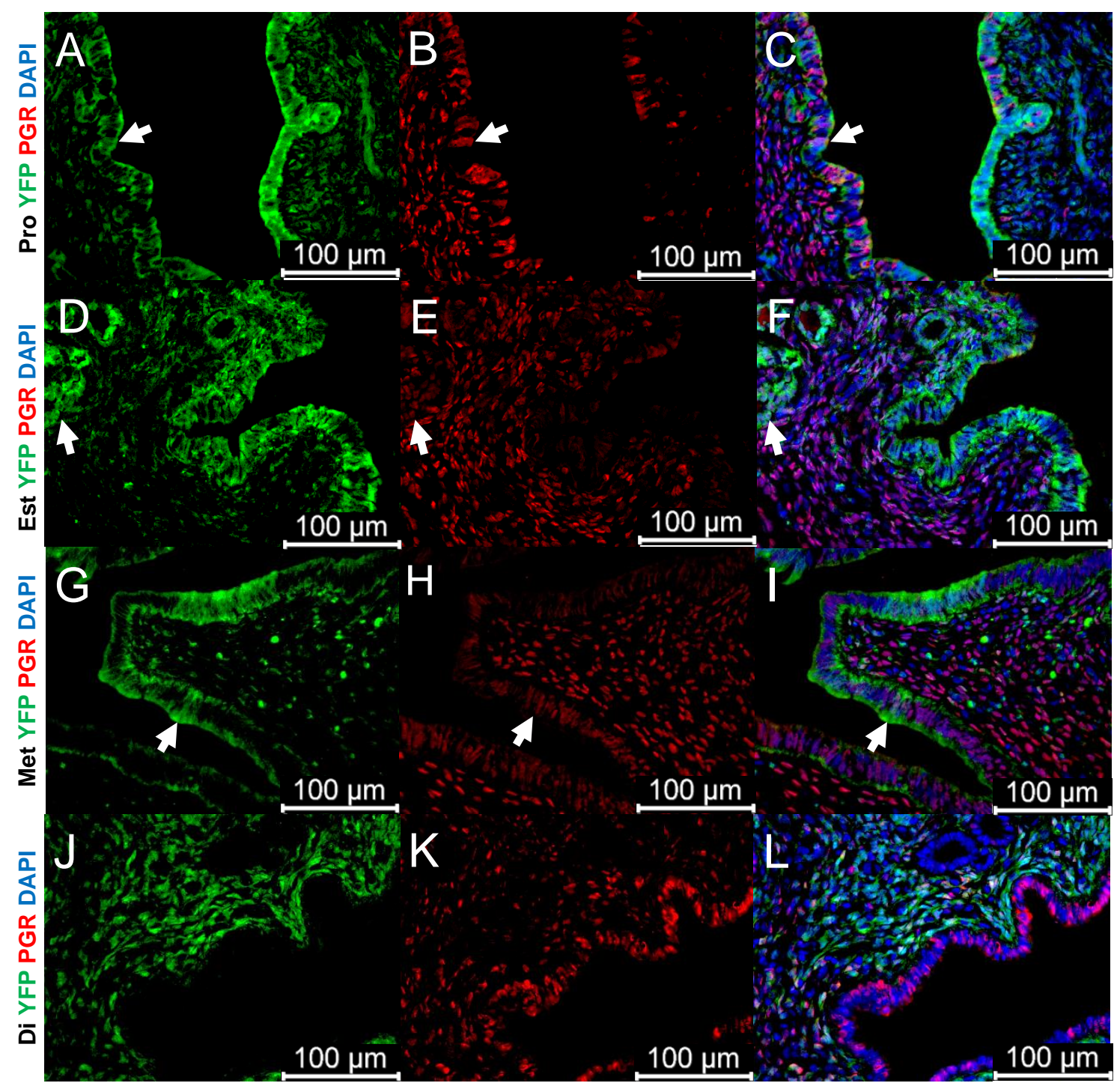

Figure S11. MDM-derived epithelial cells show similar PGR expression as non-MDM-derived epithelial cells during the estrous cycle. (A-C) PGR expression was variable during proestrus but was found to be expressed similarly in YFP+ and YFP- epithelial cells (white arrow). (D-F) Epithelial PGR expression decreased and became variable during estrus, though expression was similar between $\mathrm{YFP}^{+}$and YFP- epithelial cells (white arrow). (G-I) PGR expression began to increase in epithelial cells during metestrus, with both $\mathrm{YFP}^{+}$and YFPepithelial cells showing moderate expression (white arrow). (J-L) PGR expression was robust in both compartments during diestrus. 


\section{REFERENCES}

Ajayi, Ayodeji Folorunsho, and Roland Eghoghosoa Akhigbe. "Staging of the Estrous Cycle and Induction of Estrus in Experimental Rodents: An Update." Fertility Research and Practice 6, no. 1 (March 14, 2020): 5. doi:10.1186/s40738-02000074-3.

Apter, Dan, Lasse Viinikka, and Reizo Vihko. "Hormonal Pattern of Adolescent Menstrual Cycles*." The Journal of Clinical Endocrinology \& Metabolism 47, no. 5 (November 1, 1978): 944-54. doi:10.1210/jcem-47-5-944.

Arango, Nelson A., Akio Kobayashi, Ying Wang, Soazik P. Jamin, Hu-Hui Lee, Grant D. Orvis, and Richard R. Behringer. "A Mesenchymal Perspective of Müllerian Duct Differentiation and Regression in Amhr2-LacZ Mice." Molecular Reproduction and Development 75, no. 7 (July 2008): 1154-62. doi:10.1002/mrd.20858.

Baggish, M S, C J Pauerstein, and J D Woodruff. "Role of Stroma in Regeneration of Endometrial Epithelium." American Journal of Obstetrics and Gynecology 99, no. 4 (October 15, 1967): 459-65.

Banyard, Jacqueline, and Diane R. Bielenberg. "The Role of EMT and MET in Cancer Dissemination." Connective Tissue Research 56, no. 5 (2015): 403-13. doi:10.3109/03008207.2015.1060970.

Bartley, J., A. Jülicher, B. Hotz, S. Mechsner, and H. Hotz. "Epithelial to Mesenchymal Transition (EMT) Seems to Be Regulated Differently in Endometriosis and the Endometrium." Archives of Gynecology and Obstetrics 289, no. 4 (April 2014): 871-81. doi:10.1007/s00404-013-3040-4.

Bell, Margaret R. "Comparing Postnatal Development of Gonadal Hormones and Associated Social Behaviors in Rats, Mice, and Humans." Endocrinology 159, no. 7 (May 14, 2018): 2596-2613. doi:10.1210/en.2018-00220.

Bigsby, R.M., and G. R. Cunha. "Effects of Progestins and Glucocorticoids on Deoxyribonucleic Acid Synthesis in the Uterus of the Neonatal Mouse*." Endocrinology 117, no. 6 (December 1, 1985): 2520-26. doi:10.1210/endo-1176-2520.

Bischof, P, and A Campana. "A Model for Implantation of the Human Blastocyst and Early Placentation." Human Reproduction Update 2, no. 3 (May 1, 1996): 26270. doi:10.1093/humupd/2.3.262.

Branham, William S., and Daniel M. Sheehan. "Ovarian and Adrenal Contributions to Postnatal Growth and Differentiation of the Rat Uterus." Biology of Reproduction 53, no. 4 (October 1, 1995): 863-72. doi:10.1095/biolreprod53.4.863. 
Brasted, M., C.A. White, T.G. Kennedy, and L.A. Salamonsen. "Mimicking the Events of Menstruation in the Murine Uterus1." Biology of Reproduction 69, no. 4 (October 1, 2003): 1273-80. doi:10.1095/biolreprod.103.016550.

Brody, J. R., and G. R. Cunha. "Histologic, Morphometric, and Immunocytochemical Analysis of Myometrial Development in Rats and Mice: I. Normal Development." The American Journal of Anatomy 186, no. 1 (September 1989): 1-20. doi:10.1002/aja.1001860102.

Brosens, Jan J., Naoki Hayashi, and John O. White. "Progesterone Receptor Regulates Decidual Prolactin Expression in Differentiating Human Endometrial Stromal Cells1." Endocrinology 140, no. 10 (October 1, 1999): 4809-20. doi:10.1210/endo.140.10.7070.

Bryant-Greenwood, G. D., M. C. Rees, and A. C. Turnbull. "Immunohistochemical Localization of Relaxin, Prolactin and Prostaglandin Synthase in Human Amnion, Chorion and Decidua." The Journal of Endocrinology 114, no. 3 (September 1987): 491-96. doi:10.1677/joe.0.1140491.

Buck Louis, Germaine M., Mary L. Hediger, C. Matthew Peterson, Mary Croughan, Rajeshwari Sundaram, Joseph Stanford, Zhen Chen, et al. "Incidence of Endometriosis by Study Population and Diagnostic Method: The ENDO Study." Fertility and Sterility 96, no. 2 (August 2011): 360-65. doi:10.1016/j.fertnstert.2011.05.087.

Byers, Shannon L., Michael V. Wiles, Sadie L. Dunn, and Robert A. Taft. "Mouse Estrous Cycle Identification Tool and Images." PLOS ONE 7, no. 4 (April 13, 2012). doi:10.1371/journal.pone.0035538.

Caligioni, Claudia. "Assessing Reproductive Status/Stages in Mice." Current Protocols in Neuroscience / Editorial Board, Jacqueline N. Crawley ... [et Al.] APPENDIX (July 2009): Appendix-4I. doi:10.1002/0471142301.nsa04is48.

Carroll, Thomas J., Joo-Seop Park, Shigemi Hayashi, Arindam Majumdar, and Andrew P. McMahon. "Wnt9b Plays a Central Role in the Regulation of Mesenchymal to Epithelial Transitions Underlying Organogenesis of the Mammalian Urogenital System." Developmental Cell 9, no. 2 (August 1, 2005): 283-92. doi:10.1016/j.devcel.2005.05.016.

Cervelló, I., J.A. Martínez-Conejero, J.A. Horcajadas, A. Pellicer, and C. Simón. "Identification, Characterization and Co-Localization of Label-Retaining Cell Population in Mouse Endometrium with Typical Undifferentiated Markers." Human Reproduction 22, no. 1 (January 1, 2007): 45-51. doi:10.1093/humrep/del332. 
Cervelló, Irene, Cristina Mirantes, Xavier Santamaria, Xavier Dolcet, Xavier MatiasGuiu, and Carlos Simón. "Stem Cells in Human Endometrium and Endometrial Carcinoma." International Journal of Gynecological Pathology 30, no. 4 (July 2011): 317-27. doi:10.1097/PGP.0b013e3182102754.

Chan RW, Gargett CE. Identification of label-retaining cells in mouse endometrium. Stem Cells. 2006 Jun;24(6):1529-38. doi: 10.1634/stemcells.2005-0411. Epub 2006 Feb 2. PMID: 16456137.

Clemmons, David R., Kathryn M. Thrailkill, Stuart Handwerger, and Walker H. Busby Jr. "Three Distinct Forms of Insulin-Like Growth Factor Binding Proteins Are Released by Decidual Cells in Culture*." Endocrinology 127, no. 2 (August 1, 1990): 643-50. doi:10.1210/endo-127-2-643.

Cooke, P. S., F. D. Uchima, D. K. Fujii, H. A. Bern, and G. R. Cunha. "Restoration of Normal Morphology and Estrogen Responsiveness in Cultured Vaginal and Uterine Epithelia Transplanted with Stroma." Proceedings of the National Academy of Sciences 83, no. 7 (April 1, 1986): 2109-13. doi:10.1073/pnas.83.7.2109.

Cooke, Paul S., Gail C. Ekman, Jaspreet Kaur, Juanmahel Davila, Indrani C. Bagchi, Sherrie G. Clark, Philip J. Dziuk, Kanako Hayashi, and Frank F. Bartol. "Brief Exposure to Progesterone During a Critical Neonatal Window Prevents Uterine Gland Formation in Mice." Biology of Reproduction 86, no. 3 (March 2012). doi:10.1095/biolreprod.111.097188.

Cooke, Paul S., Thomas E. Spencer, Frank F. Bartol, and Kanako Hayashi. "Uterine Glands: Development, Function and Experimental Model Systems." Molecular Human Reproduction 19, no. 9 (September 2013): 547-58. doi:10.1093/molehr/gat031.

Critchley, H. O., R. W. Kelly, and J. Kooy. "Perivascular Location of a Chemokine Interleukin-8 in Human Endometrium: A Preliminary Report." Human Reproduction (Oxford, England) 9, no. 8 (August 1994): 1406-9. doi:10.1093/oxfordjournals. humrep.a138719.

Croy, Anne, Aureo Yamada, Francesco DeMayo, and S. Lee Adamson. "The Guide to Investigation of Mouse Pregnancy." $1^{\text {st }}$ Edition. [place unknown]: Academic Press; December 9, 2013. 832 p.

Daly, Douglas C., lla A. Maslar, and Daniel H. Riddick. "Prolactin Production during in Vitro Decidualization of Proliferative Endometrium." American Journal of Obstetrics and Gynecology 145, no. 6 (March 15, 1983): 672-78. doi:10.1016/0002-9378(83)90572-0. 
Day, M. L., K. Imakawa, P. L. Wolfe, R. J. Kittok, and J. E. Kinder. "Endocrine Mechanisms of Puberty in Heifers. Role of Hypothalamo-Pituitary Estradiol Receptors in the Negative Feedback of Estradiol on Luteinizing Hormone Secretion." Biology of Reproduction 37, no. 5 (December 1987): 1054-65. doi:10.1095/biolreprod37.5.1054.

DePace, N. L., W. Burke, M. N. Kotler, and E. E. Glazier. "An Unusual Case of BjorkShiley Mitral Valve Dysfunction Corrected Nonsurgically." Chest 80, no. 4 (October 1981): 502-4. doi:10.1378/chest.80.4.502.

DiVall, Sara A., and Carolina DiBlasi. "The Endocrinology of Puberty." In Principles of Endocrinology and Hormone Action, edited by Antonino Belfiore and Derek LeRoith, 627-58. Cham: Springer International Publishing, 2018. doi:10.1007/978-3-319-44675-2_25.

Dunlap, Kathrin A., Justyna Filant, Kanako Hayashi, Edmund B. Rucker, Gwonhwa Song, Jian Min Deng, Richard R. Behringer, et al. "Postnatal Deletion of Wnt7a Inhibits Uterine Gland Morphogenesis and Compromises Adult Fertility in Mice." Biology of Reproduction 85, no. 2 (August 2011): 386-96. doi:10.1095/biolreprod.111.091769.

Ekambaram, Gnanagurudasan, Senthil Kumar Sampath Kumar, and Leena Dennis Joseph. "Comparative Study on the Estimation of Estrous Cycle in Mice by Visual and Vaginal Lavage Method." Journal of Clinical and Diagnostic Research:

JCDR 11, no. 1 (January 2017): AC05-7. doi:10.7860/JCDR/2017/23977.9148.

Ferenczy, A. "Studies on the Cytodynamics of Human Endometrial Regeneration. I. Scanning Electron Microscopy." American Journal of Obstetrics and Gynecology 124, no. 1 (January 1, 1976): 64-74.

FERENCZY, ALEX, and RALPH M. RICHART. "Scanning and Transmission Electron Microscopy of the Human Endometrial Surface Epithelium*." The Journal of Clinical Endocrinology \& Metabolism 36, no. 5 (May 1, 1973): 999-1008. doi:10.1210/jcem-36-5-999.

Finn, C. A., and M. Pope. "Vascular and Cellular Changes in the Decidualized Endometrium of the Ovariectomized Mouse Following Cessation of Hormone Treatment: A Possible Model for Menstruation." The Journal of Endocrinology 100, no. 3 (March 1984): 295-300. doi:10.1677/joe.0.1000295.

Fleming, T. P. "A Quantitative Analysis of Cell Allocation to Trophectoderm and Inner Cell Mass in the Mouse Blastocyst." Developmental Biology 119, no. 2 (February 1987): 520-31. doi:10.1016/0012-1606(87)90055-8.

Franco, Heather L., Jae-Wook Jeong, Sophia Y. Tsai, John P. Lydon, and Francesco J. DeMayo. "In Vivo Analysis of Progesterone Receptor Action in the Uterus during Embryo Implantation." Seminars in Cell \& Developmental Biology, The 
Lens and Cornea and Molecular and Cell Biology of Embryo-Uterine Interactions, 19, no. 2 (April 1, 2008): 178-86. doi:10.1016/j.semcdb.2007.12.001.

Fuchs, Elaine, and Valerie Horsley. "Ferreting out Stem Cells from Their Niches." Nature Cell Biology 13, no. 5 (May 2011): 513-18. doi:10.1038/ncb0511-513.

Galand, P., F. Leroy, and J. Chrétien. "Effect of Oestradiol on Cell Proliferation and Histological Changes in the Uterus and Vagina of Mice." The Journal of Endocrinology 49, no. 2 (February 1971): 243-52. doi:10.1677/joe.0.0490243.

Garry, R., R. Hart, K. A. Karthigasu, and C. Burke. "Structural Changes in Endometrial Basal Glands during Menstruation." BJOG: An International Journal of Obstetrics \& Gynaecology 117, no. 10 (2010): 1175-85. doi:10.1111/j.14710528.2010.02630.x.

Ghosh, Arnab, Shafiq M. Syed, Manish Kumar, Tyler J. Carpenter, Jose M. Teixeira, Nathaniel Houairia, Sumedha Negi, and Pradeep S. Tanwar. "In Vivo Cell Fate Tracing Provides No Evidence for Mesenchymal to Epithelial Transition in Adult Fallopian Tube and Uterus." Cell Reports 31, no. 6 (May 12, 2020): 107631. doi:10.1016/j.celrep.2020.107631.

Golander, A., R. Richards, K. Thrailkill, D. Capel, D. Rogers, and S. Handwerger. "Decidual Prolactin (PRL)-Releasing Factor Stimulates the Synthesis of PRL from Human Decidual Cells*." Endocrinology 123, no. 1 (July 1, 1988): 335-39. doi:10.1210/endo-123-1-335.

Gruenwald, P. "The relation of the growing müllerian duct to the wolffian duct and its importance for the genesis of malformations." The Anatomical Record 81 (September 1941): 1-19. (1941) doi:10.1002/ar.1090810102

Guioli, Silvana, Ryohei Sekido, and Robin Lovell-Badge. "The Origin of the Mullerian Duct in Chick and Mouse." Developmental Biology 302, no. 2 (February 15, 2007): 389-98. doi:10.1016/j.ydbio.2006.09.046.

Halme, J., M. G. Hammond, J. F. Hulka, S. G. Raj, and L. M. Talbert. "Retrograde Menstruation in Healthy Women and in Patients with Endometriosis." Obstetrics and Gynecology 64, no. 2 (August 1984): 151-54.

Handyside, A. H. "Distribution of Antibody- and Lectin-Binding Sites on Dissociated Blastomeres from Mouse Morulae: Evidence for Polarization at Compaction." Journal of Embryology and Experimental Morphology 60 (December 1980): 99116.

Hayashi, Kanako, Shin Yoshioka, Sarah N. Reardon, Edmund B. Rucker, Thomas E. Spencer, Francesco J. DeMayo, John P. Lydon, and James A. MacLean. "WNTs in the Neonatal Mouse Uterus: Potential Regulation of Endometrial Gland 
Development." Biology of Reproduction 84, no. 2 (February 2011): 308-19. doi:10.1095/biolreprod.110.088161.

Hempstock, Joanne, Tereza Cindrova-Davies, Eric Jauniaux, and Graham J Burton. "Endometrial Glands as a Source of Nutrients, Growth Factors and Cytokines during the First Trimester of Human Pregnancy: A Morphological and Immunohistochemical Study." Reproductive Biology and Endocrinology : RB\&E 2 (July 20, 2004): 58. doi:10.1186/1477-7827-2-58.

Hiby, Susan E., Ashley King, Andrew M. Sharkey, and Yung Wai Loke. "Human Uterine NK Cells Have a Similar Repertoire of Killer Inhibitory and Activatory Receptors to Those Found in Blood, as Demonstrated by RT-PCR and Sequencing." Molecular Immunology 34, no. 5 (April 1, 1997): 419-30. doi:10.1016/S0161-5890(97)00032-1.

Hu, Jianbo, C. Allison Gray, and Thomas E. Spencer. "Gene Expression Profiling of Neonatal Mouse Uterine Development1." Biology of Reproduction 70, no. 6 (June 1, 2004): 1870-76. doi:10.1095/biolreprod.103.026336.

Huang, Cheng-Chiu, Grant D. Orvis, Kin Ming Kwan, and Richard R. Behringer. "Lhx1 Is Required in Müllerian Duct Epithelium for Uterine Development."

Developmental Biology 389, no. 2 (May 15, 2014): 124-36. doi:10.1016/j.ydbio.2014.01.025.

Huang, Cheng-Chiu, Grant D. Orvis, Ying Wang, and Richard R. Behringer. "Stromalto-Epithelial Transition during Postpartum Endometrial Regeneration." PLOS ONE 7, no. 8 (August 27, 2012): e44285. doi:10.1371/journal.pone.0044285.

Jackson, Timothy R., Hye Young Kim, Uma L. Balakrishnan, Carsten Stuckenholz, and Lance A. Davidson. "Spatiotemporally Controlled Mechanical Cues Drive Progenitor Mesenchymal-to-Epithelial Transition Enabling Proper Heart Formation and Function." Current Biology: CB 27, no. 9 (May 8, 2017): 1326-35. doi:10.1016/j.cub.2017.03.065.

Jeong, Jae-Wook, Inseok Kwak, Kevin Y. Lee, Tae Hoon Kim, Michael J. Large, Colin L. Stewart, Klaus H. Kaestner, John P. Lydon, and Francesco J. DeMayo. "Foxa2 Is Essential for Mouse Endometrial Gland Development and Fertility." Biology of Reproduction 83, no. 3 (September 2010): 396-403. doi:10.1095/biolreprod.109.083154.

Jin, Shiying. "Bipotent Stem Cells Support the Cyclical Regeneration of Endometrial Epithelium of the Murine Uterus." Proceedings of the National Academy of Sciences of the United States of America 116, no. 14 (02 2019): 6848-57. doi:10.1073/pnas.1814597116. 
Jones, R. L., R. W. Kelly, and H. O. Critchley. "Chemokine and Cyclooxygenase-2 Expression in Human Endometrium Coincides with Leukocyte Accumulation." Human Reproduction (Oxford, England) 12, no. 6 (June 1997): 1300-1306. doi:10.1093/humrep/12.6.1300.

Kaitu'u-Lino TJ, Ye L, Gargett CE. Reepithelialization of the uterine surface arises from endometrial glands: evidence from a functional mouse model of breakdown and repair. Endocrinology. 2010 Jul;151(7):3386-95. doi: 10.1210/en.2009-1334. Epub 2010 May 5. PMID: 20444944.

Kara, F., O. Cinar, E. Erdemli-Atabenli, B. Tavil-Sabuncuoglu, and A. Can. "Ultrastructural Alterations in Human Decidua in Miscarriages Compared to Normal Pregnancy Decidua." Acta Obstetricia et Gynecologica Scandinavica 86, no. 9 (2007): 1079-86. doi:10.1080/00016340701505457.

Kelleher, Andrew M, Francesco J DeMayo, and Thomas E Spencer. "Uterine Glands: Developmental Biology and Functional Roles in Pregnancy." Endocrine Reviews 40, no. 5 (May 10, 2019): 1424-45. doi:10.1210/er.2018-00281.

Kelleher, Andrew M., Wang Peng, James K. Pru, Cindy A. Pru, Francesco J. DeMayo, and Thomas E. Spencer. "Forkhead Box A2 (FOXA2) Is Essential for Uterine Function and Fertility." Proceedings of the National Academy of Sciences of the United States of America 114, no. 6 (February 7, 2017): E1018-26. doi:10.1073/pnas.1618433114.

Kobayashi, Akio, and Richard R. Behringer. "Developmental Genetics of the Female Reproductive Tract in Mammals." Nature Reviews Genetics 4, no. 12 (December 2003): 969-80. doi:10.1038/nrg1225.

Kobayashi, Akio, William Shawlot, Artur Kania, and Richard R. Behringer. "Requirement of Lim1 for Female Reproductive Tract Development." Development 131, no. 3 (February 1, 2004): 539-49. doi:10.1242/dev.00951.

Kurita, Takeshi, Paul S. Cooke, and Gerald R. Cunha. "Epithelial-Stromal Tissue Interaction in Paramesonephric (Müllerian) Epithelial Differentiation." Developmental Biology 240, no. 1 (December 1, 2001): 194-211. doi:10.1006/dbio.2001.0458.

Lessey, B. A., A. P. Killam, D. A. Metzger, A. F. Haney, G. L. Greene, and K. S. McCarty. "Immunohistochemical Analysis of Human Uterine Estrogen and Progesterone Receptors throughout the Menstrual Cycle." The Journal of Clinical Endocrinology and Metabolism 67, no. 2 (August 1988): 334-40. doi:10.1210/jcem-67-2-334.

Li, Carman Man-Chung, Vasilena Gocheva, Madeleine J. Oudin, Arjun Bhutkar, Shi Yun Wang, Saya R. Date, Sheng Rong Ng, et al. "Foxa2 and Cdx2 Cooperate 
with Nkx2-1 to Inhibit Lung Adenocarcinoma Metastasis." Genes \& Development 29, no. 17 (September 1, 2015): 1850-62. doi:10.1101/gad.267393.115.

Linask, Kersti K., Karen A. Knudsen, and Yong-Hao Gui. "N-Cadherin-Catenin Interaction: Necessary Component of Cardiac Cell Compartmentalization during Early Vertebrate Heart Development." Developmental Biology 185, no. 2 (May 15, 1997): 148-64. doi:10.1006/dbio.1997.8570.

Ludwig, $\mathrm{H}$., and $\mathrm{H}$. Metzger. "The Re-Epithelization of Endometrium after Menstrual Desquamation." Archiv Fur Gynakologie 221, no. 1 (1976): 51-60. doi:10.1007/BF00667681.

Ludwig, H., and U. M. Spornitz. "Microarchitecture of the Human Endometrium by Scanning Electron Microscopy: Menstrual Desquamation and Remodeling." Annals of the New York Academy of Sciences 622 (1991): 28-46. doi:10.1111/j.1749-6632.1991.tb37848.x.

Matsuzaki, Sachiko, and Claude Darcha. "Epithelial to Mesenchymal Transition-like and Mesenchymal to Epithelial Transition-like Processes Might Be Involved in the Pathogenesis of Pelvic Endometriosis." Human Reproduction (Oxford, England) 27, no. 3 (March 2012): 712-21. doi:10.1093/humrep/der442.

Mericskay, Mathias, Jan Kitajewski, and David Sassoon. "Wnt5a Is Required for Proper Epithelial-Mesenchymal Interactions in the Uterus." Development (Cambridge, England) 131, no. 9 (May 2004): 2061-72. doi:10.1242/dev.01090.

Miller, C., and D. A. Sassoon. "Wnt-7a Maintains Appropriate Uterine Patterning during the Development of the Mouse Female Reproductive Tract." Development 125, no. 16 (August 15, 1998): 3201-11.

Milne, S. A., H. O. Critchley, T. A. Drudy, R. W. Kelly, and D. T. Baird. "Perivascular Interleukin-8 Messenger Ribonucleic Acid Expression in Human Endometrium Varies across the Menstrual Cycle and in Early Pregnancy Decidua." The Journal of Clinical Endocrinology and Metabolism 84, no. 7 (July 1999): 2563-67. doi:10.1210/jcem.84.7.5833.

Monice, Fernanda L., Célia G. T. Andrade, Paulo A. Abrahamsohn, Maurício SotoSuazo, Sérgio F. Oliveira, and Telma M. T. Zorn. "Granulated Decidual Cells in the Mouse Deciduoma: A Putative Source of Decidual Prolactin in Mice." Cells Tissues Organs 168, no. 4 (2001): 252-63. doi:10.1159/000047842.

Nalaboff, Kenneth M., John S. Pellerito, and Eran Ben-Levi. "Imaging the Endometrium: Disease and Normal Variants." RadioGraphics 21, no. 6 (November 1, 2001): 1409-24. doi:10.1148/radiographics.21.6.g01nv211409. 
Ogasawara, Y., S. Okamoto, Y. Kitamura, and K. Matsumoto. "Proliferative Pattern of Uterine Cells from Birth to Adulthood in Intact, Neonatally Castrated, and/or Adrenalectomized Mice, Assayed by Incorporation of [125I]lododeoxyuridine*." Endocrinology 113, no. 2 (August 1, 1983): 582-87. doi:10.1210/endo-113-2582.

Orvis, Grant D., and Richard R. Behringer. "Cellular Mechanisms of Müllerian Duct Formation in the Mouse." Developmental Biology 306, no. 2 (June 15, 2007): 493-504. doi:10.1016/j.ydbio.2007.03.027.

Padykula, Helen A., Linda G. Coles, William C. Okulicz, Steven I. Rapaport, John A. McCracken, Norval W. King Jr., Christopher Longcope, and Ita R. KaisermanAbramof. "The Basalis of the Primate Endometrium: A Bifunctional Germinal Compartment1." Biology of Reproduction 40, no. 3 (March 1, 1989): 681-90. doi:10.1095/biolreprod40.3.681.

Patel, Bansari, Sonia Elguero, Suruchi Thakore, Wissam Dahoud, Mohamed Bedaiwy, and Sam Mesiano. "Role of Nuclear Progesterone Receptor Isoforms in Uterine Pathophysiology." Human Reproduction Update 21, no. 2 (March 2015): 155-73. doi:10.1093/humupd/dmu056.

Patterson AL, Pru JK. Long-term label retaining cells localize to distinct regions within the female reproductive epithelium. Cell Cycle. 2013 Sep 1;12(17):2888-98. doi: 10.4161/cc.25917. PMID: 24018418; PMCID: PMC3899201.

Patterson, Amanda L., Ling Zhang, Nelson A. Arango, Jose Teixeira, and James K. Pru. "Mesenchymal-to-Epithelial Transition Contributes to Endometrial Regeneration Following Natural and Artificial Decidualization." Stem Cells and Development 22, no. 6 (March 15, 2013): 964. doi:10.1089/scd.2012.0435.

Piekarski, David J., Josiah R. Boivin, and Linda Wilbrecht. "Ovarian Hormones Organize the Maturation of Inhibitory Neurotransmission in the Frontal Cortex at Puberty Onset in Female Mice." Current Biology 27, no. 12 (June 2017): 17351745.e3. doi:10.1016/j.cub.2017.05.027.

Plapinger, Linda. "Surface Morphology of Uterine and Vaginal Epithelia in Mice During Normal Postnatal Development." Biology of Reproduction 26, no. 5 (June 1, 1982): 961-72. doi:10.1095/biolreprod26.5.961.

Prunskaite-Hyyryläinen, Renata, llya Skovorodkin, Qi Xu, Ilkka Miinalainen, Jingdong Shan, and Seppo J. Vainio. "Wnt4 Coordinates Directional Cell Migration and Extension of the Müllerian Duct Essential for Ontogenesis of the Female Reproductive Tract." Human Molecular Genetics 25, no. 6 (March 15, 2016): 1059-73. doi:10.1093/hmg/ddv621. 
ROCK, JOHN, and MARSHALL K. BARTLETT. "BIOPSY STUDIES OF HUMAN ENDOMETRIUM: CRITERIA OF DATING AND INFORMATION ABOUT AMENORRHEA, MENORRHAGIA AND TIME OF OVULATION." Journal of the American Medical Association 108, no. 24 (June 12, 1937): 2022-28. doi:10.1001/jama.1937.02780240014006.

Rosenberg, S. M., I. A. Maslar, and D. H. Riddick. "Decidual Production of Prolactin in Late Gestation: Further Evidence for a Decidual Source of Amniotic Fluid Prolactin." American Journal of Obstetrics and Gynecology 138, no. 6 (November 15, 1980): 681-85. doi:10.1016/0002-9378(80)90088-5.

Rossant, Janet, and James C. Cross. "Placental Development: Lessons from Mouse Mutants." Nature Reviews Genetics 2, no. 7 (July 2001): 538-48. doi:10.1038/35080570.

Rutanen, Eeva-Marja, Riitta Koistinen, Jari Sjöberg, Mervi Julkunen, Torsten Wahlström, Hans Bohn, and Markku Seppälä. "Synthesis of Placental Protein 12 by Human Endometrium*." Endocrinology 118, no. 3 (March 1, 1986): 1067-71. doi:10.1210/endo-118-3-1067.

Salamonsen, L. A., A. R. Butt, F. R. Hammond, S. Garcia, and J. Zhang. "Production of Endometrial Matrix Metalloproteinases, but Not Their Tissue Inhibitors, Is Modulated by Progesterone Withdrawal in an in Vitro Model for Menstruation*." The Journal of Clinical Endocrinology \& Metabolism 82, no. 5 (May 1, 1997): 1409-15. doi:10.1210/jcem.82.5.3920.

Sampson, John A. "Peritoneal Endometriosis Due to the Menstrual Dissemination of Endometrial Tissue into the Peritoneal Cavity." American Journal of Obstetrics and Gynecology 14, no. 4 (January 1, 1927a): 422-69. doi:10.1016/S00029378(15)30003-X.

Sampson, John A. "Metastatic or Embolic Endometriosis, Due to the Menstrual Dissemination of Endometrial Tissue into the Venous Circulation." The American Journal of Pathology 3, no. 2 (March 1927b): 93-110.43.

Sawai, Keisuke, Noboru Matsuzaki, Takayoshi Okada, Koichiro Shimoya, Masayasu Koyama, Chihiro Azuma, Fumitaka Saji, and Yuji Murata. "Human Decidual Cell Biosynthesis of Leukemia Inhibitory Factor: Regulation by Decidual Cytokines and Steroid Hormones1." Biology of Reproduction 56, no. 5 (May 1, 1997): 1274-80. doi:10.1095/biolreprod56.5.1274.

Schmidt, André, Diana M. Morales-Prieto, Jana Pastuschek, Karolin Fröhlich, and Udo R. Markert. "Only Humans Have Human Placentas: Molecular Differences between Mice and Humans." Journal of Reproductive Immunology, Highlights presented at the congress of the European Society for Reproductive Immunology 
in Budapest (Hungary), March 29 - April 01, 2014, 108 (April 1, 2015): 65-71. doi:10.1016/j.jri.2015.03.001.

Sharman, Albert. "Post-Partum Regeneration of the Human Endometrium." Journal of Anatomy 87, no. Pt 1 (January 1953): 1-10.4.

Sherman, B M, and S G Korenman. "Hormonal Characteristics of the Human Menstrual Cycle throughout Reproductive Life." Journal of Clinical Investigation 55, no. 4 (April 1975): 699-706.

Slayden, Ov D, and Robert M Brenner. "A Critical Period of Progesterone Withdrawal Precedes Menstruation in Macaques." Reproductive Biology and Endocrinology 4, no. Suppl 1 (October 9, 2006): S6. doi:10.1186/1477-7827-4-S1-S6.

Spencer, Thomas E., Kanako Hayashi, Jianbo Hu, and Karen D. Carpenter. "Comparative Developmental Biology of the Mammalian Uterus." In Current Topics in Developmental Biology, 68:85-122. Elsevier, 2005. doi:10.1016/S00702153(05)68004-0.

St-Jean, Guillaume, Alexandre Boyer, Gustavo Zamberlam, Philippe Godin, Marilène Paquet, and Derek Boerboom. "Targeted Ablation of Wnt4 and Wnt5a in Müllerian Duct Mesenchyme Impedes Endometrial Gland Development and Causes Partial Müllerian Agenesist." Biology of Reproduction 100, no. 1 (January 1, 2019): 49-60. doi:10.1093/biolre/ioy160.

Stewart, C. Allison, Sara J. Fisher, Ying Wang, M. David Stewart, Sylvia C. Hewitt, Karina F. Rodriguez, Kenneth S. Korach, and Richard R. Behringer. "Uterine Gland Formation in Mice Is a Continuous Process, Requiring the Ovary after Puberty, But Not after Parturition." Biology of Reproduction 85, no. 5 (November 2011): 954-64. doi:10.1095/biolreprod.111.091470.

Swerdloff, Ronald S., and William D. Odell. "Hormonal Mechanisms in the Onset of Puberty." Postgraduate Medical Journal 51, no. 594 (April 1975): 200-208.

Teacher, John H. "Normal Structure of Endometrium and Decidua and the Menstrual Cycle." British Medical Journal 2, no. 3647 (November 29, 1930): 896-97.

Thiery, Jean Paul. "Epithelial-Mesenchymal Transitions in Tumour Progression." Nature Reviews Cancer 2, no. 6 (June 2002): 442-54. doi:10.1038/nrc822.

Thiery, Jean Paul, Hervé Acloque, Ruby Y. J. Huang, and M. Angela Nieto. "Epithelial-Mesenchymal Transitions in Development and Disease." Cell 139, no. 5 (November 25, 2009): 871-90. doi:10.1016/j.cell.2009.11.007.

Thiery, Jean Paul, and Jonathan P. Sleeman. "Complex Networks Orchestrate Epithelial-Mesenchymal Transitions." Nature Reviews Molecular Cell Biology 7, no. 2 (February 2006): 131-42. doi:10.1038/nrm1835. 
Vainio, Seppo, Minna Heikkilä, Andreas Kispert, Norman Chin, and Andrew P. McMahon. "Female Development in Mammals Is Regulated by Wnt-4 Signalling." Nature 397, no. 6718 (February 1999): 405-9. doi:10.1038/17068.

Verma, Sanjay, Ashley King, and Yung Wai Loke. "Expression of Killer Cell Inhibitory Receptors on Human Uterine Natural Killer Cells." European Journal of Immunology 27, no. 4 (1997): 979-83. doi:10.1002/eji.1830270426.

Villacorte, M., K. Suzuki, A. Hirasawa, Y. Ohkawa, M. Suyama, T. Maruyama, D. Aoki, et al. " $\beta$-Catenin Signaling Regulates Foxa2 Expression during Endometrial Hyperplasia Formation." Oncogene 32, no. 29 (July 18, 2013): 3477-82. doi:10.1038/onc.2012.376.

Vinketova, Kameliya, Milena Mourdjeva, and Tsvetelina Oreshkova. "Human Decidual Stromal Cells as a Component of the Implantation Niche and a Modulator of Maternal Immunity." Journal of Pregnancy 2016 (April 28, 2016): e8689436. doi:10.1155/2016/8689436.

Vue, Zer, and Richard R. Behringer. "Epithelial Morphogenesis in the Perinatal Mouse Uterus." Developmental Dynamics : An Official Publication of the American Association of Anatomists 249, no. 11 (November 2020): 1377-86. doi:10.1002/dvdy.234.

Vue, Zer, Gabriel Gonzalez, C. Allison Stewart, Shyamin Mehra, and Richard R. Behringer. "Volumetric Imaging of the Developing Prepubertal Mouse Uterine Epithelium Using Light Sheet Microscopy." Molecular Reproduction and Development 85, no. 5 (2018): 397-405. doi:10.1002/mrd.22973.

Walmer, D K, M A Wrona, C L Hughes, and K G Nelson. "Lactoferrin Expression in the Mouse Reproductive Tract during the Natural Estrous Cycle: Correlation with Circulating Estradiol and Progesterone." Endocrinology 131, no. 3 (September 1, 1992): 1458-66. doi:10.1210/endo.131.3.1505477.

Wiggan, O'Neil, Marc P. Fadel, and Paul A. Hamel. "Pax3 Induces Cell Aggregation and Regulates Phenotypic Mesenchymal-Epithelial Interconversion." Journal of Cell Science 115, no. Pt 3 (February 1, 2002): 517-29.

Wiggan, O'Neil, Alisa E. Shaw, and James R. Bamburg. "Essential Requirement for Rho Family GTPase Signaling in Pax3 Induced Mesenchymal-Epithelial Transition." Cellular Signalling 18, no. 9 (September 1, 2006): 1501-14. doi:10.1016/j.cellsig.2005.12.002.

Wilson, Mike R, Jeanne Holladay, and Ronald L Chandler. "A Mouse Model of Endometriosis Mimicking the Natural Spread of Invasive Endometrium." Human Reproduction 35, no. 1 (January 1, 2020): 58-69. doi:10.1093/humrep/dez253. 
Wood, Geoffrey A., Jimmie E. Fata, Katrina L. M. Watson, and Rama Khokha. "Circulating Hormones and Estrous Stage Predict Cellular and Stromal Remodeling in Murine Uterus." Reproduction 133, no. 5 (May 1, 2007): 1035-44. doi:10.1530/REP-06-0302.

Xu, X.B., B. He, and J.D. Wang. "Menstrual-like Changes in Mice Are Provoked through the Pharmacologic Withdrawal of Progesterone Using Mifepristone Following Induction of Decidualization." Human Reproduction 22, no. 12 (December 1, 2007): 3184-91. doi:10.1093/humrep/dem312.

Yin, Mingzhu, Huanjiao Jenny Zhou, Caixia Lin, Lingli Long, Xiaolei Yang, Haifeng Zhang, Hugh Taylor, and Wang Min. "CD34+KLF4+ Stromal Stem Cells Contribute to Endometrial Regeneration and Repair." Cell Reports 27, no. 9 (28 2019): 2709-2724.e3. doi:10.1016/j.celrep.2019.04.088.

Ziomek, C. A., and M. H. Johnson. "Cell Surface Interaction Induces Polarization of Mouse 8-Cell Blastomeres at Compaction." Cell 21, no. 3 (October 1980): 93542. doi:10.1016/0092-8674(80)90457-2. 